Portland State University

PDXScholar

Dissertations and Theses

Dissertations and Theses

Winter 2-23-2016

\title{
Star Academics: Do They Garner Increasing Returns?
}

James Jeffrey Kline

Portland State University

Follow this and additional works at: https://pdxscholar.library.pdx.edu/open_access_etds

Part of the Education Economics Commons, Education Policy Commons, and the Science and Mathematics Education Commons

Let us know how access to this document benefits you.

\section{Recommended Citation}

Kline, James Jeffrey, "Star Academics: Do They Garner Increasing Returns?" (2016). Dissertations and Theses. Paper 2713.

https://doi.org/10.15760/etd.2709

This Dissertation is brought to you for free and open access. It has been accepted for inclusion in Dissertations and Theses by an authorized administrator of PDXScholar. Please contact us if we can make this document more accessible: pdxscholar@pdx.edu. 
Star Academics: Do They Garner Increasing Returns?

\author{
by \\ James Jeffrey Kline
}

A dissertation submitted in partial fulfillment of the requirements for the degree of

Doctor of Philosophy

in

Urban Studies

Dissertation Committee:

James Strathman, Chair

Anthony Rufolo

Greg Schrock

Willliam Feyerherm

Portland State University

2016 
(C) 2016 James Jeffrey Kline 


\begin{abstract}
This study examines the criteria which help academics receive National Institute of Health funds (NIH). The study covers 3,092 NIH recipients and non-recipients in the same department or institute at twenty-four universities. The universities are drawn from those below the top twenty in terms of receipt of NIH funds. With regards to performance, non- recipients have lower performance than recipients. A key determinant of the receipt of NIH funds is individual performance, as measured by the number of articles published and average citations per article in the two years immediately prior to the grant application. Professors receive more NIH money than do associates and assistant professors. Other positive contributors are the field of study, whether the academic has both a $\mathrm{PhD}$. and Medical degree, and has licensed an innovation, been involved in the start of a new business and patented an invention through the university. To the extent that individual performance criteria represent the quality of the research proposal, allocation of NIH funds is based on merit.
\end{abstract}

A Tobit model indicates that being highly cited does not guarantee increasing returns. Likewise, career citations have only a small statistically significant impact. In addition, a negative coefficient associated with the second derivatives of both articles published in 2006-07 and their associated citations indicate diminishing marginal returns. 


\section{Dedication}

I dedicate this dissertation to my sister, Andrea Holbrook, and her husband David, whose support throughout this process has been much appreciated. This task was made the easier for it.

I also dedicate this dissertation to my cousins Betty Jean Repp, $\mathrm{PhD}$ and Jon Repp, who were taken from our lives by cancer. Though I started my PhD effort before Betty Jean, she beat me to the finish line. I celebrated her accomplishment. I would have loved to have shared this one with her and her brother. 


\section{Acknowledgements}

I would like to thank the members of my committee for their patience and constructive criticism, all of which contributed substantively to the quality of this document. I address special thanks to James Strathman, my chair, who guided me throughout this process. His wisdom and guidance is much appreciated. In addition, I would like to thank Mike Fogarty. In consideration of his health, Mike had to retire before this project could be completed, but discussions with him generated this topic. While James Strathman and the rest of the committee guided this project to completion, without Mike's prodding and initial guidance, it would never have been started. Finally, a special nod to Tony Rufolo. Tony was a member of my first committee. Family matters required that I leave the $\mathrm{PhD}$ program without completing the dissertation. Tony was kind enough to become a member of this, second committee. Between the time Mike retired and Jim became my chair, Tony provided comments and guidance, maintaining the project's momentum. Thank you all. 
TABLE OF CONTENTS

$\begin{array}{lr}\text { Abstract } & \text { i } \\ \text { Dedication } & \text { ii } \\ & \text { iii } \\ \text { Acknowledgements } & \text { vi } \\ \text { List of Tables } & \text { vii } \\ & \\ \text { List of Figures } & \\ & \\ \text { Chapter 1: Literature Review } & 1 \\ & 7 \\ \text { Background } & 9 \\ \text { Rational Actor Theory } & 13 \\ \text { Agglomeration Effects and Cumulative Advantage } & 18 \\ \text { Creative Destruction and Knowledge Spillover } & 23 \\ \text { Role of Universities } & 24 \\ \text { Star Scientists and Engineers } & 27 \\ \text { The Carnegie Ladder } & 30 \\ \text { The Entrepreneurial University } & 31 \\ \text { Universities and Research Funding } & \\ \text { University Funding and Variable Interaction } & \end{array}$

Chapter 2: Research Design

Overview 36

Research Questions $\quad 39$

Sample Characteristics $\quad 41$

Dependent Variables $\quad 42$

Independent Variables $\quad 43$

Individual Variables $\quad 44$

$\begin{array}{ll}\text { Institutional Variables } & 48\end{array}$

$\begin{array}{ll}\text { Environmental Characteristics } & 48\end{array}$

Methodological Issues $\quad 49$

Chapter 3: Results

$\begin{array}{ll}\text { Descriptive Statistics } & 50\end{array}$ 
Tobit Regression 68

Research Questions

89

Policy Implications

96

Summary

100

References

103

Appendix A: Tobit Regressions without NIH Dollar Outliers and with National Academy Members Interactive Variable

Appendix B: Sample of Academic Movement and NIH Funds Received 
List of Tables

Table $1 \quad$ Sample Universities $\quad 44$

Table $2 \quad$ Sample Distribution by Universities $\quad 52$

Table $3 \quad$ Sample Descriptive Statistics 53

Table $4 \quad$ Number of Academics and Percentage by Dollar Category 54

Table $5 \quad$ Distribution by Gender $\quad 57$

Table $6 \quad$ NIH Dollar Allocation by Gender 58

Table $7 \quad$ Comparison Total NIH Award Allocation and Percentage by Sex $\quad 61$

Table $8 \quad$ Characteristics by Academic Rank 62

Table $9 \quad$ Breakdown of Characteristics by Department 62

Table $10 \quad$ Breakdown for License Holders 63

Table $11 \quad$ Breakdown for those with Spin Outs 63

Table $12 \quad$ Breakdown for those with Patents 64

Table $13 \quad$ Breakdown for Highly Cited 65

Table 14 Breakdown of Characteristics by Number of Grants Received 66

Table $15 \quad$ Breakdown by Number and Size of Grants Received 67

$\begin{array}{lll}\text { Table } 16 & \text { Tobit Model Total NIH Dollar Iterations } & 74\end{array}$

Table $17 \quad$ Tobit Regression by Dependent Variables $\quad 75$

Table $18 \quad$ Correlation Matrix for Selected Individual Productivity Variables 76

Table 19 Correlation Matrix for Institutional Characteristics with Normalized

Variables $\quad 76$

Table 20 Diminishing Marginal Returns for Total NIH Grant to Publications 83

Table 21 Diminishing Marginal Returns for Average NIH Grant to Publications 85

Table 22 Diminishing Marginal Returns for Total NIH Grant to Citations 87

Table 23 Diminishing Marginal Returns for Average NIH Grant to Citations 88 


\section{List of Figures}

$\begin{array}{lll}\text { Figure 1 } & \text { Factors Influencing NIH Awards } & 38 \\ \text { Figure 2 } & \text { NIH 2008 Dollar Allocation } & 56 \\ \text { Figure 3 } & \text { NIH Award by Gender } & 59 \\ \text { Figure 4 } & \text { NIH Funds per Number of Grants } & 67 \\ \text { Figure 5 } & \text { Diminishing Marginal Returns for Total NIH Grant to Publications } & 84 \\ \text { Figure 6 } & \text { Diminishing Marginal Returns for Average NIH Grant to Publications } & 86 \\ \text { Figure 7 } & \text { Diminishing Marginal Returns for Total NIH Grant to Citations } & 88 \\ \text { Figure 8 } & \text { Diminishing Marginal Returns for Average NIH Grant to Citations } & 89\end{array}$


Chapter 1: Literature Review

In the future, the buildings housing those who will create well-paying, sustainable jobs, and provide the United States with a sustainable competitive advantage in the global economy are not courthouses or government offices but research labs, classrooms, and innovation centers where big ideas are hatched and subsequently translated into reality. (Thorp and Goldstein, 2010, Engines of Innovation: The Entrepreneurial University In The Twenty-First Century, p. 2)

There are limits to how much of the total talent a few universities can succeed in capturing. ... But the distribution of talent in its most extreme form is nevertheless sharply skewed. ... The greatest discoveries are made by a very small proportion of the population of professors at even the best schools. If the wealthiest dominate the "acquisition" of this group, they will in fact reduce the competitors to a farm system of universities, whose function will increasingly be to prepare those who demonstrate the greatest talent to move up to the "final eight" or the "final four”. (Cole, 2009, The Great American University, p. 47)

\section{Background}

The statements reproduced above represent the promise and the dilemma associated with American universities and colleges, which provide the wherewithalgraduates and intellectual capital—needed to compete successfully in a global economy. Though they are important institutions, needed for economic growth, their underlying principle of academic excellence, which has evolved since World War II, has created a number of challenges. First and foremost is the use of rankings to determine academic excellence. This system, called climbing the Carnegie Ladder, places research universities on the top rung of the ladder. Colleges and universities compete to reach the top rung. The problem, as Cole expressed above, is that those at the top of the ladder, 
considered to be the elite, garner the largest amounts of research funds and alumni contributions, which in turn attracts the most talented researchers: the stars. Thus the rich get richer. This makes it difficult for lower-ranked universities and colleges to compete effectively. A second challenge is the pressure associated with the expectations placed on the academic entrepreneur. The academic entrepreneur, as initially defined, is concerned with obtaining research grants and economic sponsorship from private and government sources. Over the past few decades, this term has taken on a more businessoriented meaning, in that such academics are actually entrepreneurs who found businesses, which happens particularly frequently in the field of biotechnology.

After World War II, university administrators made a conscious effort to make the academic entrepreneur the "normative behavior" for university professors. This behavior was encouraged through a reward system in which salaries and promotion were based on the amount of outside grant money received (Lowen, 1997).

Since the academic system has been considered a meritocracy, academics who are considered "stars" obtain a disproportionate amount of the rewards and acclaim, which is known as the Matthew Effect (Merton, 1968). Further, because of that acclaim, "star” academics are the most sought-after by universities attempting to maintain or improve their ranking relative to other universities. Consequently, they can demand premium salaries and other benefits from current or suitor institutions. However, once hired, exceptional performance is expected of them. The resulting pressure, critics such as Rhode (2006) have argued, has led to too little attention given to teaching and too much 
given to producing research. While this criticism may be justified, the underlying

problem concerns the atmosphere and culture surrounding the academic entrepreneur:

In an ideal world, research priorities would be determined by what is most likely to advance the pursuit of knowledge. In the world as we know it, the focus is often on what is most attractive to government, foundation, corporate, or individual funders. And when institutions or their faculty can take a cut of the revenues through patents or partial ownership interests, or when sponsors insist on secrecy or controls over publications to protect their investment, the corrosive possibilities are still greater. Why should so much effort focus on basic research when all the money is in developing no-snag panty hose? (Rhode, 2006: 20-21)

The purpose of this dissertation is not to address the validity of these criticisms. Rather, this research will attempt to answer three questions at the heart of the existing approach followed by university administrators. First, are there specific characteristics that positively affect the receipt of federal research funds? Second, are there increasing returns associated with attracting star academics to a university? Third, can lower-ranked universities move up in the rankings, or do those who are considered elite have such a cumulative advantage that it is almost impossible to reach the top tier?

As a foundation for addressing these three, primary research questions, I make one assumption and put forward two propositions. The assumption is that university officials and faculty researchers at universities, as well as policy makers, are rational actors. The first proposition is that at the strategic level there are two economic models at work. The second proposition is that university officials do not operate in a vacuum; their decisions are shaped by the norms of the university.

I first consider two economic models. The first model, clearly expressed above by Cole (2009), stresses the positive agglomeration effects and cumulative advantage 
early entrants obtain over time. The rich get richer and early entrants have an absolute advantage that later entrants have a difficulty overcoming. his model primarily views the university as one of many economic entities, albeit a somewhat-isolated ivory tower.

The second model is associated with creative destruction, disruptive technology, and institutional lock-in. This model is expressed by the statement above of Thorp and Goldstein (2010), and those who support space allocation for startups. Under this model, entrepreneurs appropriate the spillover benefits of university research. This model emphasizes the entrepreneur who starts new firms using acquired or retained knowledge. Moreover, universities interact differently with different types of entrepreneurs. For instance, the history of the electronics industry indicates that new firms were often created by dissatisfied employees who left existing firms. Silicon Valley’s rise was in part due to a close working relationship with Stanford University’s scientists and engineers. In biotechnology, meanwhile, the entrepreneurs are frequently academics. The software industry’s entrepreneurs are sometimes students who begin from their research at university to start new companies (Battelle, 2005; Darby and Brewer, 1997, Zucker; Friedman, 2004; Friedman, 2009; Lecuyer, 2007; Livingston, 2007).

It should be noted that these economic models are not mutually exclusive, with the second model often considered a subset of the first (Ellison and Glaeser, 1997; Fujita and Thisse, 2001). However, their different emphasis could lead to different policy decisions and differently structured local or regional economies. Consequently, they are treated here as two models. 
The treatment of these models as distinct is not unreasonable, since certain agglomeration effects are often stressed over others. Christophe Lecuyer (2007) attributes Silicon Valley’s growth to Marshall-associated agglomeration effects, primarily technology efficiency, with organizations adopting flatter and more flexible structures. He deemphasizes the public-good aspects of knowledge spillovers, the free ridership of social networks identified by Saxenian (1996), the monopoly rents associated with sectors dominated by intellectual capital, and lock lock-in effects, because of consumer choice or standardization, have allowed companies like Microsoft and Intel to dominate their markets and reap near-monopoly rents (Liebowitz and Margolis, 1999). On the empirical side, Henderson (2008) contends that economies of agglomeration and knowledge spillovers have not been sufficiently separated for analysis.

Two universities exemplify the polar distinctions between these models. At one end is Johns Hopkins University, which for much of its history has had a culture that discourages professors from collaborating with the private sector (Feldman and Desrochers, 2003; 2004). At the other end is Stanford University, which has actively encouraged collaboration and spin-offs and has had a policy to provide incubator space (O’Mara, 2005). In the case of Stanford, Battelle (2005, p. 67) stated, “Students don’t come to Stanford just for training. They come for the dream: to start a company, grow rich, make their mark on the history of technology, and maybe change the world.”

One difficulty is that neither strategic model leads to a clear-cut winner. Historically, Johns Hopkins has been the largest university recipient of federal research and development (R\&D) money, receiving almost twice as much annually as MIT and 
Stanford. Yet, Johns Hopkins “...lags behind other universities in measures of technology transfer performance, such as number of patents granted, licensing revenues and university-based spin-offs” (Feldman and Desrochers, 2004, p. 107).

Overlaying the strategic models and example universities are the organizational and cultural norms associated with university growth and prestige (the second proposition I mentioned above). Christensen and Eyring (2011) call this climbing the Carnegie ladder. The top rung of the ladder is a designation as a research university. To climb the ladder, lower-ranked universities attempt to emulate elite research universities by adding laboratory space and hiring star academics. The underlying assumption is that by emulating the elite research universities, those ranked lower will reap increasing returns by garnering a greater share of research funds, thereby attracting better academic talent and more graduate students. Two difficulties are presented, however. One, moving up the ladder is an expensive and high-risk venture. The winners of such a move appear to be faculty and administrators, with the costs being born by taxpayers, donors, fundraisers, and students. "But, whether the additional prestige is worth the gamble is another question, and one that has become increasingly important in light of the escalating costs of higher education” (Rhode, 2006, p. 14). The second difficulty is that the cumulative advantage of the elite research universities may be such that lower-ranked universities will always be subservient; in other words, the gamble may never pay off at all.

Having presented the assumption and propositions, the next step in developing the research model is to assess the assumption and to evaluate what prior research says about 
the propositions. Prior research will also help identify the most important variables to include in the model.

\section{Rational Actor Theory}

A consistent assumption in neoclassical economics is that humans are rational beings and will act in their own self-interest. Given the choice between two goods, an individual will seek to maximize his or her wellbeing, selecting the good that maximizes utility. A similar assumption is made about private and public organizations. Firms and organizations, of course, are legal entities, not individuals with individual preferences. Nevertheless, it is assumed that such entities seek to maximize institutional self-interest, as perceived by those who are in control. Such self-interest, when combined with the desire to make a profit, results in actions that impact the economy and long-term growth. North (1990, p. 74) notes the potential broader economic impact of one of the contributors to economic growth, knowledge: "The kinds of knowledge and skills that will be acquired by the organization to further its objective will in turn play a major role in the way the stock of knowledge evolves and is used.”

While organizations act in their self-interest, it is essential to distinguish between the interests and objectives of the individuals who control the organization and the needs of the firm. Andrew Grove recounted the story of how Intel exited the memory chip business. He was talking to Gordon Moore, Intel's Chairman and CEO at the time. "If we got kicked out and the board brought in a new CEO, what do you think he would do? Gordon answered without hesitation, 'He would get us out of memories.' I stared at him 
numb, then said, 'Why shouldn't you and I walk out the door, come back in and do it ourselves?’”(Grove, 1988, p. 89)

Grove called this incident a strategic inflection point, a point in time at which decisions become critical for a company’s growth, even its survival. Such points, however, are difficult to recognize and even more difficult to implement if the needed change is radical. This is particularly true if the organization has been very successful. Prior success can blind decision-makers, leading them to make decisions that seem foolish in hindsight.

The rational actor concept has also been generally accepted in the field of public administration. In a review of the literature on this topic, Camerer and Fehr (2006) conclude that under certain conditions, models based on self-regarding preferences and homogeneous rationality predict aggregate behavior rather well. In short, such models can be used to predict behavior, because that behavior is frequently consistent and rational.

Because an organization's goals and needs sometimes differ from those of its individual members, organizations have developed procedures to unify and channel individual actions. The primary mechanisms for doing so include:

1. Dividing work and assigning tasks.

2. Establishing work rules and standards of behavior.

3. Establishing a hierarchy through a system of authority and influence.

4. Indoctrinating members in the values of the organization, through training and informal means. 
5. Developing and articulating organizational goals and strategic objectives. (Argyris, 1973, Simon, 1973a)

Organizational and group norms are particularly important for moderating the conflict between individual goals and organizational needs. With respect to academic research, a number of norms have evolved over time and seem widely accepted. These norms, as articulated by Robert Merton (1968), are communism, universalism, disinterestedness, and organized skepticism. More simply put, academic findings must be published (communism), knowledge must be subjected to impersonal criteria for evaluation (universalism), personal interest must be excluded from procedures for acquiring knowledge (disinterestedness), and criticism is permitted and encouraged (organized skepticism; Centina, 1991). The general acceptance of these norms “...guarantee that, unlike other social systems, stratification and scientific inequalities in science grow by the application of universal criteria, so the most significant contributors are also the best rewarded” (De Bellis, 2009, p. 56). Feldman and Desrochers (2004) observe that these norms significantly influenced Johns Hopkins University’s approach to research, while Thursby and Thursby (2003) assumed the presence of these norms in their research design.

\section{Agglomeration Effects and Cumulative Advantage}

The concept of agglomeration effects is derived from the work of Alfred Marshall, who identified four main factors that contribute to and are the consequences of agglomeration: 1) the existence of “thick markets” for specialized labor; 2) the existence 
of knowledge and technology spillovers; 3) the emergence of subsidiary trades; and 4) the reduction of transportation and communication costs (Fingleton et al., 2007). More recently, the work of Arrow (1962; 2000) and Romer (1986) has expanded the concept of externalities to include the interactions between industries and organizations in a model of knowledge accumulation. Romer's work is sometimes associated with what is called new growth theory. In general, the production of new knowledge is said to have decreasing returns at the firm level. It takes considerable time and energy (some of which may not prove useful) to produce knowledge. However, there are positive returns to co-located firms via knowledge spillovers and free-rider appropriation. Co-located firms can sift through knowledge that is placed in the public domain or obtained through networking, take what they find useful, and leave the rest. At the initial level of commercialization, where a new product is dominated by intellectual capital or where path dependence and market lock-in control, there are increasing returns to generating knowledge. In knowledge-dominated products, once the knowledge is developed and transferred to the product, the cost of replication becomes minimal. For instance, the cost of a computer disk containing Microsoft Office is far less than the cost of developing the software. In addition, the cost of reproducing millions of copies of the code is equally small relative to the development cost. Lastly, if the commercializing firm is an early entrant and is able to establish its product as the standard, it will then gain a majority share of the market and reap monopoly-like profits. The theory of increasing returns also emphasizes the importance of timing: it makes little sense to enter a market that is already close to being locked-in (Arthur, 1996). 
Glaeser and Gottlieb (2009) conclude that while some manufacturing firms cluster to reduce the cost of moving goods, there appears to be a shift in factor intensity, particularly with respect to education levels. Education levels in metropolitan areas are positively associated with per capita income and employment growth (Gottlieb and Fogarty, 2003). High levels of education also appear to help lagging areas reorient and better adjust to economic shocks (Glaeser and Saiz, 2003). The presence of a research university helps facilitate economic growth in up-cycles, while also reducing the magnitude of contraction in a downturn (Lendel, 2010). Thus, urban areas with a high level of education and higher-ranked universities appear to have an advantage over those with lower levels of education and lower-ranked universities.

These contributions of education and associated skills appear to hold particularly well for science-based industries. In examining the expansion of knowledge stock in the field of nanotechnology, Darby and Zucker (2003) found that the size of the knowledge stock in a particular geographic area, in terms of both patents and articles published, is positively related to the creation of knowledge in the field. Similarly, the amount of National Science Foundation funding awarded to an area is also positively associated with the development of knowledge stock.

Consistent with new growth theory, entrepreneurial firms tend to locate near research facilities in order to appropriate knowledge spillovers (Jaffe, Fogarty, and Banks, 2002). Reinforcing the concentration of such firms is the tendency of star scientists and engineers to gravitate to highly ranked universities (Zucker and Darby, 2006). Finally, to complete and reinforce this pattern of growth, cumulative advantage 
and positive returns also appear to be at work in the distribution of federal funding. As Rose (1986, p. 96) observed: “The newest and most modern facility attracts eminent scientists to an institution; the scientists win vast numbers of research grants; and the resulting prestige makes the host institution a prime candidate for any additional facility support that becomes available. The elite research universities are quite naturally pleased with this process.”

In summation, the presence of highly skilled workers and knowledge diffusion are seen as key ingredients for economic success. Skill-based cities are both more productive and have higher rates of economic growth. In fact, there appears to be a cumulative advantage associated with highly skilled areas: such areas attract higher levels of talent, larger amounts of research funds, and more firms that want to appropriate the knowledge stock. Lastly, skill composition may be one of the most powerful predictors of urban growth.

In another respect, high skill levels, when combined with high levels of research and development (R\&D), provide the seed corn for innovation and entrepreneurship. This can lead to the development of disruptive technologies and processes, which in turn allow emerging firms that use new inventions and technologies to replace the old. This is the second model. 


\section{Creative Destruction and Knowledge Spillover: A Theory of Entrepreneurship}

Creative destruction is a dynamic process whose main actor is the entrepreneur, who creates something new: a technology, a process, a new supply source, or a new organizational structure. By placing these innovations in the market, the entrepreneur challenges existing firms and their products. In some cases, the new innovation commands a decisive cost or quality advantage that challenges not just the margins, but the very profit foundation of existing products (McGraw, 2007; Swann, 2009). New technologies or processes disrupt the existing economic balance and, over time, supersede older, previously established technologies. This succession forces existing firms to adapt or go out of business. The implications of this process extend beyond the simple succession of market-dominant firms and products. Caballero and Jaffe (2002, p. 148) found that the general decline in labor productivity from the 1960s to the mid1980s “...can be traced to a fall in research productivity connected to a decrease in the potency of old knowledge in generating new ideas.”

To the extent that a metropolitan area is dominated by older firms with technologies or products that are being challenged or superseded in the marketplace, the entire area will have a harder time competing. If the metropolitan area becomes unable to attract or keep highly skilled workers or unable to create an atmosphere conducive to innovation, the city may slip into a downward spiral. By contrast, “cities of knowledge” evolve and are sustained because they place considerable emphasis on building university research capabilities, generating industrial research, and attracting highly skilled workers, primarily scientists and engineers (O’Mara, 2005). 
The knowledge stock in a geographic area is primarily endogenous and a result of the local educational system, in which the university plays a major role. As an institution, the university consumes goods and services and prepares its graduates for the workforce with professional training and advanced degrees. Academics provide consulting services and engage in research and development activities that spill over into the economy. Other university outputs include capital investment and provision of regional leadership (Goldstein and Renault, 2004).

Emphasis on the entrepreneur shifts the focus of economic decision-making away from the exogenous firm to "individual agents with endowments of new economic knowledge"; however, these agents cannot function if the knowledge stock that results from R\&D is entirely appropriated by existing firms (Aces et al., 2009). Audretsch (2007) argues that high-technology hubs like Silicon Valley, Austin, San Diego, Boston’s Route 128, and North Carolina’s Research Triangle Park represent economic cultures and clusters that exhibit the attitudes, actions, and values necessary for an entrepreneurial society. As Audretsch (2007, p. 190-91) observes: “The flagship institutions and policies in an entrepreneurial society must have an entirely different focus than their counterparts did in the managed economy. The entrepreneurial society institutions are a departure from the managed economy stalwarts: unions, big government programs, and corporate hierarchy.”

In her study of the growth of Silicon Valley, Saxenian (1996) revealed the importance of network linkages and flatter organizational structures for dynamic economic environments. Her analysis indicated that, in the semiconductor industry, at 
least, the Route 128 corridor was more closely linked to Audretsch’s “managed economy.” Further, she observed that the vertical integration, structural hierarchies, and secrecy that typified Route 128 corporations prevented them from responding quickly enough to the accelerated pace of technological and market change in semiconductors.

Examining labor mobility and patent citations, Almeida and Kogut (1999) found that networks and labor mobility were stronger in Silicon Valley than in other semiconductor clusters in the United States. Labor mobility helped diffuse knowledge and reinforced an entrepreneurial orientation. In San Diego, a cadre of managers associated with Hybritech, a company formed in the early 1980s, was instrumental in founding or strengthening relationships with other local biotechnology companies. These companies and their associated linkages became the basis for San Diego’s biotechnology cluster (Casper, 2007).

Networks of relationships are one of the differences between older, established economic areas and emerging ones. Looking at patent issuance and subsequent citations, Auerswald and Kulkarni (2008) found that the infrastructure and culture of regions with emerging technology clusters also differ from older, established regions. Emerging regions lead in patents for new technology, as well as in "hot patents," which are previous generations of patents that lead to innovation. According to their analysis, many areas with emerging technology economies are on urban peripheries and in small to midsized cities.

These findings of Saxenian (1996), Almeida and Kogut (1999), O’Mara (2005), Audretsch (2007), and Auerswald and Kulkami (2008) support the idea that knowledge 
spillovers and disruptive innovations facilitate the development of new economic clusters. This is especially true when technological/institutional lock-in and path dependence substantially limit the ability of existing firms to appropriate or absorb new knowledge.

New technologies and ideas challenge the established order, yet because they are not as well-developed or mature, they may seem inconsequential when compared with existing products. An early example is provided by the reaction of a British Parliament committee upon reviewing Thomas Edison's idea for electrical lighting. The committee noted that while Edison's wild dreams might be “good enough for our transatlantic friends," they were "unworthy of the attention of practical or scientific men” (Jones, 2003, p. 59) A more recent example concerns the development of the personal computer. Commenting on the rise of Apple Computer, Berkum (2010) noted that two decisions facilitated Apple’s success. First, two leading companies-Atari and Hewlett-Packard—declined to manufacture Apple’s computer. Second, Xerox chose not to market the Alto computer developed by its California research laboratory. Given the later growth of the personal computer market, these decisions today seem foolish. However, the managers of Atari, Xerox, and HP must have believed they were making reasonable business decisions. Another recent example is the development of the "proof of concept" data for Genentech’s underlying science. According to Robbins-Roth (2000), when Keichi Itakura and Art Riggs, two of the scientists associated with the development of the proof of concept, applied for federal funding, "the reviewers doubted they could do it in the 3year grant time frame and also doubted the scientific merit. Genentech funding did it in 9 
months, and Philip Handler, President of the National Academy of Science, called it a scientific triumph of the first order” (p. 16).

More generally, seemingly minor decisions made early in the establishment of a new technology can have large subsequent impacts (Arthur, 1996, 2009; Swann, 2009). Once a technology or process is established, it becomes harder for the organization using it to change. "If it were desirable to re-establish an excluded technology—say steam propulsion—an ever widening technical changeover gap would have to be closed” (Arthur, 1996, p. 46). Intellectually and technologically, organizations using dominant technologies or ideas tend to be locked in. "It's both a psychological and economical phenomenon: as people and companies’ age, they have more to lose. ... Attitudes focused on security, risk aversion, and optimization of the status quo eventually become the dominant positions, and even become organizational policy at companies that were once young, nimble and innovative” (Berkum, 2010, p. 62)

Under conditions of lock-in and path-dependence, the attackers-new firms using new technology or processes - have an advantage. If a technology or process happens to become dominant and locked-in, a company using it will reap monopoly profits and expand substantially, just as Microsoft and Intel did. The growth of new companies under such conditions can help create both critical mass and a comparative advantage for the geographic regions in which they are located. 


\section{The Role of Universities}

The role that universities play in economic development is both historically important and wide-ranging. Reviewing the development of the Industrial Revolution in Western Europe, Mokyr (2002) argued that the presence of academies, universities, and research institutes, along with the “...rules by which they play (such as open science, credit by priority, reproducibility of experiments, and rhetorical rules of acceptance) helped determine its historical path” (p. 288). Mokyr also argued that technological advances are in part determined by the ability of educational systems to teach technical skills and enhance workers' ability to absorb new knowledge and employ it in innovative ways.

Thorp and Goldstein (2010), Audretsch (2007), O’Mara (2005), Zucker et al. (1998), and Saxenian (1996) all emphasized the importance of entrepreneurship and universities for creating the culture and infrastructure urban areas and regions need to reach critical mass and sustain economic growth. Universities are also uniquely qualified to bring disparate groups together to find solutions to problems that seem intractable. As Trani and Holsworth (2010) observed: “The upshot is that modern colleges and universities possess resources—scientific, commercial, medical, and cultural — that are vital to the entire range of community and regional development activities relevant to the contemporary knowledge economy” (p. 220).

Universities provide the ingredients regions need to develop and sustain their comparative advantage (Feldman, 2007; Jaffe, Fogarty, and Banks, 2002). As noted above, they provide employment and training. University research also contributes 
substantially to the development of new innovations and technologies (Mansfield, 1991). Equally importantly, universities contribute to the stock of knowledge from which new innovations and technologies are drawn. Academic papers have a greater spillover effect than do industry papers (Adams, Clemmons, and Stephan, 2006). In addition, coauthorship between star scientists and/or top-ranked university scientists and company scientists increases the number and citations of that firm’s patents (Zucker, Darby and Armstrong, 1998).

Firms tend to locate near major research universities in order to tap into tacit knowledge (Darby and Zucker, 2003). However, Bania, Eberts, and Fogarty (1993) found that the impact of universities on startups may be industry-specific. Their analysis found a significant association between university research and electrical and electronicequipment industries. However, for instruments and related products, the relationship was insignificant. Moreover, they found that greater numbers of scientists and engineers in the workforce did not have an effect on number of startups.

Biotechnology is one area where there is a strong linkage between the university and the development of economic clusters (Friedman, 2004; Friedman, 2009; Zucker, Darby and Brewer, 1998). The rise of the Washington, DC area as a biotechnology center is one example. The Washington area had little biotechnology presence in 1973, with only ten biotechnology companies. By the late 1990s, however, there were over 300 biotechnology companies in the DC area. Maryland ranked third in 1999, behind California and Massachusetts, among US states in the number of biotechnology companies, and the state ranked third, behind California and New York, in the number of 
scientists and engineers with doctorates working in biotechnology (Feldman and Francis, 2003). Reviewing the growth of the DC biotechnology industry, Feldman (2007) noted “...conditions favored new-firm formation, perhaps in part due to the lack of an established large pharmaceutical company that could engineer mergers or acquisitions” (p. 256). A key factor in the growth of biotechnology in the Washington area appears to have been a reduction in federal employment, which left many government scientists out of work, creating a surplus of highly skilled labor. Slowly, networks of entrepreneurs, policymakers, and suppliers began to form. At the same time, local universities, colleges, and technical centers recognized the need for more high-technology-oriented training and began to offer needed programs.

Case studies of San Diego and Atlanta (Walcolt, 1999; 2002) and Cincinnati (Ferrand et al., 2009) have indicated that the presence of local universities facilitated biotechnology development there. Lester's (2005) examination of economic activity and growth in localities worldwide found that the contribution universities make to economic growth depends on the type of economic growth that is occurring, concluding as follows:

In cases of new industry creation a local university or public research laboratory typically played the role of anchor institution, whereas in the case of upgrading the anchor institution was more likely to be a lead firm or lead customer. In science-based industry formation the highest-impact educational outputs of local universities were PhD-level scientists and engineers with an interest in entrepreneurial careers and some exposure to entrepreneurial business practices. (p. 23)

Regardless of the model—agglomeration or creative destruction-existing research appears to agree on three points. First, universities are important contributors to areas' economic development and stability (Feldman and Florida, 1994; O’Mara, 2005; 
Zucker, Darby and Brewer, 1998). Second, money to sustain research, generally channeled through a research university, is a key contributor to economic growth, although the impact of research funds is still unsettled. For example, Bloom-Kohout, Kumar, and Sood (2009) found that for every dollar of federal extramural research funding received in the life sciences, non-federal funding increased by $\$ 0.33$. In pharmaceuticals, a 1\% increase in public basic research (specifically, NIH funding) ultimately led to a $1.8 \%$ increase in the number of new firms (Toole, 2012). Woodward, Figueiredo, and Guimaraes (2006) found that the impact of research funds is generally marginal, ranging from 0.04 to 0.004 percent per million-dollar increase in R\&D funding. Third, there must be an intertwining of government, universities, and private companies, which is called the Triple Helix (Etzkowitz, 2008; Etzkowitz and Leydesdorff, 2000; O’Mara, 2005). In the Triple Helix, each entity reinforces and challenges the others with new ideas and new needs. The result is a capitalization of knowledge similar to the development of physical infrastructure. Etzkowitz (2008) concludes as follows:

When knowledge is transformed into capital, persons from any originating organization may be potential entrepreneurs and founders of firms. A triple helix in which each strand may relate to the other, two can be expected to develop an "overlay of communications, networks, and organizations among the helices”. (p. 20).

This combination results in a constructive advantage, which is defined as “... a strategic policy perspective of practical use to business firms, associations, academics and policy makers” (Cooke, 2006, p. 188). The need for such a policy is one of the lessons O’Mara (2005) draws from the growth of “Cities of Knowledge”: hightechnology development must be “the end, not the means.”(p. 230) 
Yale University provides a practical example of the Triple Helix. Its experience also suggests that internal changes in the university are often necessary. Prior to 1993, Yale had a culture regarding innovation that cost it foregone remuneration from a number of faculty inventions. Between 1993 and 1996, “...the arrival of young faculty members from universities traditionally collaborating with industry contributed to a cultural change at Yale. Moreover, successful commercialization has also contributed to the creation of a new culture at Yale that supports technology transfer” (Breznitz, 2014, p. 75).

As a result of this cultural change, the staff in Yale’s Office of Technology Transfer (OTT) was upgraded. By 2004, the OTT employed eighteen professionals with five-to-seven years of experience in private industry. The process of licensing and spinning-out companies was changed to make it easier for faculty to do so. The focus was also shifted from simply licensing and patenting to transferring inventions to the public domain.

Between 1996 and 2011, royalties increased from a little over \$5 million annually to $\$ 11$ million. By 2012, Yale was averaging 24 patents a year and had had 55 spin-outs and companies, of which 29 were biotechnology spin outs.

To catalyze the capitalization of new businesses, Yale brought together venture capitalists, local companies, and local and state government agencies with the goal of facilitating the development of economic clusters in New Haven and Connecticut. In sum, without the cultural change and committed leadership at Yale, New Haven’s biotechnology cluster might not exist. 


\section{$\underline{\text { Star Scientists and Engineers }}$}

The case of Yale and biotechnology suggests that there is often a direct linkage between startups and university scientists. Zhang and Patel (2005) found that between 1990 and 2000, scientists working at universities or research laboratories founded close to half of venture-backed biotechnology startups, about two-thirds of which stayed in the same state as the university or laboratory. Examining the relationship between human capital and the birth of biotechnology companies in various regions throughout the United States, Zucker, Darby and Armstrong (1998) found three significant factors: 1) a concentration of what the authors term "star scientists" or what Audretsch (2001) calls the "best scientific talent”; 2) the presence of major research universities; and 3) federal funding. Of the three factors, the presence of star scientists and engineers was considered the most important. In fact, once the number of star scientists is statistically controlled, the effects of the local and national economic infrastructures disappear (Zucker and Darby, 1996). Stars, defined as scientists with twenty or more discovery articles, account for a higher percentage of new innovations than do their counterparts (Zucker, Darby and Brewer, 1998). While star scientists represented only $0.8 \%$ of scientists listed in the GenBank through 1990, they accounted for 17.3\% of published articles, or about 22 times the average Gen-Bank scientist (Zucker and Darby, 1996). Star scientists also tend to congregate, moving from lower- to higher-ranked universities and to locations with greater opportunity. The presence of star scientists and engineers is positively associated with firm location and new-firm creation, which contributes to a concentration of hightechnology industries in their vicinity (Zucker and Darby, 1996). 


\section{The Carnegie Ladder}

The Carnegie Ladder refers to a classification of academic institutions developed by the Carnegie Foundation, as follows: Research Universities, Doctoral Universities, Comprehensive Institutions, Liberal Arts Colleges and Two Year Colleges, and Specialized Institutions. While there is evidence of a cumulative advantage among toptier institutions, some convergence in terms of publication volume has also occurred. Evidence of publication convergence led Dey, Milem, and Berger (1997) to observe that

"it is not surprising that institutions at the lower levels in the hierarchy are attempting to be more isomorphic with regard to the publication-productivity rates of the top-tier institutions, given the higher visibility and greater influx of research funds that result from high rates of productivity” (p. 320).

Reviewing the approach taken by the University of Chicago in assembling the faculty in economics that became known as the Chicago School and which is associated with a number of Nobel Laureates, Overtveldt (2007) remarked that the approach taken in the earliest days was simple: "We look for home runs” (p. 29). Administrators sought economists that, because of their extensive scholarship, were very likely to make breakthroughs in the discipline.

Obtaining the best possible academic talent has long been the conventional wisdom in higher education. Cole (2009) considered talent accumulation a necessary condition for institutional excellence. His historical analysis of research universities reinforced the notion of an accumulative advantage and points to the allure of being one of the best. He concludes as follows: 
The oldest private and public universities used their early advantagebetter faculty attracted stronger students, stronger students meant greater alumni contributions, greater alumni contributions led to better research facilities, better research facilities drew better faculty and so on. Advantages such as these allowed top universities to accumulate even more resources from individuals and institutional backers in order to create still greater advantages in competing for talent. (p. 34-35)

Stanford University's history of growth illustrates the cumulative advantage of a top-ranked university, but it also serves as evidence that middling institutions can become powerhouses. Leland Stanford and his wife founded a junior college as a memorial for their son. Centered on farmland in Palo Alto, California, Stanford opened its doors in 1891. By 1945 it was a regional university "with aspirations.” By 1961, it had ten departments in the top echelon of U.S. universities, as rated by the American Council on Education. By 1984, the American Council on Education ranked Stanford's engineering school third, just behind UC Berkeley and MIT (Adams, 2009).

The guiding light for Stanford's ascent was Fredrick Terman, the provost and Dean of Engineering. Terman implemented a number of significant changes in the way Stanford operated. He sought to create strong connections with the local business community. He created steeples of excellence by attracting eminent scholars, under the belief that these stars would attract other stars, as well as attracting money from federal and private sources. He also encouraged faculty to supplement their university income by consulting for private companies. Lastly, he helped create the Stanford Industrial Park, where new and existing firms could be in close proximity to the university's facilities and faculty. 
Stanford's development was a slow process and not without controversy. The shifting of the political science department to a behavioral approach (which eventually raised its rankings) is a case in point. In 1957, Terman and Stanford's President Sterling blocked the department's choice for chair, Mulford Q Sibley. This created a confrontation with faculty members and a furor in the press. However, Terman wanted to hire a star with a behavioral approach, consistent with his view of the direction the university needed to take in order to align with the preferences of potential funders. Ultimately, the university hired Gabriel Almond as chair in 1963. Sidney Verba, a leader in comparative politics with a behavioral approach, moved from Princeton to Stanford a year later. During this seven-year period, the department's ranking rose from thirteenth to seventh (Lowen, 1997).

While Terman did not build steeples of excellence across the entire university, his overall approach was successful. The symbiotic relationship between Stanford University and local businesses would lead to an economic dynamo that became known as Silicon Valley. Between 1988 and 1996, startup companies linked to Stanford accounted for $60 \%$ of the revenue generated by all Silicon Valley firms (Gibbons, 2000). By 1998, Silicon Valley’s publicly held companies had a market capitalization of $\$ 743$ billion—while Detroit’s automotive industry was capitalized at \$136 billion and Hollywood’s entertainment firms were capitalized at \$76 billion (Nevens, 2000).

As Silicon Valley companies flourished, Stanford's standing as a top-tier research university became firmly established. As of 2006, its 264 National Academy-elected members ranked behind only Harvard (with 284 members). Also in 2006, the size of 
Harvard's endowment ranked first, while Stanford's ranked third. In research dollars received, Stanford ranked eighth behind top-ranked Johns Hopkins (The Center for Measuring University Performance, 2008). Thus, Stanford has become a prime example of an entrepreneurial university.

\section{The Entrepreneurial University}

The aura of Silicon Valley and its symbiotic relationship with Stanford has led other universities, as well as governments, to seek to replicate Stanford's strategy. The University of Louisville, for instance, was able to increase its NIH funding between 1996 and 2006 from $95^{\text {th }}$ to $73^{\text {rd }}$ place, or from $\$ 20$ million to over $\$ 90$ million. This was accomplished through a series of initiatives that included "bucks for brains," a statefunded program used to create and fill endowed chairs with faculty who are exceptional contributors to their fields. University and local leadership expected that these faculty would "bring major extramural grants and contracts to the university" (Schweitzer, Sessler, and Martin, 2008, p. 564).

At the national level, Congress endorsed the concept of an entrepreneurial university in passing the Bayh-Dole Act of 1980, which allows universities to license and patent inventions and innovations derived from federally sponsored grants. The expectation was that a greater amount of university-to-industry technology transfers would occur, which in turn would garner additional revenues from fees and licenses (Mowery et al., 2004). 
The Bayh-Dole Act has contributed to the creation of technology transfer offices within universities and has also resulted in an increase in the number of patents issued to colleges and universities. The impact of the Bayh-Dole Act is still being debated.

Aldridge and Audretsch (2010) found that 70\% of university scientists with grants from the National Cancer Institute (NCI) who commercialize their research do so through their university's office of technology, while the other thirty percent use the back door of commercializing their research through spinouts. Mowery et al. (2004) questioned whether the Act has been an important contributor to the university's impact on economic growth and development, noting that universities had conducted research and made substantial economic contributions to local economies long before the Bayh-Dole Act. The research of Thorp and Goldstein (2010) fall somewhere in the middle. They noted that only a few universities have reaped substantive financial rewards from licensing. Among these is Emory University, with \$320 million from the AIDS drug Emtriva, the University of Florida, with $\$ 80$ million from Gatorade, and Columbia University, with \$600 million from Axel genetic-engineering techniques. Consequently, they argued that universities ought to be less concerned about the revenue generated by licensing and more concerned about how the office of technology transfer can be used to simplify the process of licensing and patenting products and inventions:

By making it easier for faculty to obtain patents and negotiate license deals and spin out-out companies, the university keeps faculty engaged and connected and therefore less likely to leave. Providing faculty with equity ownership is cheaper than a salary increase, especially if money for an increase must come from an endowment where, typically, only 5 percent per year is expendable. (Thorp and Goldstein, 2010, p. 35) 
Improvements to the technology transfer system are but one aspect of Thorp and Goldstein's argument. The overall thrust of their argument is that to stay competitive in a knowledge-based and increasingly global economy, universities need to reorient their culture to become more entrepreneurial. This includes seeking out a wider variety of funding, which often facilitates collaboration and the flow of information. They believe that an entrepreneurial emphasis also encourages labs to focus on outputs and results, which increases the impact of their research. This in turn helps garner additional funds for research.

Thorp and Goldstein’s argument that universities are not entrepreneurial enough emphasizes the competing strategies that underpin the drive to move up the Carnegie Ladder. Comparing Stanford's rise with the standing of UC Berkeley, Adams (2009) concludes that Stanford had three things that Berkeley did not: 1) the right leader; 2) a long-term strategy; and 3) it faced a financial predicament that made entrepreneurial activity both attractive and necessary. In a review of Fredrick Terman's attempts to replicate Stanford’s success elsewhere, Leslie and Kargon (1996) found few successful examples. They conclude that Terman did not recognize how much his leadership and the circumstances associated with post-World War II spending combined with the unique characteristics of the small start-ups in Silicon Valley to create an economic dynamo. In short, the development of Silicon Valley might be an isolated example of fortunate circumstances.

If the Stanford experience was unique, attempts to replicate its dynamics might be futile. Along the same lines, becoming more entrepreneurial might not garner a 
university a very large return, as evidenced by the limited number of universities that garner substantive funding from licensing. The question then becomes: is it possible to move up the university rankings, or do those at the top have such an absolute advantage that doing so is futile?

\section{Universities and Research Funding}

Research regarding the relationship between a university’s funding and its ranking indicates a degree of fluidity. Geiger and Feller (1995) analyzed total federal research funds distributed to American universities from 1952 to 1990, showing that the percentage of total federal research funds received by the ten largest performers decreased over that time from $43.4 \%$ to $20.1 \%$. There were ten Tier I losers, while Tier II Universities increased their share, with 14 gainers and six losers. The financial condition of universities did not explain these changes; rather, gaining institutions became more like the Tier I institutions (Geiger and Feller, 1995). In an examination of research awards to universities from 1972 to 1994, Brewer, Gates, and Goldman (2001) found little overall change. In 1972, ten institutions attracted $25 \%$ of the research funding, and 29 attracted 50\%. In 1994, 13 institutions had 25\%, and 35 had 50\%. However, among individual institutions there was fluidity. There were more gainers (12) than losers (7). The authors postulated that more institutions sought research funds because total research funding increased over this period. Quon (2001) found that the NIH funding rankings of medical schools from 1990 to 2000 were likewise fluid: 
In general, large changes in rank were more frequent for schools ranked lower to begin with, no doubt in part because the actual dollar amounts of their total awards were proportionately less. Nevertheless, large moves also occurred in the top-tier schools, illustrating that even the most research-intensive schools can experience substantial and sustainable changes in ranking. (p. 2)

More broadly, Bania et al. (1991) found that increases in NIH funding contributed to a shift in university positions. The top universities moved up by being more competitive within fields rather than by specializing in the right mix of fields. University degree programs were a vital contribution to the area's research base. Another major contributor to university's ability to obtain NIH funding was investment in infrastructure, particularly science and engineering facilities and equipment.

\section{University Funding and Variable Interaction}

Studies of the relationship between university funding and performance have sometimes used a basic production function approach (Bania, Eberts, and Fogarty, 1993; Adams and Griliches, 1998; Lendel, 2010). The university receives funds and produces products: students and publications. However, the nature of the relationship between funding and output, particularly publications, is inconclusive. Summarizing his own and other research, Landel (2010) noted two major conditions that impact the relationship: 1) top-ranked scientists receive more funding because they are better-connected and have better reputations for producing solid research; and 2) recurrent funding is important for sustaining focused research, and better-funded universities have the capability to provide recurrent funding. In a review of the impact of industry funding in the life sciences, 
Campbell, Koski, and Blumenthal (2004) found that such funding allowed academics to publish more.

Reviewing the research on publication productivity among scientists, Fox (1983) concluded that one of the main determinants of successful publication is location at a prestigious university. Because the elite institutions have resources to advance the work of their academicians, superior talent gravitates to these locations, which in turn furthers their advantage. Pessimistically, but consistent with the notion of cumulative advantage, he concluded that since the elite institutions already have sufficient opportunities to obtain resources, there is probably no help for those institutions at the bottom.

Publications are an important output of universities and are an important determinant of their receipt of research funds. McAllister and Condon (1985), Pagel and Hudetz (2011a; 2011b), and Pao (1991) all found a positive association between NIH funding and the quantity and nature of university publications. This association also appears to hold true for papers in biomedical subfields (McAllister and Condon, 1985). Jacob and Lefgren (2007) estimated that NIH funding results in the publication of one additional article over a five-year period. Boyack and Jordan (2011), also looking at NIH grants and associated publications, found that the median time lag to publication was three years and that each grant leads to approximately 1.7 new articles. Further, articles acknowledging NIH grants were cited twice as much as non-grant-acknowledging articles. Lastly, Pagel and Hudetz (2011a; 2011b) found that the H-index, an indicator of reputation as represented by citations per article, was positively associated with receipt of NIH funds. 
Understanding what drives publication activity has important implications for a university’s impact on the larger community. Individual motivation, as opposed to outside activity, plays a part in publication. Agrawal and Henderson (2002) found that researchers at MIT are driven primarily by interest in the research field, making publishing decisions on a case-by-case basis. Academics who license an invention or who are involved in a startup continue to publish at a rate consistent with or higher than their peers (Lowe and Gonzalez-Brambila, 2007; Thursby and Thursby, 2003). Star scientists, regardless of their level of involvement with private-sector firms, tend to generate a larger number of publications than do their peers (Zucker and Darby, 1996). Agrawal, McHale, and Oettle (2012), examining the impact of star scientists on departmental productivity, found that productivity increases with the arrival of a star.

However, there is a view that as researchers age, their publications decline in quantity (Baser and Pema, 2004; Gingras et al., 2008; Levin and Stephan, 1991). However, Wray (2003) found that young scientists are not necessarily more frequent publishers than older ones, because they are not as well-positioned to make revolutionary discoveries. He concluded that middle-aged scientists are the best-positioned.

There also appears to be an aging effect with respect to citations of published work. Parolo et al. (2015) found that citations reach their peak a few years after the date of publication, decaying rapidly thereafter. Papers with fewer citations decay more rapidly. Pollman (2000) found that aging occurs by at least four years from publication. Redner (2005), looking at citations of work published in the journal Physical Review over 
a 110-year span, found that average citation age was 6.2 years but found it to be less than two years with only 3.6 citations for articles published before 2000.

Institutionally, there may be some convergence in terms of publications. A timeseries analysis of the publications of Carnegie-categorized universities by Dey, Milem, and Berger (1997) found evidence to support both the cumulative-advantage and mobility perspectives. The universities at the top of the Carnegie ladder had high rates of publication. However, many institutions in the middle also had high rates of publication. They conclude that those institutions in the middle with higher rates of publication have an opportunity to join the elite.

While the relationship between research funding and publication is complex, it may also be mutually reinforcing. As McAllister and Condon (1985) noted, “it takes money to do research, but one has great difficulty obtaining awards without a good publication record” (p. 74). Further, when research funding is linked directly to publication, there is a direct impact on the level and type of publications (Butler, 2004; Jimenez-Contreras et al., 2003; Reinhart, 2009).

At the institutional level, research on the relationship between total NIH funding received and average articles published per faculty member is inconclusive. Sandstrom (2009) found that the association between publications and federal funding is generally weak. Alternatively, Adams and Griliches (1998) found decreasing returns to the effect of publications on grant funds received. One possible reason for these decreasing returns is the growing number of journals and virtual media in which an academic can present research findings (Kim, Morse, and Zingales, 2006). The growing number of options for 
information dissemination makes it more difficult to assess the impacts of scholarly activity. Ali, Bhattacharyya, and Olejniczak (2010), however, found a strong statistical relationship between publications in 2002-03 and grant dollars received. They also found decreasing returns for the number of publications versus grant dollars received and a disparity in grant dollars by academic field. For instance, academics in the Biological and Biomedical Sciences field receive larger amounts of total grant funds than do academics in the Physical and Mathematical Sciences field.

In summary, history indicates that universities have moved up the Carnegie Ladder. Sustained federal funding provides the resources institutions need to develop the infrastructure required to create a virtuous cycle and move up the ladder. Conventional wisdom indicates that attracting star scientists and engineers is a key component to movement up the ladder. Stars have higher publication rates, and because of the positive and possibly mutually reinforcing association between publications and federal funding, conventional wisdom and prior research indicate that stars attract higher levels of federal funding. However, citation rates peak soon after publication, decreasing rapidly thereafter, which calls into question the conventional wisdom that stars automatically generate positive returns. Further, the distribution of research funds may be sensitive to field-specific activity; thus, broad generalization may not be appropriate. 


\section{Chapter 2: Research Design}

\section{$\underline{\text { Overview }}$}

In an economy driven by innovation and entrepreneurship, research universities generate the discoveries and spillovers that help develop a constructive advantage. A key element in this regard is the level of research funding received; without support for $R \& D$, the ability to develop a constructive advantage is diminished. This dissertation will attempt to determine which variables contribute to universities successfully obtaining research funds. It will also attempt to determine if star scientists garner a higher share of research funds and estimate the extent to which their presence produces spillover benefits among their university colleagues.

The bulk of public funding for R\&D comes from the federal government. The main recipient of federal research dollars is the individual academic, who submits requests for funding through his or her grant proposals. In addition to the technical aspects of any proposal, the characteristics, productivity, and reputation of the researcher play a role in awards of grant funding (Boyack and Jordan, 2011; Kienholz and Berg, 2014; McAllister and Narin, 1985; Pao, 1991; Zucker, Darby, and Armstrong, 2002).

One criticism of the federal research-funding process is that peer review panels steer funds to those institutions with which the members of the panel are affiliated (Rose, 1996). To the extent that grant funds are allocated based on characteristics beyond the specific merits of research proposals, there might exist a normative profile of who is best qualified. The policies of the university and its reputation may also contribute to the 
successful receipt of grant funds (Bania et al., 1991). The extent to which such a profile exists can be assessed by examining the statistical effects of personal and university characteristics on the receipt of federal funds.

Once an academic submits a proposal, the funding agency determines if the proposal merits funding. The dominant funding sources in the biotechnology disciplines in the United States are the National Institutes of Health (NIH). NIH grants are also a dominant funding source for Nobel Laureates in the United States (Tatsioni, Vavva, and Ioannidis, 2010).

Grant proposals to the NIH are subject to a rigorous review process that is divorced from the input of staff (Ross, 2000). The Center for Scientific Review, with 17,000 external experts, reviews at least a portion of $70 \%$ of NIH funding requests. The review process is also considered to be the most consistent in funding use-inspired basic research (Stokes, 1997).

Figure 1 presents the broad categories into which specific variables that influence $\mathrm{NIH}$ funding can be arranged. Broadly, these fall into four categories: 1) General Environmental, including general geographic and population characteristics; 2) Institutional/University, including variables associated with the university; 3) Departmental, including variables associated with the department or institute in which the researcher is located; and 4) Researcher Characteristics. 


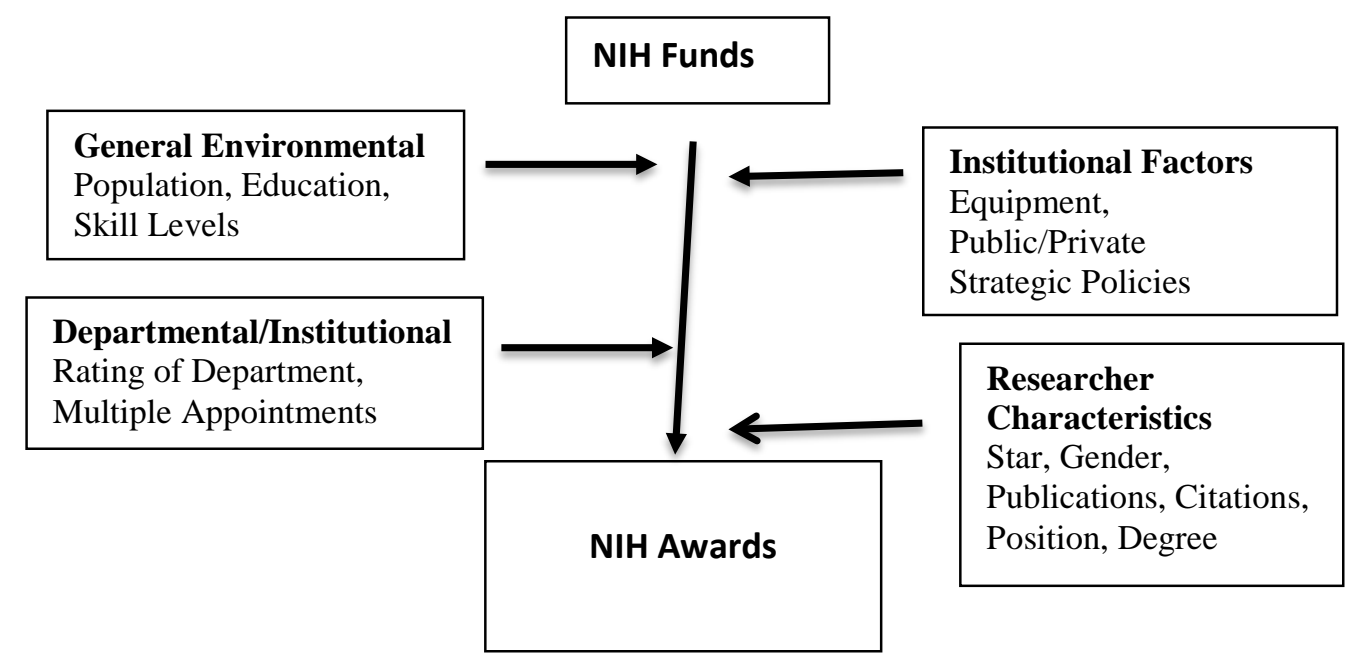

Figure 1. Factors Influencing NIH Awards.

Except for the work of Bania et al. (1991), little has been done to analyze key characteristics distinguishing NIH recipients from non-recipients. While Hendrix (2008) estimated the relationship between NIH funding received and the number of articles published per faculty member, he focused on the university rather than the individual. Zucker and Darby (1996) compared the performance of star scientists with that of nonstars but did not look specifically at NIH recipients, nor did they explore whether increasing returns are associated with NIH funding received. Ali, Bhattacharyya, and Olejniczak (2010) investigated the receipt of federal grant money from multiple sources, academic productivity, and institutional characteristics using a Tobit model. The independent variables included whether the university is a public or private member of the American Association of Universities, the percent of university academics who have published articles, broad department breakdowns, number of articles published, the 
number of articles squared, and those articles’ associated citations for the time frame 2003 to 2004. They did not consider whether there is a difference among highly cited researchers, grant recipients and non-recipients, and institutional academic rank. While they included a geographic distribution, they did not include variables such as university rank, metropolitan size, whether or not there is a medical school, or the number of institutional NIH recipients in the geographic area. This work examines a larger number of possible contributing factors.

\section{$\underline{\text { Research Questions }}$}

This dissertation will attempt to address some of the gaps in the research by exploring the following empirical questions:

1. Do Highly Cited Researchers receive significantly more NIH funding than do others?

2. Does the number of members of the National Academy of Arts and Sciences at a university positively contribute to NIH funding? (Is there a faculty-level halo effect?)

3. Does having a degree from a top-ranked university contribute positively to the amount of NIH funding received?

4. Does the number of articles published in the two years immediately preceding the receipt of NIH funds have a positive impact on the level of NIH funding?

5. Does the average number of citations per article published in the preceding two years positively affect the level of NIH funding? 
6. Is there a difference in publication performance between NIH recipients and nonrecipients?

7. Do academics who license an innovation or invention through the university's Office of Technology Transfer (OTT) receive more NIH funding than other recipients?

8. Do academics who are part of a spinout receive more NIH funding than do other recipients?

9. Does being listed as an inventor on a patent application by the university contribute positively to the receipt of NIH funding?

The research design builds on the work of Ali, Bhattacharyya, and Olejniczak (2010), Sandstrom (2009), Hendrix (2008), McAllister and Condon (1985), and McAllister and Narin (1983). In its simplest form, the design postulates a direct relationship between a researcher's NIH funding and his or her prior publications. A key assumption is that current funding is in part a function of the number of articles an academic published in prior years. The most recent preceding years, in this case 2006 to 2007, are assumed to be the most important. A further assumption is that research is driven more by individual interest and professional norms than by funding levels. These professional norms, as noted in the previous chapter, are communism, universalism, disinterestedness, and organized skepticism. The postulated existence of these norms allows for the possibility that peer reviewers, consciously or unconsciously, follow a set of standards by which they measure professional credibility. 
Both the underlying assumptions and prior research results indicate that a model with just two variables_-funding and total publications—is too simplistic. Additional variables are needed to account for other possible factors influencing NIH awards. Some of the factors to be tested include whether the recipient is a star scientist, the recipient's gender, whether the recipient's degree is from a top-ranked university nationally or globally, the number of high-caliber academics located at the university, the type of degree the recipient has received, the average citations per recipient's article published in 2006 to 2007, his or her career citations to 2007, the number of patents issued the recipient prior to funding, whether or not he or she has licensed innovations/inventions, and whether or not he or she is involved in the spin out of a company. Most of these factors have been considered in research at the individual level (Audretsch and Aldridge, 2009; Buccola, Ervin, and Yang, 2009; Thursby and Thursby, 2003; Van den Besselaar and Leydesdorff, 2009; Wood, 1990).

\section{$\underline{\text { Sample Characteristics }}$}

The sample includes all NIH recipients for 2008 from 24 universities and all nonrecipients who have a $\mathrm{PhD}$ or $\mathrm{MD}$, who are tenured or assistant professors, and who are in the same department or institute in which the recipients are located.

Non-recipients of NIH awards are included in order to allow comparisons among non-recipients, recipients, and stars in terms of the various performance measures. Since the members of the non-recipient group have zero funding, a censored condition exists in 
the dependent variable; thus, a Tobit estimation procedure is employed (Gujarati, 2003; Kennedy, 2003).

Table 1 shows the twenty-four universities that have been selected for analysis. The sample includes three universities from the 1996 NIH funding recipient categories of 1-50, five from 51-100, six from 101-150, four from 151-200, and five from 201 and above, along with Portland State University (which is not ranked). With respect to geographic representation, the universities are distributed as follows: Northeast -3 ; Southeast-6; Midwest-4; Mountain West-5; and Pacific—5.

\section{$\underline{\text { Dependent Variables }}$}

The three metrics representing the NIH awards that have been chosen to serve as dependent variables are as follows: 1) 2008 NIH total funds received per individual; 2) 2008 average amount of NIH Grants received per individual; and 3) 2008 total number of grants received per individual (source: NIH Extramural research grants).

$\mathrm{NIH}$ funding was chosen for this analysis for four reasons: 1) $\mathrm{NIH}$ is the major federal funding source for biomedical research; 2) the NIH peer review process is substantive and merit-driven; 3) the review process is considered to be the most consistent in funding use-inspired basic research; and 4) allocation of funds is based in part on the concept of "contribution to the field."

The use of all funds received is based on the idea that regardless of type, federal money contributes to a researcher's reputation and is a basis for receipt of additional funds. Thus, no distinction is made between the types of funds received (i.e., research 
project grants, individual or institutional training grants, or construction grants). Further, while there are different NIH Institutes, it is assumed all Institutes follow similar procedures for allocating NIH funds, in short, that there is a unity in the allocation process. This assumption is consistent with the approach of other studies. For instance, Ali, Bhattacharyya, and Olejniczak (2010) treated grants from the NIH, the National Science Foundation (NSF), and the U.S. Department of Agriculture as having had similar approaches to allocation. Druss and Marcus (2005), while focusing on NIH grants, treated the allocation criteria of R01 grants the same regardless of awarding institute. Feeney and Welch (2014) simply focused on the amount of the academic’s successful grant award and whether or not the individual is a Principal Investigator or Co-Principal Investigator.

Where multiple grants are awarded, the total award is used, which may cause some measurement error, because the individual variables are counted once regardless of whether a person received one grant of $\$ 300,000$ or three for $\$ 100,000$. While the total amount an academic receives seems more reflective of stature, in order to ensure robust analysis, the average size of grant award and the number of grants awarded per individual will also be used as dependent variables.

\section{Independent Variables}

The model's independent variables are grouped into three categories: 1) individual; 2) institutional; and 3) environmental. Insufficient data or inconsistency in University reports prevented the use of departmental-level data. 
$\underline{\text { Individual Variables }}$

Characteristics of the individuals in the model related to prior scholarship include:

1) number of articles published in 2006 and 2007; 2) average number of citations per

article published in 2006 and 2007; 3) total career citations; and 4) highly cited

researcher, a binary variable (0, 1 ; source: Thomason Reuters Science Citation Index).

Table 1. Sample Universities.

\begin{tabular}{|c|c|c|c|c|c|}
\hline \multicolumn{2}{|c|}{ NIH Funding Rank } & & \multirow[b]{2}{*}{ State } & \multirow[b]{2}{*}{ City } & \multirow[b]{2}{*}{ Region } \\
\hline 1996 & 2005 & University & & & \\
\hline 17 & 18 & Case Western Reserve University & $\mathrm{OH}$ & Cleveland & Middle \\
\hline 30 & 30 & U of Colorado Health Science Center & $\mathrm{CO}$ & Denver & West \\
\hline 44 & 49 & University of Utah & UT & Salt Lake City & West \\
\hline 54 & 59 & University of Arizona & AZ & Tucson & West \\
\hline 65 & 33 & Oregon Health Sciences University & OR & Portland & Pacific \\
\hline 72 & 60 & University of Cincinnati & $\mathrm{OH}$ & Cincinnati & Middle \\
\hline 71 & 80 & Virginia Commonwealth University & VA & Richmond & SE \\
\hline 99 & 105 & University of Memphis & TN & Memphis & SE \\
\hline 109 & 110 & University of Missouri & $\mathrm{MO}$ & Columbia & Middle \\
\hline 108 & 119 & Temple University & PA & Philadelphia & $\mathrm{NE}$ \\
\hline 117 & 108 & University of Oklahoma & $\mathrm{OK}$ & Norman & Middle \\
\hline 114 & 99 & Brown University & RI & Providence & $\mathrm{NE}$ \\
\hline 139 & 128 & University of Georgia & GA & Athens & SE \\
\hline 147 & 165 & University of Oregon & OR & Eugene & Pacific \\
\hline 157 & 133 & Arizona State University & AZ & Tempe & West \\
\hline 160 & 171 & Washington State University & WA & Pullman & Pacific \\
\hline 167 & 193 & University of Mississippi & MS & University & SE \\
\hline 181 & 214 & Oregon State University & OR & Corvallis & Pacific \\
\hline 411 & 197 & Georgia Institute of Technology & GA & Atlanta & SE \\
\hline 204 & 78 & University of Louisville & KY & Louisville & $\mathrm{SE}$ \\
\hline 214 & 185 & University of Nevada & NV & Reno & West \\
\hline 224 & 317 & University of Rhode Island & RI & Kingston & $\mathrm{NE}$ \\
\hline 240 & 257 & Wright State University & $\mathrm{OH}$ & Dayton & Middle \\
\hline & & Portland State University & OR & Portland & Pacific \\
\hline
\end{tabular}


Problems are associated with several of these measures. First, the focus on publications and citations limits the representation of scholarship, excluding meetings, editorial material, and book chapters. Second, variations in authors' names create difficulty determining precise publication and citation counts. In this instance, the author's last and first names are used. For articles and citations from 2006-07, the university is also identified. For career citations, the university is added when it is difficult to link a specific article to the person in the sample. This procedure will likely cause an undercount. An additional problem occurs, because of the use on a university identifier, where an academic moves from one university to another. To alleviate this problem, I add two additional variables: 1) the second derivatives of the total number of 2006-07 articles published, which mitigates some of the problems associated with career cites and also helps test for increasing or decreasing returns; and 2) the total number of citations for each article published in 2006-07.

Another problem is that I assume that the Principal Investigator (PI) is the key determinant in the receipt of NIH funds. The work of Feeney and Welch (2014) provides support for this assumption, as they find that PIs have higher productivity than CoPrincipal Investigators and other team members. Highlighting the importance of the PIs, Mangematin et al. (2014) stated, “The necessity for universities and public research centers to identify high performance scientists with the potential to become star principal investigators at an early stage in their career is apparent” (p. 6). Druss and Marcus (2005), looking at the publication patterns of NIH R01 (basic research) grants, found that Principal Investigators publish more than do junior investigators. This implies an 
apprentice model, in which Principal Investigators obtain funding and more junior members share in writing the results.

The Highly Cited Research designation reported by Thomason Reuters differs from Darby and Zucker's (2003), who define Stars as scientists with twenty or more discovery articles. By contrast, Thomason Reuters’ Highly Cited Researcher is defined as being among the 250 most-cited individuals in a defined discipline for the period 1981 to 2011.

Characteristics of individuals related to their educational background are as follows (sources: University, Vitae, Google):

- Degree Received: $\operatorname{PhD}(0,1)$

- Degree Received: MD $(0,1)$

- Degree Received: both PhD and MD $(0,1)$ Characteristics of individuals related to their field of research are as follows:

- Basic Science—Biology, Chemistry, Physics, Engineering, etc. $(0,1)$

- Microbiology, Molecular Biology, Biochemistry $(0,1)$

- Neuroscience, Genetics $(0,1)$

- Medicine, Dentistry, Nursing, Psychiatry $(0,1)$

- Other-Anatomy, Public Health, etc. $(0,1)$

Where multiple fields are listed, I use the first department notation listed in the NIH grant award or the department listed first in the individual's Vita. 
Individual patent activity is represented by being listed as an inventor on a university’s patent application during the period of 2000-2007 (source: U.S. Patent Office). This measure is limited only to patents issued to the current university at which the academic is located, which likely undercounts since other universities or patents issued directly to individuals are not included. The decision to use issuance, as opposed to application, reflects a desire to more closely link final results with NIH funding. On average, the patent award process takes 2.77 years (Merges, Menell, and Lemley, 2010). The period 2000 to 2007 was used to ensure adequate coverage.

Licensing and spinout activity by individuals is represented as follows (source: University OTT):

- Listed by the university’s OTT (or equivalent) as having licensed an innovation or invention $(0,1)$.

- $\quad$ Listed by the university’s OTT as being involved in a spinout $(0,1)$.

Due to confidentiality agreements, not all inventions are listed on OTT websites, which can result in an undercount. OTT websites are not uniform in their display or identification of spin outs, nor are company websites uniform in how they identify involved university researchers.

The final individual characteristic relates to gender, a binary variable $(0,1$; sources: first names, University, Vita, and Google). 
$\underline{\text { Institutional Variables }}$

The university-level characteristics represented in the model include the following (sources: The Center for Measuring University Performance; National Science Foundation; Shanghai Ranking of World Universities):

- Number of National Academy of Arts and Sciences members at the university in 2008 .

- The ranking of the university from which the individual received his or her degree.

- $\quad$ Public or private university $(0,1)$.

- University space allocated to research and development in 2005.

- Number of institutes listed by the university.

\section{$\underline{\text { Environmental Variables }}$}

Environmental characteristics include the regional location of the university, a metropolitan indicator of human capital, and the population of the metropolitan area, as follows (source: American Community Survey):

- Regional location - a binary variable for each of Northeast, Southeast, Midwest, Mountain West, and Pacific $(0,1)$.

- Percentage of the metropolitan population with a bachelor's degree or higher in 2008 .

- $\quad$ Metropolitan population in 2008. 


\section{$\underline{\text { Methodological Issues }}$}

The main concern with the model's specification is the problem of simultaneity. As noted above, there may be a bidirectional relationship between funding and publications. A common test for simultaneity, the Hausman Specification Test, will be performed on the model to determine whether simultaneity is a problem. If it is, a 2-Stage Least Squares or an Indirect Least Squares method can be used to handle the simultaneity problem. 
Chapter 3: Results

\section{$\underline{\text { Descriptive Statistics }}$}

The sample obtained from the 24 selected universities comprises 3,092 individuals from a total population of 5,806 (53\% coverage). Table 2 shows the distribution by university. The sample coverage ranges from a low of $22.5 \%$ for the University of Mississippi to a high of $89.5 \%$ for the University of Cincinnati. The sample had 2,210 men (71.5\%) and 883 women (28.5\%). By academic rank, the sample had 1,739 professors (56.3\%), 833 associate professors (26.9\%), 513 assistant professors (16.6\%), and seven of unknown rank (0.2\%).

It is difficult to determine the actual representativeness of the sample regarding academic rank. The 2011 U.S. Census Bureau Statistical Abstract of the United States provides a roughly comparable breakdown by gender in the life, physical, and social sciences occupational category, with women comprising $28.7 \%$ of the three occupational categories in this sample — biological scientists, medical scientists, and chemists and materials scientists—in 2009.

It should be noted that comparable does not mean an exact correspondence. Other occupational categories are included in the sample, and their presence could contribute to undercounting. However, examining the overall internal breakdowns suggests that this may not be a serious problem.

Table 3 presents the descriptive statistics for the sample. The 2008 NIH Fund Facts indicate that the total research grants awarded to the amounted to $\$ 20,375,000,000$ 
in 46,437 individual grants. This is an average award of $\$ 439,618$. This is greater than the sample’s average grant award of $\$ 366,100.83$ (see Table 4). With respect to the other reported independent variables, NIH award recipients in the sample clearly have higher levels of performance in terms of articles published, citations per publication, and career citations.

Table 4 and Graph 1 show the distribution by grant-dollar category. Forty-two (3.2\%) received two million to four million, while five $(0.4 \%)$ received over four million dollars. These skewed results, where only a few researchers obtain a very large share of grant funds, are consistent with the findings of Zucker and Darby (2006). 
Table 2. Sample Distribution by University.

\begin{tabular}{l} 
University \\
\hline Brown \\
Memphis \\
Oregon State \\
Rhode Island \\
Georgia Tech \\
Washington State \\
Wright State \\
Oregon \\
Nevada (Reno) \\
Mississippi \\
Temple \\
Oregon Health Science \\
Arizona State \\
Cincinnati \\
Missouri \\
Colorado Health Science Ctr \\
Oklahoma \\
Case Western Reserve \\
Utah \\
Louisville \\
Georgia \\
Portland State \\
Arizona \\
Virginia Commonwealth \\
Total
\end{tabular}

\begin{tabular}{|c|c|c|}
\hline Population & Sample & Percent \\
\hline 261 & 151 & 57.9 \\
\hline 117 & 53 & 45.3 \\
\hline 115 & 71 & 61.7 \\
\hline 83 & 54 & 65.1 \\
\hline 150 & 76 & 50.7 \\
\hline 155 & 73 & 47.1 \\
\hline 93 & 73 & 78.5 \\
\hline 143 & 91 & 63.6 \\
\hline 137 & 61 & 44.5 \\
\hline 151 & 34 & 22.5 \\
\hline 200 & 81 & 40.5 \\
\hline 413 & 233 & 56.4 \\
\hline 284 & 152 & 53.2 \\
\hline 171 & 153 & 89.5 \\
\hline 288 & 161 & 55.9 \\
\hline 24 & 13 & 54.2 \\
\hline 134 & 78 & 58.2 \\
\hline 398 & 249 & 62.6 \\
\hline 592 & 367 & 62.0 \\
\hline 279 & 186 & 66.7 \\
\hline 292 & 146 & 50.0 \\
\hline 84 & 34 & 40.5 \\
\hline 583 & 302 & 51.8 \\
\hline 659 & 200 & 30.3 \\
\hline 5806 & 3092 & 53.3 \\
\hline
\end{tabular}


Table 3. Sample Descriptive Statistics.

\section{Category}

Total Sample

NIH Recipients

Non-NIH

Average NIH Dollars for Total

Average Dollars per NIH Recipient

Average Dollars per NIH Non-Recipient (NR)

Average 2006-07 Articles Total

Average 2006-07 Articles NIH

Average 2006-07 Articles NIH NR

Average Cites per 2006-07 Article Total

Average Cites per 2006-07 Article NIH

Average Cites per 2006-07 Article NIH NR

Average Career Cites Total

Average Career Cites NIH

Average Career Cites NIH NR

Total Number of Grants

Average Grant Award per Academic

Average Number of Grants per Academic $\underline{\text { Statistic }}$

3,092

1,324

1,768

$\$ 230,769$

$\$ 538,927$

0

3.87

5.31

2.8

1.46

2.03

1.03

430.83

637.19

275.76

1,856

\$366,100.83

1.4 
Table 4. Number of Academics and Percentage by Dollar Category.

NIH Dollar Range

0

250,000

500,000

750,000

$1,000,000$

$1,250,000$

$1,500,000$

$1,750,000$

$2,000,000$

$2,250,000$

2,500,000

$2,750,000$

$3,000,000$

$3,250,000$

$3,500,000$

$3,750,000$

$4,000,000$

$4,250,000$

$4,500,000$

$4,750,000$

$5,000,000$

$6,000,000$

$7,000,000$

$8,000,000$

$9,000,000$

Total
Number of Academics

1768

308

570

221

75

57

26

17

10

9

9

5

3

3

3

1

0

1

0

2

0

1

1

1

1

3092
Percent of Total

57.18

9.96

18.43

7.15

2.43

1.84

.84

.55

.32

.29

.29

.16

.10

.10

.10

.03

0

.03

0

.06

0

.03

.03

.03

.03

Table 5 shows the distribution of men and women by selected independent variables. The percentages of each specific category are in parentheses. The data indicate that NIH non-recipients are the majority of the sample, with similar distribution 
for women (58.5\%) and for men (56.6\%). With regard to performance measures, and consistent with the results shown in Table 3, NIH non-recipients have lower performance than do NIH recipients. The $41.5 \%$ of NIH recipients in the sample who are women is higher than the percentage of actual awards to women in 2008 (approximately 25\%; NIH Data Book), so women may be overrepresented in this study.

While female overrepresentation may be a problem, the publication and citation difference between NIH Recipients and NIH Non-Recipients implies that the direction or statistical significance of the individual performance variables may not be a significant issue. Moreover, the difference in publication rates between men and women is consistent with that found in other studies (Evans, 2011; Hesli and Lee, 2011). That women in the sample have lower citation rates than men is also consistent with earlier work (Ferber, 1988). 


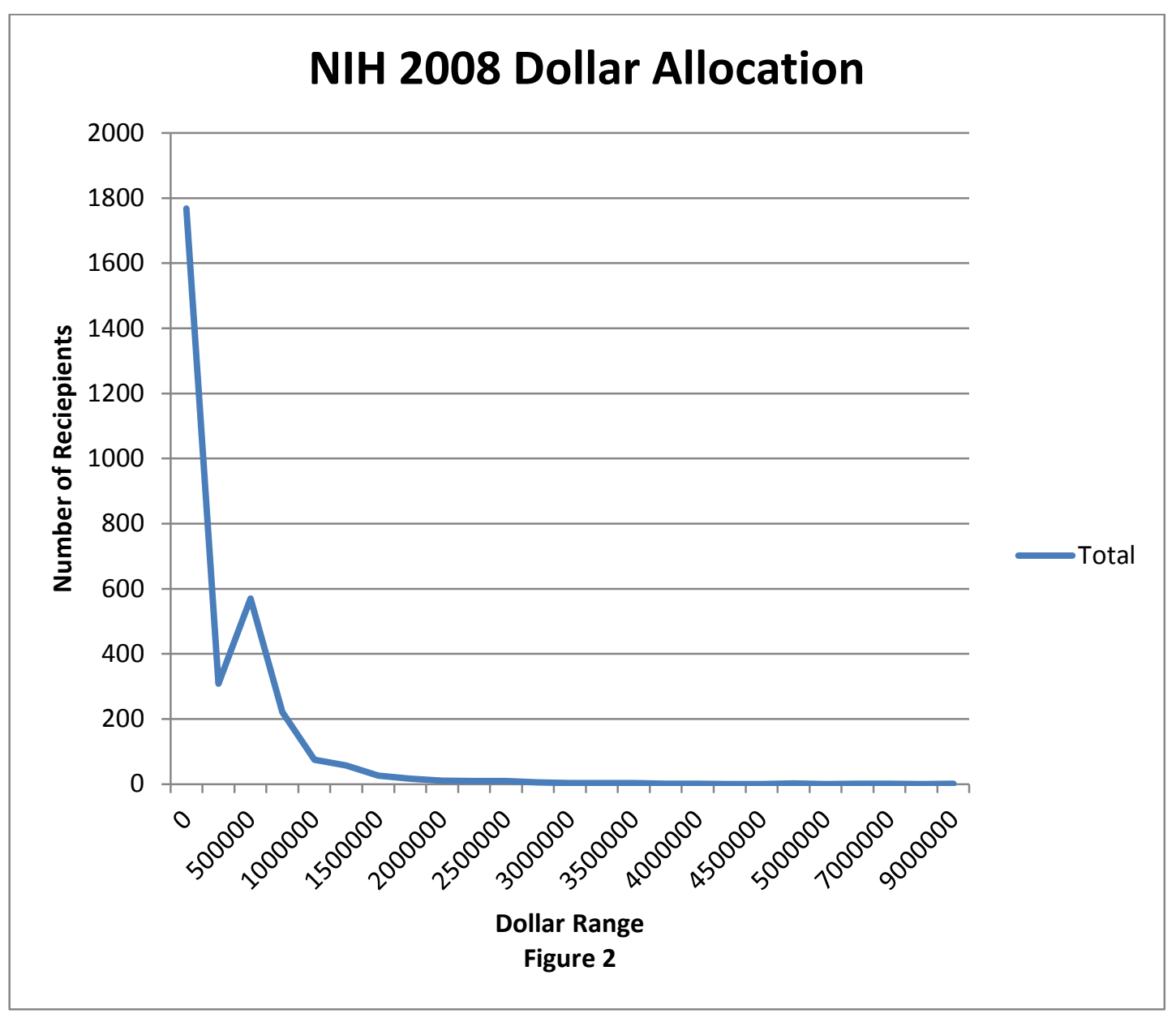


Table 5. Distribution by Gender.

\section{Category}

Total

NIH Recipients

Non NIH Recipients

Average Dollars for Total

Average for NIH Recipients

Average for NIH Non-Recipients (NR)

Average 2006-07 Articles Total

Average 2006-07 Articles NIH

Average 2006-07 Articles NIH NR

Average Cites per Article 2006-07 Total

Average Cites per Article 2006-07 NIH

Average Cites per Article 2006-07 NIH NR

Average Career Cites Total

Average Career Cites NIH

Average Career Cites NIH NR

Average Number of Grants

Average Dollars per Grant
Male

2199 (71.7)

$953(43.4)$

1246 (56.6)

$\$ 238,342$

$\$ 576,321$

0

4.19

5.71

3.03

1.53

2.17

1.04

469.57

728.84

318.82

1.40
Female

893 (28.5)

371 (41.5)

522 (58.5

$\$ 183,992$

$\$ 442,871$

0

3.09

4.26

2.25

1.27

1.66

1.00

273.61

403.89

180.78

1.30

$\$ 379,561.70 \quad \$ 330,536.60$

Table 6 and Figure 3 show a distributional breakdown of the percentage of total grant funds received by each gender. A greater percentage of sampled women who received NIH awards in 2008 are in the \$1-\$500,000 range. They are slightly under$6.4 \%$ versus $7.4 \%$ - in the category $\$ 500,001-\$ 750,000$, but women fall off considerably beyond this threshold.

Table 7 compares the grant percentage distribution between genders. A higher percentage of women than men receive awards from \$1-\$25,000 (28.1\% versus $21.3 \%)$. Similarly, women receive proportionately more awards in the $\$ 250,001-\$ 500,000$ range (45.7\% versus $42.1 \%$ ). In all other categories, males receive proportionally more total NIH grant dollars. 
Table 6. NIH Dollar Allocation by Gender.

$\begin{array}{ccccc}\text { NIH Dollars } & \text { Male } & \% & \text { Female } & \% \\ 0 & 1246 & 0.566621 & 522 & 0.584546 \\ 250,000 & 203 & 0.092273 & 104 & 0.116461 \\ 500,000 & 401 & 0.182273 & 169 & 0.18925 \\ 750,000 & 163 & 0.074091 & 58 & 0.06495 \\ 1,000,000 & 62 & 0.028182 & 14 & 0.015677 \\ 1,250,000 & 46 & 0.020909 & 11 & 0.012318 \\ 1,500,000 & 22 & 0.01 & 4 & 0.004479 \\ 1,750,000 & 14 & 0.006364 & 3 & 0.003359 \\ 2,000,000 & 8 & 0.003636 & 2 & 0.00224 \\ 2,250,000 & 8 & 0.003636 & 1 & 0.00112 \\ 2,500,000 & 6 & 0.002727 & 3 & 0.003359 \\ 2,750,000 & 5 & 0.002273 & 0 & 0 \\ 3,000,000 & 2 & 0.000909 & 1 & 0.00112 \\ 3,250,000 & 3 & 0.001364 & 0 & 0 \\ 3,500.00 & 3 & 0.001364 & 0 & 0 \\ 3,750,000 & 1 & 0.000455 & 0 & 0 \\ 4,000,000 & 2 & 0.000909 & 0 & 0 \\ 5,000,000 & 1 & 0.000455 & 1 & 0.00112 \\ 6,000,000 & 1 & 0.000455 & 0 & 0 \\ 7,000,000 & 1 & 0.000455 & 0 & 0 \\ 8,000,000 & 1 & 0.000455 & 0 & 0 \\ \text { Total } & 2199 & & 893 & \end{array}$




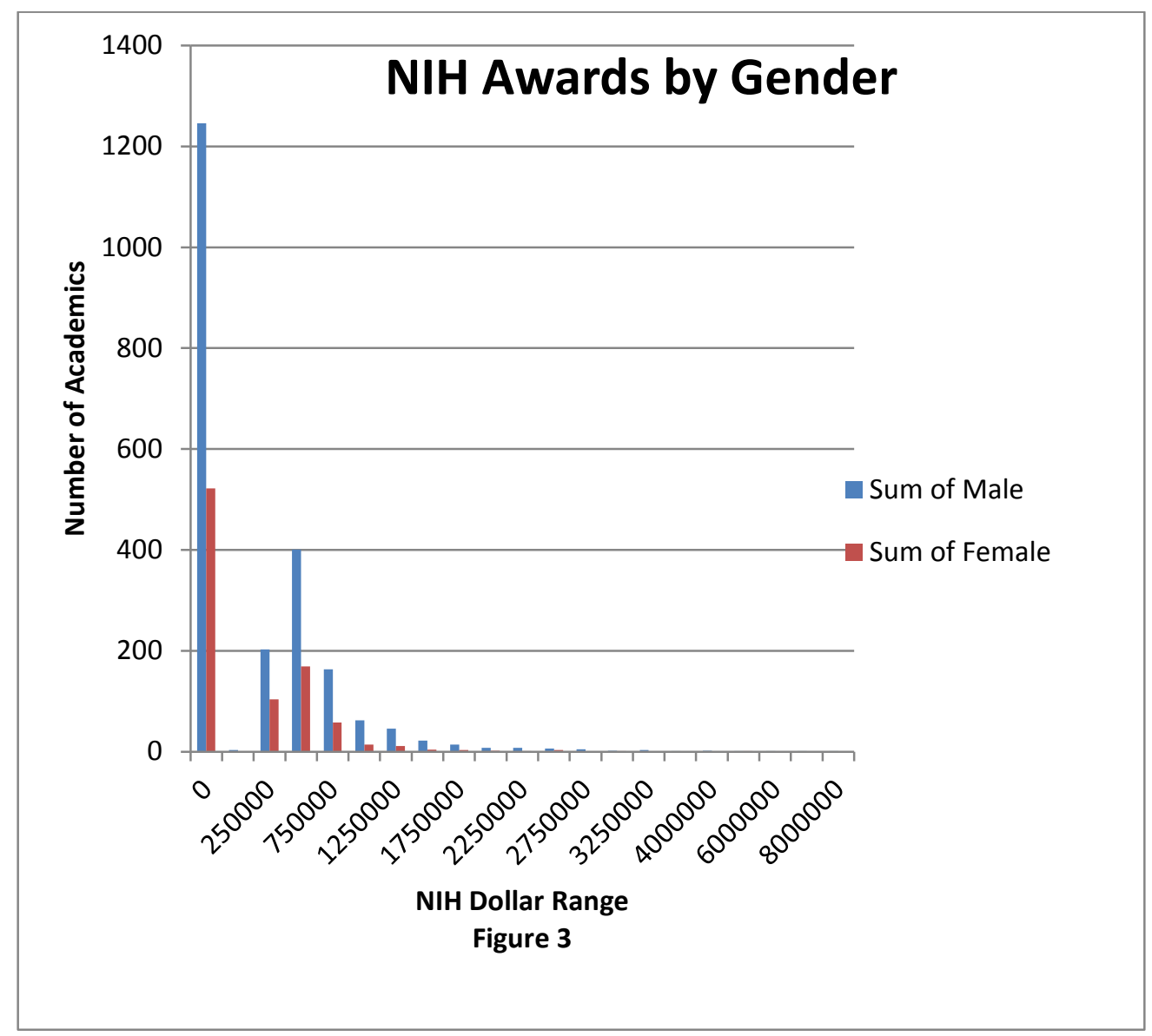

Table 8 breaks down awards by academic rank. Professors receive more NIH money than do associate and assistant professors. Similarly, professors produce more articles and have higher citations rates. Consistent with the trends that appear in the other tables, NIH grant recipients produce more articles and have higher citation rates than do NIH non-recipients.

Tables 9, 10, 11, 12, and 13 present the results by department, for academics who have licensed an invention, for those who have spun out a company, for those who have patented an invention, and for those who are highly cited, respectively. The number of 
academics in the sample licensing inventions, spinning out new companies, or patenting is very small—one hundred or 3.2\% for licensing, six or $0.2 \%$ for spinouts, and 162 or $5.2 \%$ for patenting. However, those who license, are involved in spinning out a company, or who patent an invention receive higher levels of NIH grant funds and have higher production levels than do NIH non-recipients.

Surveying 345 Highly Cited Researchers in 2008, Parker, Lortie, and Allesina (2010) found that the average extramural funding for U.S. scientists in their survey was $\$ 534,594$, reporting that "fifty percent of respondents receive $\$ 250,000$ or less each year, and $81 \%$ receive $\$ 500,000$ or less” (p. 135). Six percent of their respondents reported receiving over $\$ 1,000,000$. Their respondents’ average extramural grant total was $\$ 387,909$.

Table 13 indicates that the highly cited individuals in this study received an average total of $\$ 927,189$ with an average of $\$ 478,113$ per grant. This is considerably higher than reported by Parker, Lortie, and Allesina (2010). It is also higher than the average amount received by all NIH recipients in this sample. The average number of articles published in 2006-07 by highly cited researchers and the average citations per article are also higher than the sample averages for these categories, consistent with the findings of Zucker and Darby (2006).

The differences in publication levels and citations among departments are consistent with other research (e.g., Adams and Griliches, 1998; Warner, Lewis, and Gregorio, 1981). Similarly, the publication levels of individuals with licenses and spin 
outs are consistent with previous findings that academics who license an invention have published as much or more than their peers (Thursby and Thursby, 2003).

Table 7. Total NIH Award Allocation and Percentage Compared by Gender.

\begin{tabular}{|c|c|c|c|c|}
\hline Dollars & Men & $\%$ of Men & Women & $\%$ of Women \\
\hline 250,000 & 203 & 21.3 & 104 & 28.1 \\
\hline 500,000 & 401 & 42.1 & 169 & 45.7 \\
\hline 750,000 & 163 & 17.1 & 58 & 15.7 \\
\hline $1,000,000$ & 62 & 6.5 & 14 & 3.8 \\
\hline $1,250,000$ & 46 & 4.8 & 11 & 3 \\
\hline $1,500,000$ & 22 & 2.3 & 4 & 1 \\
\hline $1,750,000$ & 14 & 1.5 & 3 & 0.8 \\
\hline $2,000,000$ & 8 & 0.8 & 2 & 0.5 \\
\hline $2,250,000$ & 8 & 0.8 & 1 & 0.3 \\
\hline $2,500,000$ & 6 & 0.6 & 3 & 0.8 \\
\hline $2,750,000$ & 5 & 0.5 & 0 & 0 \\
\hline $3,000,000$ & 2 & 0.2 & 1 & 0.2 \\
\hline $3,250,000$ & 3 & 0.3 & 0 & 0 \\
\hline $3,500,000$ & 3 & 0.3 & 0 & 0 \\
\hline $3,750,000$ & 1 & 0.1 & 0 & 0 \\
\hline $4,000,000$ & 2 & 0.2 & 0 & 0 \\
\hline $5,000,000$ & 1 & 0.1 & 1 & 0.2 \\
\hline $6,000,000$ & 1 & 0.1 & 0 & 0 \\
\hline $7,000,000$ & 1 & 0.1 & 0 & 0 \\
\hline $8,000,000$ & 1 & 0.1 & 0 & 0 \\
\hline Total & 953 & & 370 & \\
\hline
\end{tabular}


Table 8. Characteristics by Academic Rank.

$\begin{array}{lcccc}\text { Category } & \text { Professor } & \text { Associate } & \text { Assistant } & \text { Unknown } \\ \text { Total } & 1739 & 833 & 513 & 7 \\ \text { NIH } & 900 & 307 & 112 & 6 \\ \text { NIH Non-Recipients (NR) } & 840 & 526 & 401 & 1 \\ \text { Average \$ NIH Total } & \$ 332,626 & \$ 119,528 & \$ 68,400 & \$ 195,008 \\ \text { Average \$ NIH } & \$ 643,342 & \$ 324,321 & \$ 313,297 & \$ 227,509 \\ \text { Average \$ NIH NR } & 0 & 0 & 0 & 0 \\ \text { Av Art 2006-07 Total } & 5.0 & 2.93 & 1.57 & 2.71 \\ \text { Av Art 2006-07 NIH } & 6.13 & 3.67 & 3.28 & 3.17 \\ \text { Av Art 2006-07 NIH NR } & 3.8 & 2.5 & 1.09 & 0 \\ \text { Av Cites 2006-07 Total } & 1.64 & 1.46 & .82 & .93 \\ \text { Av Cites 2006-07 NIH } & 2.1 & 2.02 & 1.57 & 1.08 \\ \text { Av Cites 2006-07 NIH NR } & 1.16 & 1.13 & .61 & 0 \\ \text { Av Career Cites Total } & 675.23 & 151.14 & 56.74 & 791.71 \\ \text { Av Career Cites NIH } & 852.99 & 190.3 & 142.3 & 923.67 \\ \text { Av Career Cites NIH NR } & 484.30 & 128.28 & 33.00 & 0 \\ \text { Average Number of Grants } & 1.5 & 1.19 & 1.17 & 1.0 \\ \text { Average Dollars per Grant } & \$ 414,834 & \$ 269,265 & \$ 244,519 & \$ 227,508\end{array}$

Table 9. Breakdown of Characteristics by Department.

Total

NIH

Non NIH

Av \$ Total

Av \$ NIH

Non NIH

Av Art 2006-07

Av Art NIH

Av Art non NIH

Av Cites Total

Av Cites NIH

Av Cites Non NIH

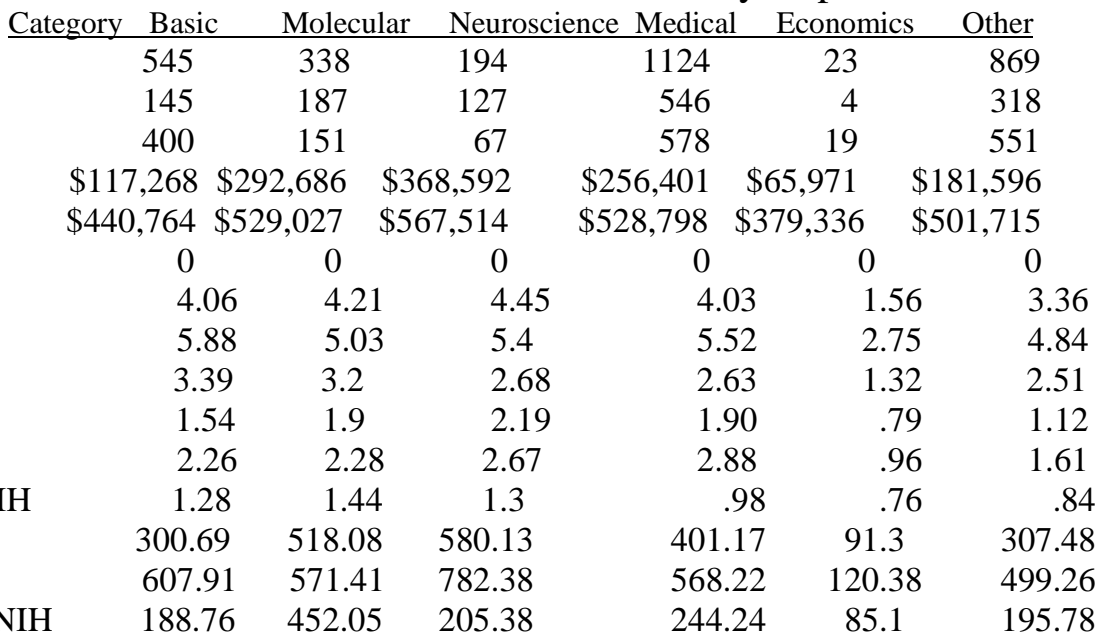

Av Career NIH

Av Career Non NIH

$\begin{array}{lll}188.76 & 452.05 & 205.38\end{array}$

244.24

95.78 
Table 10. Breakdown for License Holders.

Category

Total 100

$\mathrm{NIH} \quad 70$

NIH Non-Recipients (NR) 30

Av \$ Total \$386,590

Av \$ NIH \$552,156

Av \$ NIH NR 0

Av 2006-07 Art Total $\quad 6.6$

Av 2006-07 Art NIH 7.5

Av 2006-07 Art NIH NR 4.5

Av Cites 2006-07 Total $\quad 2.48$

Av Cites 2006-07 NIH 2.84

Av Cites 2006-07 NIH NR 1.64

Career Cites $\quad 1,136.62$

Career Cites NIH $\quad 1,363.79$

Career Cites NIH NR $\quad 606.57$

Average Number of Grants $\quad 1.6$

Average Dollars per Grant \$345,258.40

Table 11. Breakdown for Academics with Spin Out Companies.

Total

Category

$\mathrm{NIH}$

NIH Non-Recipients (NR)

Av $\$$ Total

Av $\$ \mathrm{NIH}$

Av $\$$ Non NIH

Av Total 2006-07 Art

Av Total 2006-07 Art NIH

Av Total 2006-07 Art NIH NR

Av Cites 2006-07 Total

Av Cites 2006-07 NIH

Av Cites 2006-07 NIH NR

Av Career Cites Total

Av Career Cites NIH

Av Career Cites NIH NR

Average Number of Grants

Average Dollars per Grant

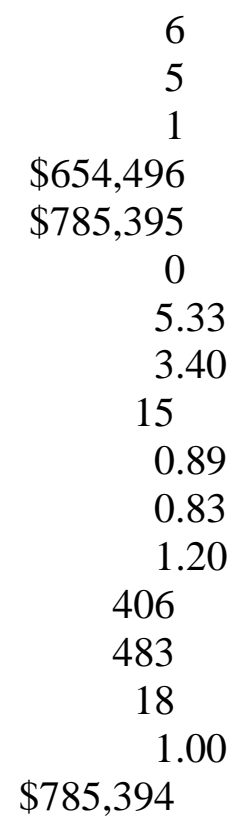


Table 12. Breakdown for Academics with Patents.

$\begin{array}{ll}\text { Category } & \\ \text { Total } & 162 \\ \text { NIH } & 97 \\ \text { NIH Non-Recipients (NR) } & 65 \\ \text { Av \$ Total } & \$ 459,747 \\ \text { Av \$ NIH } & \$ 767,825 \\ \text { Av \$ NIH NR } & 0 \\ \text { Av Total 2006-07 Art } & 7.44 \\ \text { Av Total 2006-07 Art NIH } & 7.69 \\ \text { Av Total 2006-07 Art NIH NR } & 7.06 \\ \text { Av Cites 2006-07 Total } & 2.58 \\ \text { Av Cites 2006-07 NIH } & 3 \\ \text { Av Cites 2006-07 NIH NR } & 1.96 \\ \text { Av Career Cites Total } & \$ 887.98 \\ \text { Av Career Cites NIH } & \$ 944.34 \\ \text { Av Career Cites NIH NR } & \$ 803.88 \\ \text { Average Number of Grants } & \$ 1.60 \\ \text { Average Dollars per Grant } & \$ 436,110.70\end{array}$


Table 13. Breakdown for Highly Cited Academics.

Category

Total

NIH Recipients

NIH Non-Recipients (NR)

Av \$ Total

Av \$ NIH

Av \$ NIH NR

Av 2006-07 Art Total

Av 2006-07 Art NIH

Av 2006-07 Art NIH NR

Av Cites 2006-07 Total

Av Cites 2006-07 NIH

Av Cites 2006-07 NIH NR

Av Career Cites Total

Av Career Cites NIH

Av Career Cites NIH NR

Average Number of Grants

Average Dollars per Grant

45
20
25
$\$ 412,084.00$
$\$ 927,189.00$
$\$ 0.00$
10.76
13.60
8.48
3.61
3.84
3.96
$2,618.58$
$4,716.55$
940.20
1.85
$\$ 478,113.70$

Table 14 breaks down personal and performance characteristics by the number of grants received. Just over $69 \%$ of awardees received only one grant, and another $22.6 \%$ received two grants. Only four $(0.3 \%)$ received five grants. The fact that the number of total articles and average and career citations increase with the number of grants received indicates that merit plays a substantive role in the award process. At five grants, these dynamics change, which may reflect that the number of individuals receiving this many grants is small. Only $42.2 \%$ of the highly cited individuals received NIH grants. The majority of the highly cited researchers (57.9\%) received one NIH grant, while another $21.1 \%$ received two awards. 
Table 14. Breakdown of Characteristics by Number of Grants Received.

\begin{tabular}{|c|c|c|c|c|c|}
\hline \multirow[b]{2}{*}{ Characteristics } & \multicolumn{5}{|c|}{ Number of Grants } \\
\hline & $\underline{1}$ & $\underline{2}$ & $\underline{3}$ & $\underline{4}$ & $\underline{\mathbf{5}}$ \\
\hline Total & 914 & 297 & 80 & 22 & 4 \\
\hline Men & 634 & 226 & 65 & 19 & 3 \\
\hline Women & 280 & 71 & 15 & 3 & 1 \\
\hline Assistant & 92 & 18 & 1 & 0 & 0 \\
\hline Associate & 254 & 45 & 7 & 0 & 0 \\
\hline Professor & 562 & 234 & 72 & 22 & 4 \\
\hline Unknown & 6 & 0 & 0 & 0 & 0 \\
\hline $\mathrm{PhD}$ & 736 & 238 & 52 & 16 & 2 \\
\hline MD & 120 & 41 & 17 & 4 & 2 \\
\hline $\mathrm{PhD} / \mathrm{MD}$ & 58 & 18 & 11 & 2 & 0 \\
\hline Basic & 116 & 21 & 5 & 2 & 0 \\
\hline Molecular & 127 & 41 & 15 & 3 & 0 \\
\hline Neuroscience & 77 & 42 & 5 & 1 & 0 \\
\hline Economics & 3 & 0 & 1 & 0 & 0 \\
\hline Med/Nurse/Dent & 363 & 124 & 40 & 10 & 3 \\
\hline Other & 288 & 69 & 14 & 6 & 1 \\
\hline Average Total Articles 2006-07 & 4.54 & 6.6 & 7.29 & 12.95 & 5.75 \\
\hline Average Cites 2006-07 & 1.89 & 2.18 & 2.96 & 2.41 & 1.23 \\
\hline Career Cites & 492.03 & 875.22 & 1062.04 & 1869.96 & 1848.75 \\
\hline Average Total NIH Dollars & $\$ 347,909$ & $\$ 808,048$ & $\$ 1,306,246$ & $\$ 1,627,127$ & $\$ 3,231,624$ \\
\hline Highly Cited & 11 & 4 & 2 & 2 & 0 \\
\hline
\end{tabular}

Table 15 and Graph 3 show grant award information by dollar category and number of grants. A substantial majority of grants awarded were in the $\$ 250,000-\$ 500,000$ range, with $80.5 \%$ receiving one to two grants. There are very few large multiple awards of grants, with only four multiple awards over $\$ 2,250,000$ or more. In fact, the quadrants for three, four, and five grants at $\$ 2,500,000$ and above have no awards. 
Table 15. Breakdown by Number and Size of Grants Awarded.

$\begin{array}{llllll}\text { Grant Dollars } & 1 & 2 & 3 & 4 & 5 \\ 250,000 & 301 & 54 & 11 & 2 & 0 \\ 500,000 & 518 & 195 & 54 & 13 & 3 \\ 750,000 & 53 & 26 & 10 & 6 & 0 \\ 1,000,000 & 12 & 10 & 3 & 1 & 1 \\ 1,250,000 & 8 & 5 & 1 & 0 & 0 \\ 1,500,000 & 4 & 3 & 0 & 0 & 0 \\ 1,750,000 & 8 & 1 & 1 & 0 & 0 \\ 2,000,000 & 4 & 0 & 0 & 0 & 0 \\ 2,250,000 & 1 & 0 & 1 & 0 & 0 \\ 2,500,000 & 0 & 1 & 0 & 0 & 0 \\ 2,750,000 & 0 & 0 & 0 & 0 & 0 \\ 3,000,000 & 2 & 1 & 0 & 0 & 0 \\ 3,250,000 & 2 & 0 & 0 & 0 & 0 \\ 3,500,000 & 0 & 0 & 0 & 0 & 0 \\ 3,750,000 & 0 & 0 & 0 & 0 & 0 \\ 4,000,000 & 0 & 1 & 0 & 0 & 0 \\ 4,250,000 & 1 & 0 & 0 & 0 & 0\end{array}$

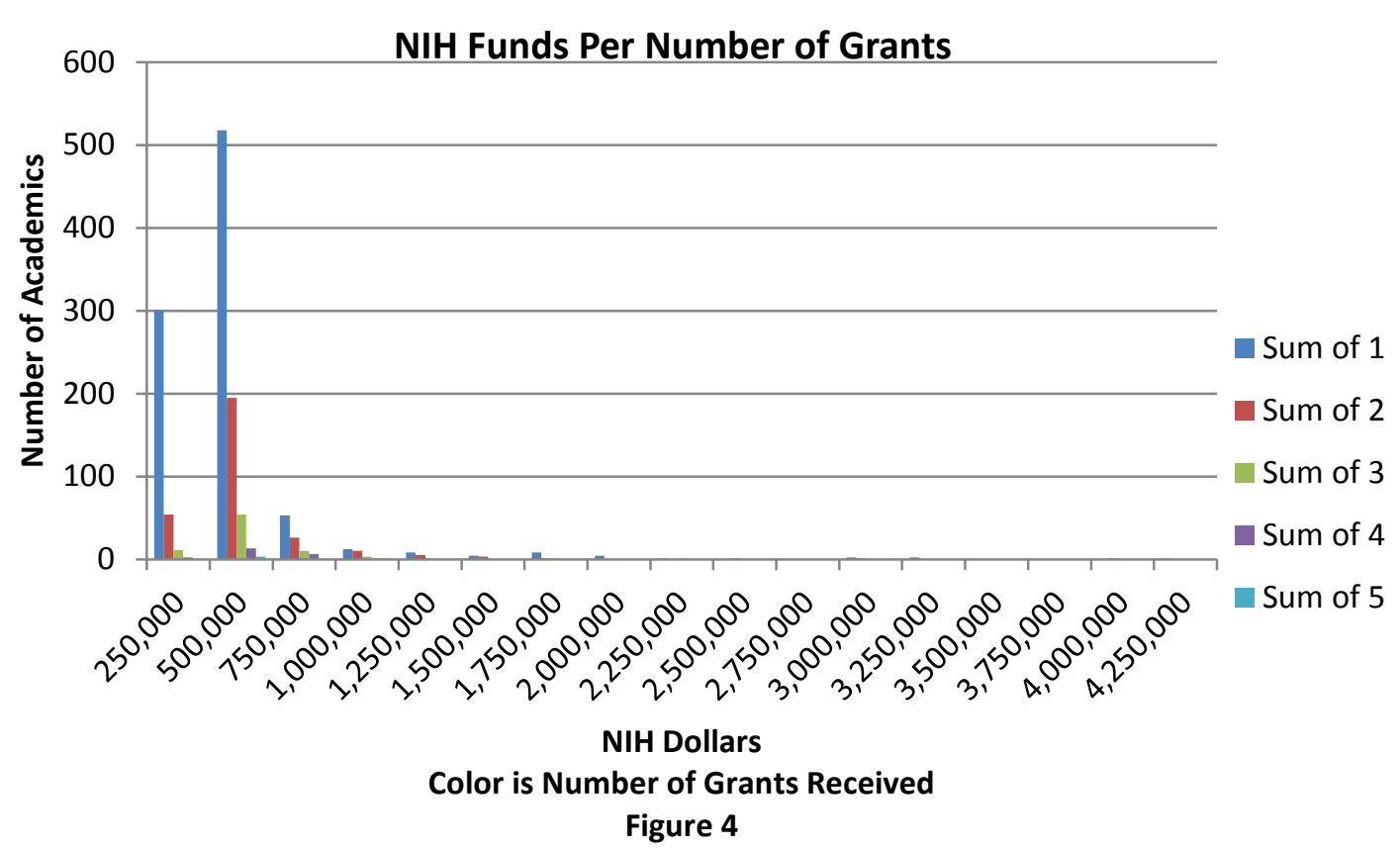




\section{$\underline{\text { Tobit Regression }}$}

Having presented the descriptive statistics and identified the consistencies with and differences from prior research, I turn now to the results of the Tobit Regression. I used a Tobit Regression because there is censored data associated with those researchers who received no NIH extramural grant funds. The Tobit regression model was run using STATA Version 13.

Only one variable is normalized: science and engineering space. Science and engineering space is not allocated across all faculty members in a university; instead, it is allocated to those who are doing laboratory-related work. In this case, the science and engineering space divided by the study population per university is used as a reasonable approximation.

Tables 16 and 17 present the results of the Tobit models. Table 16 presents models with total grant dollars awarded as the dependent variable. The basic iterations are all the individual performance measures, including the rank of the university for the terminal degree and whether or not an individual is highly cited. The second iteration adds institutional variables, and the third iteration adds environmental variables. The iterations demonstrate the basic stability of the coefficients of the productivity variables.

The difference between iteration three in Table 16 and the total-grant-amount model in Table 17 is that the rank of the university for the terminal degree and highly cited researcher were dropped as variables, while the rank of total R\&D expenditures was added. The rank of university for the terminal degree was dropped for two reasons: 1) it 
is not statistically significant; and 2) doing so increases the number of observations from 2,346 to 3,076 to use in the Tobit regression models for total grant awards, average grant amount, and number of grants.

As can be seen in the correlation matrix (Table 18), the highly cited categorical variable has a .432 correlation with career citations. Even though highly cited status is significant at the ten percent level, it is excluded for four reasons: 1) it is a binary variable, while career citations are an interval variable; 2) career citations are significant at the stronger five percent level; 3) career citations covers more published work, and therefore provides better analytics; and 4) the highly cited coefficient is perhaps counterintuitively negative, while career citations carries a positive coefficient.

Moreover, the use of the total articles and citation per article variables alone meaningfully limits the measure of productivity. The use of the second derivative substantially extends the limited base - the citation range and variance. This allows better identification of positive and negative returns. It thus compensates for the exclusion of the highly cited dummy variable.

Given the relatively high correlation (39.1\%) between total articles and career citations, as seen in Table 18, there is the possibility of simultaneity. As noted earlier, a common test for simultaneity is the Hausman statistic. Below are the Hausman statistics for the three Tobit independent variables.

$\begin{array}{lc}\text { Total Grant Amount } & \chi(28) 0.60 \\ \text { Prob }>\chi^{2} & 1.00 \\ \mathrm{~B}=\text { consistent under } \mathrm{H}_{\mathrm{o}} \text { and } \mathrm{H}_{\mathrm{a}} \text {; obtained from Tobit } \\ \mathrm{B}=\text { inconsistent under } \mathrm{H}_{\mathrm{a}} \text {, efficient under } \mathrm{H}_{\mathrm{o}} \text {; obtained from Tobit }\end{array}$


Test: $\mathrm{H}_{0}$ : differences in coefficients not systematic

Average Grant Amount $\quad$ (29) 1.76

Prob $>\chi^{2} \quad 1.00$

$\mathrm{B}=$ consistent under $\mathrm{H}_{\mathrm{o}}$ and $\mathrm{H}_{\mathrm{a}}$; obtained from Tobit

$\mathrm{B}=$ inconsistent under $\mathrm{H}_{\mathrm{a}}$, efficient under $\mathrm{H}_{0}$; obtained from Tobit

Test: $\mathrm{H}_{0}$ : differences in coefficients not systematic

Number of Grants $\quad$ $\quad \chi(29) 3.43$

Prob $>\chi^{2} \quad 1.00$

$\mathrm{B}=$ consistent under $\mathrm{H}_{\mathrm{o}}$ and $\mathrm{H}_{\mathrm{a}}$; obtained from Tobit

$\mathrm{B}=$ inconsistent under $\mathrm{H}_{\mathrm{a}}$, efficient under $\mathrm{H}_{\mathrm{o}}$; obtained from Tobit

Test: $\mathrm{H}_{\mathrm{o}}$ : differences in coefficients not systematic

The statistics indicate no systematic difference in the estimates. Thus, simultaneity is not a major problem.

Table 17 presents the results of the Tobit regression for the three dependent variables - NIH total funds awarded, average dollars per grant, and number of grants. Across all three regressions, the basic measures of productivity (total articles 2006-07 and average citations of articles 2006-07) are positive and statistically significant at the 0.00 probability level. Career citations is positive at the 0.00 level in the total-dollars model and at the 0.10 level for the average-grant-dollars model, while this variable is not statistically significant in the number-of-grants model. The second derivatives of the total articles and average citations variables are statistically significant for each dependent variable at either the 0.00 or 0.05 level of significance. In each instance, the derivative is negative, which indicates decreasing returns.

In terms of the variables' impact on the amount of total NIH dollars received in 2008, the results of the regression indicate that a key determinant is the number of articles 
published in 2006-07. These results are consistent with the findings of Ali, Bhattacharyya, and Olejniczak (2010). The average number of citations per article published in 2006-07 is another important determinant. Whether one is an assistant or associate professor has a statistically significant and negative impact compared to holding the rank of professor. This is consistent with the descriptive statistics presented in Table 5, which show that professors received larger amounts of NIH grant money than do assistant and associate professors.

In isolation, most of the institutionally related variables are estimated to have a negative effect on the receipt of NIH funds, with two exceptions: 1) having a medical school and 2) the university's rank in terms of total R\&D expenditure. Having a medical school associated with the university is statistically significant at the 0.05 level in the total-dollars model, at the 0.05 level in the average-grant-dollars model, and at the 0.00 level in the number-of-grants model, consistent with the historical trend found by Graham and Diamond (1997) and by Geiger (2008).

University rank in terms of total R\&D expenditures has a negative coefficient, which is expected given that the highest possible ranking is one. Its statistical significance at the 0.00 level indicates that there is a halo effect associated with $R \& D$ rank, though the coefficient is small $(-\$ 3,042.67$ in the total-dollars model). The small coefficient indicates two things. First, as a university moves up the ranking, there is only a marginal gain for individuals based on reputation alone. Second, if the small coefficient is any indication, it appears that for this sample of NIH-receiving universities, 
the peer-review process demonstrates little allocation bias oriented towards university rank.

Having a medical degree has a significant effect only in the number-of-grants model. Having both an MD and a PhD is statistically significant, as is being in a medically related department. This likely reflects the changing nature of research in the biomedical field, as does the statistical significance of the molecular biology and neuroscience department dummy coefficients. However, there is a subtle aspect here. The fact that having a dual degree is statistically significant indicates that research in the biomedical field increasingly draws on a combination of the rigorous research designs associated with a $\mathrm{PhD}$ and the advanced medical training associated with MD programs.

The correlation matrix (Table 19) highlights two subtle relationships which underpin the broader ranking of universities by total R\&D expenditures. First, there is a .72 correlation between the rank in terms of total $R \& D$ expenditure and the number of National Academy members at a university, which may indicate that researchers are moving from lower- to higher-ranked institutions. Such a pattern would be consistent with Zucker and Darby’s (2006) results for star scientists. Second, there is a strong correlation between the number of graduate students, the number of National Academy members (.67), and ranking in terms of total R\&D expenditure (.64). While the data in this study do not capture the differences in quality of graduate students at the included universities, the above correlations are consistent with the findings of Zucker and Darby (2006) and of Agrawal, McHale, and Oettle (2012) that graduate students tend to gravitate to higher-ranked or more star-filled universities. The correlations of number of 
graduate students, number of tenured faculty, endowment, and number of National Academy members with rank in terms of total $R \& D$ add credence to the idea that there is a reputational halo effect, albeit a small one. These correlations also indicate that a number of institutional variables indirectly impact the receipt of NIH funds.

The small coefficient for career citations and the negative coefficients and statistical significance of the second derivative of articles published and citations of those articles all demonstrate that there are diminishing returns to publications and citations in the receipt of NIH funding.

Controlling for the effects of rank, publication, and citations, the regressions indicate that NIH awards are not affected by a researcher's gender. However, it should be noted that the number of academics who receive total grant awards of $\$ 750,000$ or more is relatively small, and most are male (see Graph 2 and Tables 3 and 5).

Professorial rank plays a significant role in the receipt of NIH funds. Professors are estimated to garner more NIH dollars. Again, even when controlling for publications and citations, being a professor is statistically significant. As noted in Table 8, professors have higher numbers of citations, which in turn enhances their reputation. There is also likely a practice effect present; over their careers, professors have learned by trial and error how to write winning grant proposals. 
Table 16. Tobit Model Total NIH Dollar Iterations.

\begin{tabular}{|c|c|c|c|c|}
\hline Variables & Basic & Basic/Inst & Basic/Inst/Envirn & $\begin{array}{r}\text { Probability } \\
* 0.00\end{array}$ \\
\hline Percentage Bachelor & & & 4978.55 & $* 0.00$ \\
\hline Metro Pop & & & $* 0.02$ & $* * 0.05$ \\
\hline Number NIH Org & & & -8347.96 & $* * * 0.10$ \\
\hline Basic Science & & *-366991.2 & $*_{-35844.8}$ & \\
\hline MolBiochem & & **171414.6 & $* * 169707$ & \\
\hline NeroSciGenetics & & *340654.1 & *329594.7 & \\
\hline Economics & & -397804.2 & -448586 & \\
\hline MedNursDental & & 59259.6 & 51797.73 & \\
\hline Private University & & -92887.38 & ***-222145 & \\
\hline NE Region & & -31435.11 & 159042.4 & \\
\hline SE Region & & -102575.7 & $* * *-161094.6$ & \\
\hline Middle & & 67895.6 & -193251 & \\
\hline West & & -87364.94 & -5146.16 & \\
\hline Academy Member & & -1373.95 & $* * *-12429.08$ & \\
\hline Land Grant & & -63903.28 & -50973.9 & \\
\hline Number Institutes & & -2469.78 & -1804.58 & \\
\hline Med School & & **164376.7 & **144820.3 & \\
\hline Tenured Faculty 2012 & & -60.4 & -15.67 & \\
\hline Full Time Grad Std & & 25.49 & $* * * 79.62$ & \\
\hline Endowment 2008 & & 0 & $* * 0$ & \\
\hline SciEng Space per Study Pop & & -302.55 & -701.59 & \\
\hline Rank Univ Last Degree R\&D 2008 & -362.11 & -395.28 & -353.45 & \\
\hline Highly Cited & $* *-474720.1$ & ***-299802.2 & ***-308222 & \\
\hline Sex Female & 56448.59 & 22881.23 & 23529.82 & \\
\hline MD degree & *234506.1 & 87035.98 & 66573.91 & \\
\hline MD/PhD degree & *432575 & *304346.5 & *295802.5 & \\
\hline Total Articles 2006-07 & *73321.6 & *69873.67 & *70929.1 & \\
\hline Articles 2006-07 Squared & *-1475.46 & *-1308.92 & *-1351.96 & \\
\hline Ave Cites 2006-07 & *90701.04 & *73908.09 & *73524.6 & \\
\hline Ave Cites 2006-07 Squared & *-3028.93 & $* *-2467.99$ & $* *-2445.57$ & \\
\hline Career Citation as of 2007 & *42.39 & $* * 30.91$ & $* * 33.83$ & \\
\hline Assistant Professor & $*-521283.9$ & $*_{-538194.4}$ & *-547157 & \\
\hline Associate Professor & *-337319.5 & *-340241.9 & *-335241.2 & \\
\hline License & 118146.8 & 155027.2 & 178399.6 & \\
\hline Spin Out & 586308.2 & $* * * 620143.4$ & 566160.1 & \\
\hline Patent Applications 2000-07 & 117086.3 & $* * * 174291.2$ & $* * * 168065$ & \\
\hline Constant & -542244.2 & -512696.8 & -752921 & \\
\hline
\end{tabular}


Table 17. Tobit Regressions by Dependent Variables.

\begin{tabular}{|c|c|c|c|}
\hline \multirow{2}{*}{ Variable } & \multicolumn{3}{|l|}{ Coefficients } \\
\hline & Total Grant Dollars & Av Grant \$ & Number of Grants \\
\hline Gender Female & 29455.37 & 31318.09 & 0.1 \\
\hline Medical Degree & -53874.47 & -46136.43 & $*-0.28$ \\
\hline MD/Phd Degree & *200969.6 & *135813.4 & $* 0.51$ \\
\hline Total Articles 2006-07 & *64885.47 & *34813.1 & $* 0.12$ \\
\hline Articles Squared* & *-1264.7 & *-715.7 & $*_{0}$ \\
\hline Average Cites 2006-07 & *55672.5 & *34849.11 & $* 0.12$ \\
\hline Average Cites Squared & $* *-1666.69$ & $*-1076.75$ & $*_{0}$ \\
\hline Career & $* 22.2$ & $* * * 10.69$ & 0 \\
\hline Basic Science Dept & *-275284.3 & *-149805.7 & $*_{-}-0.53$ \\
\hline MolBioChem & *195686.1 & *121022.9 & $* 0.39$ \\
\hline NeroSciGenetics & *280920.2 & *178200.5 & $* 0.47$ \\
\hline Economics & -335984.3 & -250113.9 & -0.54 \\
\hline MedNursDental & *113767.4 & **61389.92 & $* 0.21$ \\
\hline Assistant Professor & $*_{-523570.8}$ & *-326669.3 & $*_{-} 0.94$ \\
\hline Associate Professor & *-297491.6 & *-169672.4 & $*_{-} 0.46$ \\
\hline License & $* * * 154244.7$ & $* * * 89970.81$ & $* 0.58$ \\
\hline Spin Out & $* * * 586712.8$ & *660607.9 & 0.46 \\
\hline Private University & -126139.3 & 110483 & -0.2 \\
\hline Northeast Region & 192219.5 & 114404.6 & $* * * 0.36$ \\
\hline Southeast Region & **-177528.1 & -85076.05 & ${ }^{*}-0.38$ \\
\hline Middle Region & -109074.1 & -56160.2 & -0.29 \\
\hline West Region & 26742.11 & 60797.18 & -0.03 \\
\hline Percent Bachelors & 2062.4 & 1862.35 & 0.01 \\
\hline Metro Pop 2010 & $* * 0.017$ & $* * 0.01$ & $*_{0}$ \\
\hline Academy Members & $* *-14384.16$ & *-10159.35 & $*_{-} 0.03$ \\
\hline Land Grant Univ & $* * *-137616$ & -76816.14 & $* *-0.36$ \\
\hline Number of Orgs NIH 2008 & $* * *-4235.4$ & $* *-2672.04$ & $* *-0.01$ \\
\hline Medical School & $* * * 125037.1$ & $* * * 68330.73$ & $* 0.31$ \\
\hline Rank Total R\&D Exp 2008 & **-3042.67 & $* * 1507.21$ & $* *-0.01$ \\
\hline Tenured Faculty & -71.6 & -52.78 & 0 \\
\hline Full Time Grad Std & 13.09 & 25.32 & 0 \\
\hline Patent Application 2008 & $* * * 136346.4$ & 40098.87 & 0.11 \\
\hline Endowment 2008 & 0.000067 & 0 & 0 \\
\hline Science/Eng Sp per Pop & -911.22 & -565.81 & 0 \\
\hline Constant & -78206.03 & -104105.2 & 0.12 \\
\hline Number Observations & 3076 & 3076 & 3076 \\
\hline$* 0.00$ probability $\quad * *$ & . & & \\
\hline
\end{tabular}


Table 18. Correlation Matrix for Selected Individual Productivity Variables.

$\begin{array}{llllllll}\text { Variable } & \begin{array}{l}\text { NIH Funds } \\ \text { NIH Funds }\end{array} & \begin{array}{l}\text { Articles } \\ 2006-07\end{array} & \begin{array}{l}\text { Average } \\ \text { Cites }\end{array} & \begin{array}{l}\text { Career } \\ \text { Cites }\end{array} & \begin{array}{l}\text { Highly } \\ \text { Cited }\end{array} & \begin{array}{l}\text { Number } \\ \text { Grants }\end{array} & \begin{array}{l}\text { Grant } \\ \text { Dollars }\end{array} \\ \begin{array}{l}\text { Total Articles } \\ \text { 2006-07 }\end{array} & 1 & 0.2954 & 1 & & & & \\ \begin{array}{l}\text { Average Cites } \\ \text { 2006-07 }\end{array} & 0.1489 & 0.2421 & 1 & & & & \\ \begin{array}{l}\text { Career Cites } \\ \text { Highly Cited }\end{array} & 0.1859 & 0.3913 & 0.2052 & 1 & & \\ \begin{array}{l}\text { Number of } \\ \text { Grants }\end{array} & 0.0452 & 0.1776 & 0.0996 & 0.432 & 1 & & \\ \begin{array}{l}\text { Average Grant } \\ \text { Dollars }\end{array} & 0.71 & 0.3187 & 0.187 & 0.1501 & 0.0321 & 1 & \\ \end{array}$

Table 19. Correlation Matrix for Institutional Characteristics with Normalized Variables.

$\begin{array}{lccccccc} & \text { Rank } & \text { NIH } & \text { Academy } & \text { Faculty } & \begin{array}{c}\text { Studen } \\ \mathrm{t}\end{array} & \begin{array}{c}\text { Endo } \\ \mathrm{w}\end{array} & \begin{array}{c}\text { EngSp } \\ \mathrm{c}\end{array} \\ \text { Rank Total 2008 } & 1 & & & & & & \\ \text { NIH Fund 2008 } & -0.0809 & 1 & & & & & \\ \text { Academy Members } & -0.7216 & 0.0131 & 1 & & & & \\ \begin{array}{l}\text { Tenured Faculty 2012 } \\ \text { Full Time Graduate }\end{array} & -0.216 & -0.0513 & 0.2333 & 1 & & \\ \text { Students } & -0.6373 & 0.0049 & 0.6690 & 0.1465 & 1 & & \\ \text { Endowment } & -0.2557 & 0.0935 & 0.2290 & 0.1232 & 0.2906 & 1 & \\ & -0.0281 & -0.0319 & 0.0467 & 0.1170 & 0.0124 & 5 & 1 \\ \text { EngSpace per Pop } & & & & & & & \\ \end{array}$

Another factor that impacts the receipt of NIH funds is the individual's specific field of study. While the categories used in this study are broad, there is clearly an orientation of NIH funding toward specific fields, even though the productivity levels are similar in terms of articles published and average number of citations. Basic science (biology, chemistry, physics, etc.), for instance, has a negative coefficient, which is 
statistically significant at the 0.00 level across all models. Molecular biology and microbiology, neuroscience, genetics, and medical/nursing/dental departments have positive and statistically significant coefficients, which is also consistent with the findings of Ali, Bhattacharyya, and Olejniczak (2010).

The region in which a university is located generally has no effect on the amount of NIH funds received, except for the Southeast region, the presence in which has a negative and significant impact at the 0.05 level. However, further study would be needed to determine the extent to which this relationship holds across a broader selection of geographically distributed universities. Whether a university is private or public has no significant consequence in any of the regression models, which differs from the findings of Ali, Bhattacharyya, and Olejniczak (2010) that public universities receive fewer federal grant dollars than do private universities. They may have found such a difference because they include a broader range of federal funding sources than the NIH dollars used here.

A land grant designation is negative and significant at the 0.10 level for the totalNIH-dollars model and significant at the 0.05 level for the average-grant-dollars and the number-of-grants models. This may reflect the fact that land grant institutions have historically had greater access to other federal funds, such as those provided by the U.S. Department of Agriculture.

Variables associated with the percentage of metropolitan residents with bachelor degrees, the number of university institutes, the number of tenured faculty, and the number of full-time graduate students is estimated to have no significant impact on the 
receipt of NIH funds. Endowment size also had no significant impact in any of the estimated models, inconsistent with the view that endowments help facilitate grant applications (Cole, 2009; Rose, 1986). However, endowments, while often allocated to departments, are frequently subject to specific restrictions, which may limit their impact (Lapovsky, 2009). Further, since the universities in this study do not represent any beyond the top 20 NIH recipients. The impact of endowments may be significant when universities in the top 20 NIH recipients are considered.

A puzzling result is the negative coefficient associated with Science and Engineering Space. Although not at a significant level, the negative coefficient is inconsistent with the findings of Bania et al. (1991).

Across all models, the direction of the coefficient associated with number of members of the National Academy does not change, indicating that the presence of National Academy members does not have a positive spillover effect on individual researcher's success in obtaining NIH awards. The fact that being in the highly cited category has a negative coefficient and significant impact at the ten percent level and the finding that the career-citations variable has a small coefficient provide further indication that spillover effects are limited.

Three external variables have significant effects on NIH awards: 1) metropolitan population; 2) the number of organizations in the metropolitan area receiving NIH funds; and 3) rank in terms of total R\&D expenditures. The size of the urban area matters, possibly indicating a contribution of agglomeration economies. However, the number of organizations in the metropolitan area competing for NIH funds also is estimated to have 
a mitigating effect on such economies of agglomeration. The estimated negative effect associated with the rank of total R\&D expenditures is as expected; its inverse relationship with NIH dollars received suggests that there is a halo effect associated with reputation.

Turning to the economic impact of the independent variables for Total NIH funds, funding is clearly a complex process. Citations of recent articles are estimated to add about $\$ 55,000$ per citation to NIH awards. Having both a PhD and an MD contributes an estimated \$201,000 per award. Specializing in molecular biology, biochemistry, or microbiology contributes $\$ 196,000$, while a focus on neuroscience and genetics contributes $\$ 281,000$. When an individual has licensed an invention or has been involved in a spinout, the estimated effects on NIH awards are $\$ 154,900$ and $\$ 587,000$, respectively. Considering that the average NIH recipient receives a total amount of $\$ 538,927$ and an average per-grant amount of $\$ 366,100$, the effects of these variables clearly become very important.

Table 20 and Graph 4 show the predicted total NIH funds by number of articles, along with the number of academics in the sample who published each number of articles. The prediction is based on the derivative of the regression equation with respect to the number of publications. Clearly, there are decreasing marginal returns for greater numbers of published articles.

Holding other funding determinants constant, if an academic wanted to receive a modest additional amount of NIH funds, he or she must publish at least two articles. If an academic sought to be in the middle of the pack (45.2\%), he or she must have four publications over the previous two years, which would garner an estimated additional 
$\$ 122,180$. If an individual wanted to break out of the pack, he or she would on average have five or six publications over the prior two-year period, which would place the person in the $64 \%$ to $72 \%$ range, garnering an estimated additional $\$ 286,475$ to $\$ 336,180$, respectively. This amount can be compared with the average total grant amount of $\$ 515,927$.

These estimates indicate that in order to receive NIH grant dollars, a researcher must publish. The positive statistical relationship between publication performance and total NIH grant funds indicates that there is an implicit normative performance standard used to allocate NIH grant dollars.

Table 21 and Graph 5 present the estimated average grant award per article, again showing diminishing returns. These diminishing returns, when combined with the results of Parolo et al. (2015), make it clear that publications and citations have a short shelf life, which affects the amount of NIH funding received in that the concept of "contribution to the field” increasingly requires that the work an academic produces be current.

Table 22 and Graph 6 show the predicted total NIH dollars by average citations per published article, along with the number of academics receiving each rate of citation. Table 23 and Graph 7 show the predicted average NIH grant dollars in the same terms. As with the number of articles published, the results indicate diminishing marginal returns.

Comparison of the coefficients across the models indicates a fair degree of consistency and stability. Succinctly summarized, the models indicate that individual scholarly performance is a key determinant in obtaining NIH extramural grants. 
Specifically, the number of articles published in the prior two years is an important determinant of successfully receiving a grant.

In this study, $68 \%$ of those receiving NIH funds fell in the range of one-to-four citations per article. Eight percent had between five and eight citations per article, and only six (0.005\%) had seventeen or more citations per article. The skewed nature of the estimated citation effect is similar to that found by Redner (2005). Because the citations considered here are only associated with articles published in 2006 and 2007, the number of citations is relatively small in 2006 and becomes larger in 2007 as the articles became more widely reviewed. While an article may be cited for many reasons, average citations within the first two years of publication may be seen to represent at least two factors. The first is a reputational effect. The greater one's reputation, the sooner peers tend to read and cite the article. The second is the impact of a breakthrough article, as breakthroughs often become known to the field in advance and are reviewed and published more quickly.

Because the skewed nature of the NIH dollars disbursed might substantively impact the basic model, I ran an additional Tobit regression excluding those fourteen academics, one of whom is Highly Cited, who received more than \$3 million. I also ran a regression with a National Academy Member interactive variable in order to determine if there was a spillover effect between the number of academy members at a university and academic rank. The interactive variable was the product of the number of academy members at the university and the value of the individual's rank: $0=$ Unknown, 
1 = Assistant, 2 = Associate, and 3 = Professor. The results of these two regressions are presented in Tables A and B, respectively, in Appendix A.

Eliminating the outliers had minimal impact. Having a Medical Degree changes from negative but not statistically significant, to negative and statistically significant at the 0.05 level of probability. Patent Applications become non-significant, though the coefficients of the variables also shift. The most noticeable shifts are in Total Articles, which change from $\$ 64,885.47$ to $\$ 51,465.32$, and Average Citations, which drop from $\$ 55,672.5$ to $\$ 42,919.48$.

For the regression including the interactive variable, the results found that the interactive variable had a value of $-5,762.67$ and was significant at the 0.05 level of probability. No significant change in the probability levels of the other variables occurred. Further, the changes in the coefficients are modest. For instance, Total Articles moved from $\$ 64,885.47$ to $\$ 65,061.52$, while Average Citations moved from $55,672.56$ to $55,863.86$. 
Table 20. Diminishing Marginal Return for Total NIH Grants to Publications.

$\begin{array}{llll}\text { Article } & \text { Total Dollars } & \text { Number of Academics } & \text { Percentage } \\ 0 & 0 & 92 & 0.069856 \\ 1 & 62,355 & 179 & 0.135915 \\ 2 & 59,825 & 185 & 0.140471 \\ 3 & 57,295 & 141 & 0.107062 \\ 4 & 54,765 & 139 & 0.105543 \\ 5 & 52,235 & 116 & 0.088079 \\ 6 & 49,705 & 98 & 0.074412 \\ 7 & 47,175 & 71 & 0.05391 \\ 8 & 44,645 & 55 & 0.041762 \\ 9 & 42,115 & 43 & 0.03265 \\ 10 & 39,585 & 33 & 0.025057 \\ 11 & 37,055 & 29 & 0.02202 \\ 12 & 34,525 & 26 & 0.019742 \\ 13 & 31,995 & 21 & 0.015945 \\ 14 & 29,465 & 12 & 0.009112 \\ 15 & 26,935 & 14 & 0.01063 \\ 16 & 24,405 & 11 & 0.008352 \\ 17 & 21,875 & 8 & 0.006074 \\ 18 & 19,345 & 9 & 0.006834 \\ 19 & 16,185 & 11 & 0.008352 \\ 21 & 11,755 & 4 & 0.003037 \\ 22 & 9,225 & 3 & 0.002278 \\ 24 & 4,165 & 1 & 0.000759 \\ 25 & 1,635 & 2 & 0.001519 \\ 26 & -895 & 1 & 0.000759 \\ 27 & -3,425 & 1 & 0.000759 \\ 28 & -5,955 & 1 & 0.000759 \\ 29 & -8,485 & 2 & 0.001519 \\ 30 & -11,015 & 2 & 0.001519 \\ 31 & -13,545 & 2 & 0.001519 \\ 32 & -16,075 & 2 & 0.001519 \\ 34 & -21,135 & 1 & 0.000759 \\ 53 & -69,205 & 2 & 0.001519 \\ & & & \end{array}$




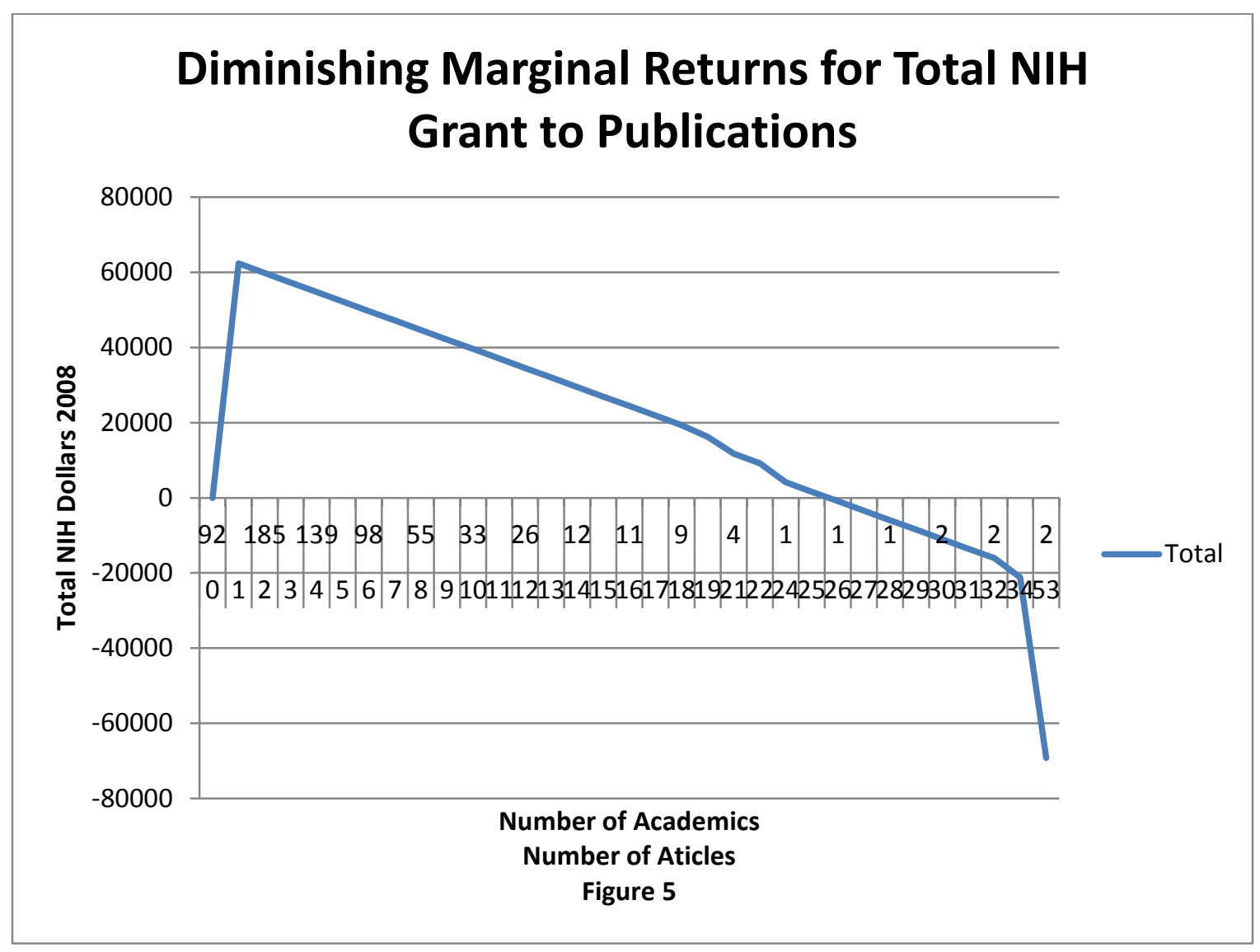


Table 21. Diminishing Marginal Return for Average NIH Grant to Publications.

Articles

0

1

2

3

4

5

6

7

8

9

10

11

12

13

14

15

16

17

18

19

21

22

24

25

26

27

28

29

30

31

32

34

53
Academics Est Average Grants

92

179

185

141

139

116

98

71

55

43

33

29

26

21

12

14

11

8

9

11

4

3

1

1

2

1

1

1

2

2

2

2

2

1

2
0

32,695.61

$30,542.11$

28,388.61

26,235.11

$24,081.61$

21,928.11

19,774.61

$17,621.11$

$15,467.61$

$13,314.11$

11,160.61

9,007.11

6,853.61

4,700.11

2,546.61

393.11

$-1,760.39$

$-3,913.89$

$-6,067.39$

$-10,374.40$

$-12,527.90$

$-16,834.90$

$-18,988.40$

$-21,141.90$

$-23,295.40$

$-25,448.90$

$-27,602.40$

$-29,755.90$

$-31,909.40$

$-34,062.90$

$-38,369.90$

$-79,286.40$ 


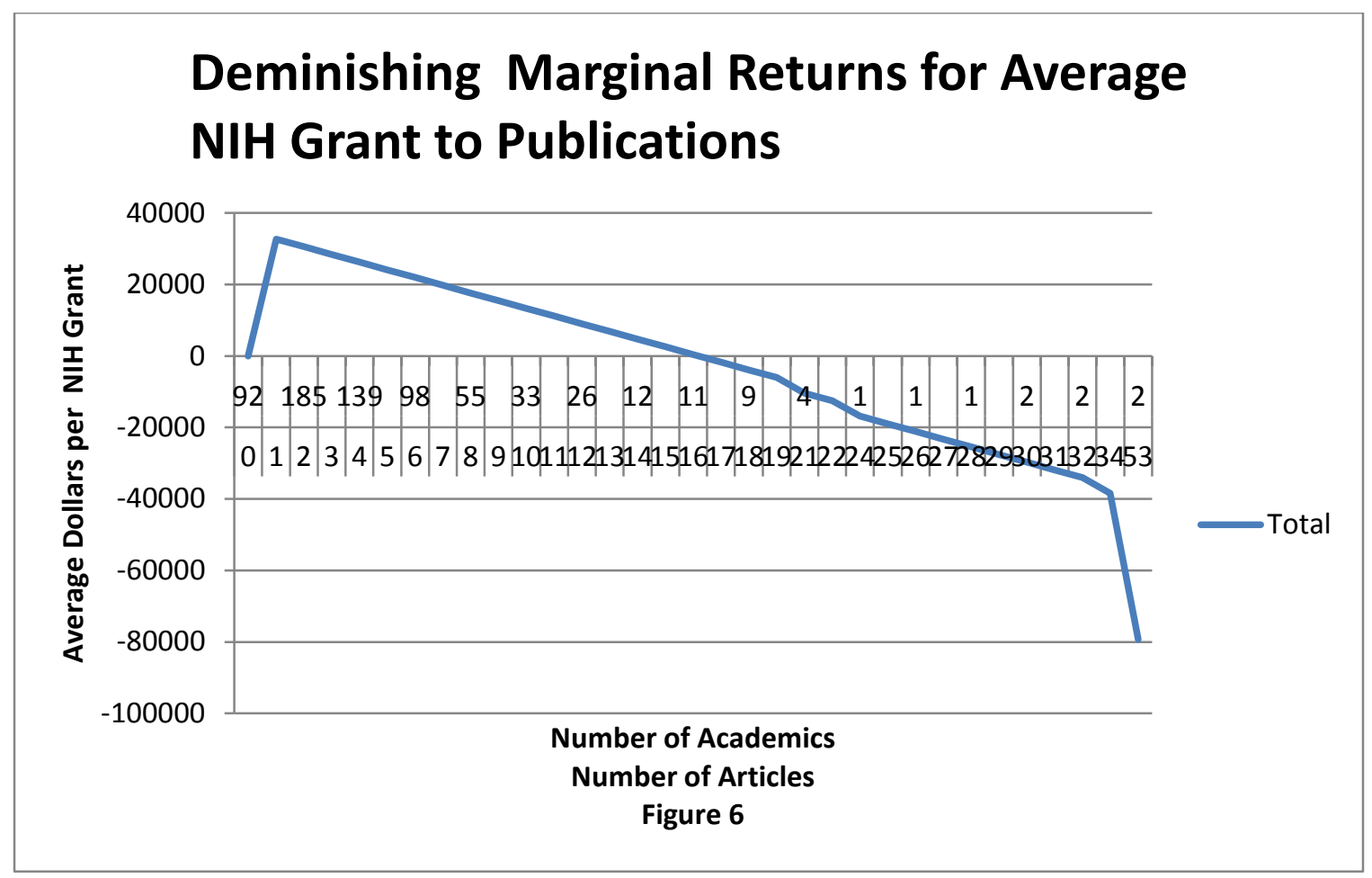


Table 22.Diminishing Marginal Returns to Citations in Terms of Total NIH Grants.

\begin{tabular}{rrr} 
Articles & Academics & \multicolumn{2}{l}{ lverage NIH } \\
0 & 267 & 0 \\
1 & 349 & $33,818.77$ \\
2 & 270 & $32,537.36$ \\
3 & 176 & $31,112.22$ \\
4 & 107 & $29,726.21$ \\
5 & 63 & $28,211.39$ \\
6 & 19 & $26,914.79$ \\
7 & 20 & $25,245.62$ \\
8 & 9 & $24,095.09$ \\
9 & 9 & $22,563.50$ \\
10 & 9 & $20,744.48$ \\
11 & 6 & $19,353.98$ \\
12 & 1 & $17,636.30$ \\
13 & 4 & $16,562.75$ \\
14 & 1 & $16,004.50$ \\
15 & 5 & $13,820.19$ \\
16 & 3 & $12,321.03$ \\
17 & 1 & $10,479.30$ \\
20 & 1 & $6,185.10$ \\
26 & 1 & $-2,403.30$ \\
27 & 1 & $-3,834.70$ \\
28 & 1 & $-5,266.10$ \\
38 & 1 & $-19,580$ \\
& &
\end{tabular}




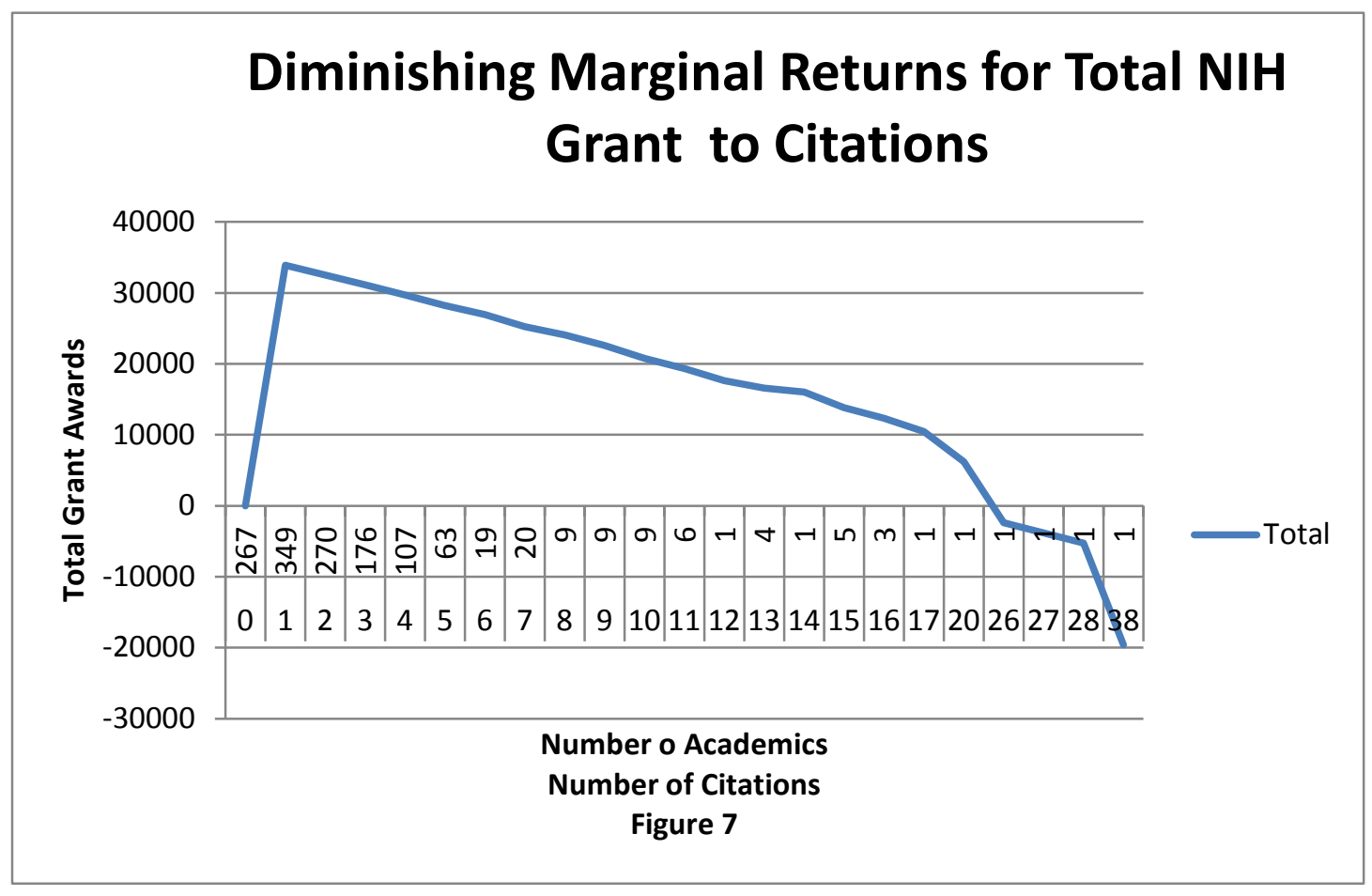

Table 23. Diminishing Marginal Returns for Average NIH Grant to Citations.

Number of Citations 0

1

2

3

4

5

6

7

8

9

10

11

13

17

20

27

38
Number of Academics 267

349

270

176

107

63

19

20

9

9

9

6

4

1

1

1

1
Average NIH Grant 0

33,353.50

31,425.65

$29,281.57$

$27,196.36$

24,917.36

$22,966.65$

$20,455.45$

$18,724.51$

$16,420.27$

$13,885.12$

$11,591.64$

7,393.32

$-1,760.06$

$-8,220.56$

$-23,295.10$

$-46,983.60$ 


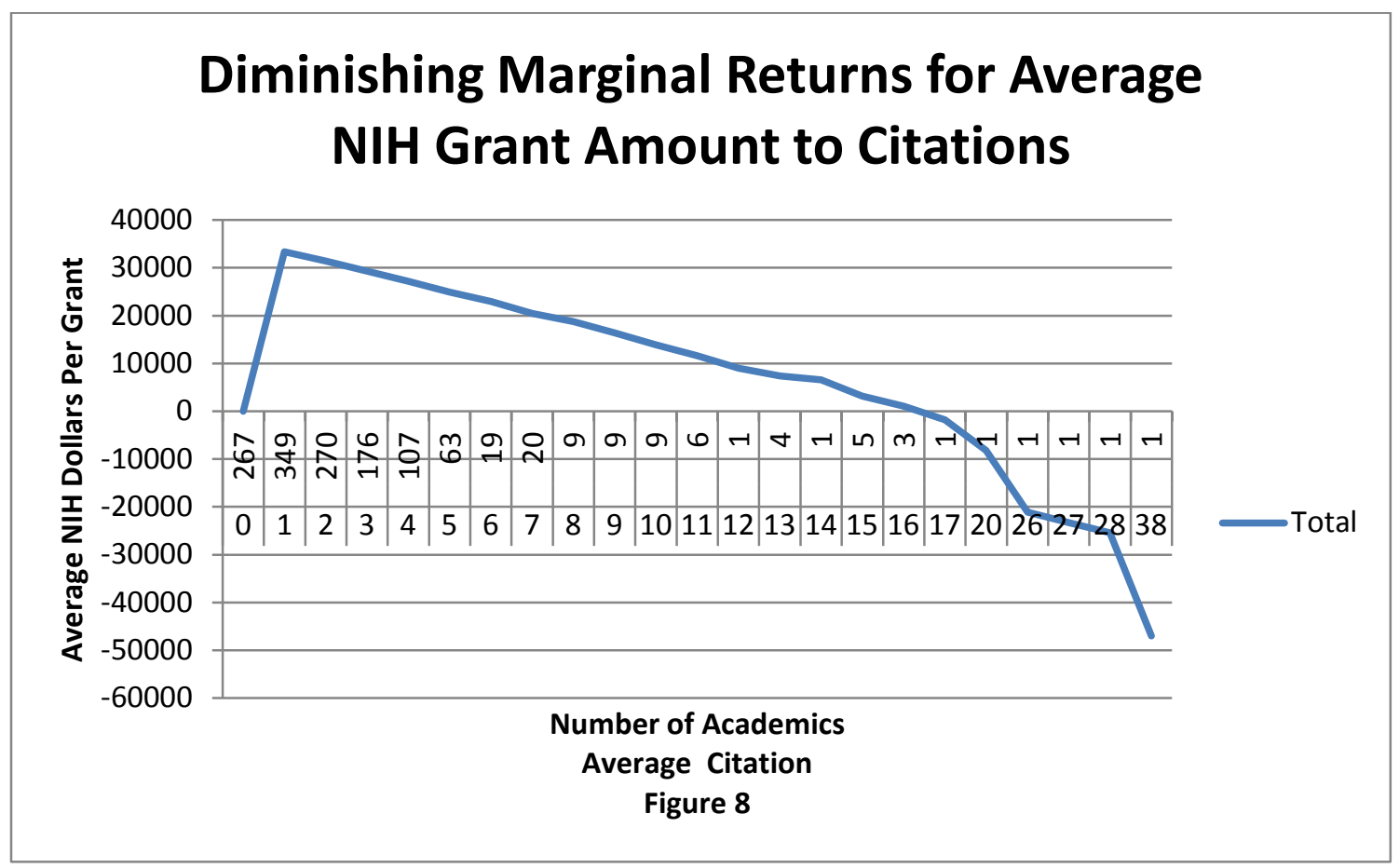

Let us turn now to the research questions.

$\underline{\text { Research Questions }}$

1. Do Highly Cited Researchers receive significantly more NIH funding than do others?

The answer to this question is both clear and nuanced. The descriptive statistics show that highly cited $\mathrm{NIH}$ recipients on average receive $\$ 927,189$ compared to $\$ 538,927$ for the entire sample. Similarly, the average total publications over 2006-07 for highly cited NIH recipients is 13.6, compared to an average of 5.31 for the entire NIH recipient sample. Thus, consistent with other studies, highly cited academics are more productive and on average receive more NIH funds than others do. 
Of the forty-five highly cited academics in this study, nineteen (42.2\%) received NIH grants. Of those receiving NIH extramural grants, 57.9\% received one grant, and another $21 \%$ received two grants. Of the remaining four, two received three grants and two received four grants.

However, the Tobit results indicate that, while the highly cited variable is statistically significant at the ten percent level, the negative coefficient actually reduces the amount of Total NIH Grant funds by $\$ 308,222$. The Tobit results also indicate that the number of career citations-which represent the reputation of the highly cited academics — while having a positive coefficient and statistical significance at the ten percent level, has a small \$22.2 coefficient for total grant funds. The negative coefficient for the second derivative for articles published from 2006-07 and their associated citations indicates that for these key performance indicators there are diminishing returns for both total grant and average grant funds, consistent with the findings of Adams and Griliches (1998) and of Ali, Bhattacharyya, and Olejniczak (2010).

The perishability of articles and citations (Parolo et al., 2015, Pollman, 2000; Redner, 2005), combined with the diminishing marginal returns and small coefficient for the number of career citations, indicates that current publications and citations are more important than past performance. In the highly competitive environment for NIH grant funding - only $28 \%$ of the applicants received NIH funds in 2008 - the idea of publish or perish is not far from the economic truth, as indicated by these results. Moreover, there is a positive and reinforcing association between ongoing publication and government funding (McAllister and Condon, 1985; Pagel and Hudetz, 2011a; Pagel and Hudetz, 
2011b; Pao, 1991). NIH funding increases the number of publications by one additional article over a five-year period (Jacob and Lefgren, 2007). With an estimated time lag of about three years between NIH funding and publication (Boyack and Jordan, 2011), any disruption in the receipt of NIH funds could negatively impact publication and the subsequent receipt of NIH funds.

Recurrent funding is therefore important for sustaining focused research and publication. The results of this study indicate that endowments, after controlling for such factors as number of articles, their citations, gender, and number of career citations, do not effect the receipt of NIH extramural grant funds to any statistically significant extent. Yet better-funded universities may have the capability to provide recurrent funding (Landel, 2010), which could reflect the negative coefficient. Further, highly cited academics may also have access to non-NIH funds. Barring these, continued “contribution to the field” requires a strong current record of publication. Depending on one's past publication history and citation record, the criteria required for the designation of "Highly Cited” may be insufficient.

2. Does the number of members of the National Academy of Arts and Sciences at a university positively contribute to NIH funding? (Is there a faculty-level halo effect?)

Regardless of model or dependent variable, this coefficient is negative and statistically significant at the 0.05 or 0.00 level of probability. This association probably reflects two conditions. First, the total number of Academy Members at a university reflects 
members in all fields. Academics in many of these fields, exemplified by the Economics Department in this study, generally neither seek nor receive significant amounts of NIH funds. Second, highly cited Academy Members — the stars - may have access, because of their reputations, to funds other than from the NIH (Campbell, Koski, and Blumenthal, 2004; Lendel, 2010).

3. Does having a degree from a top-ranked university contribute positively to the amount of NIH funding received?

There is no statistically significant relationship here. There has been criticism that the NIH review panels steer money to universities with which they are somehow affiliated (Rose, 1965). This research suggests that NIH funds appear not to be allocated based on the university from which an academic graduated. Further, the small Total R\&D Expenditures coefficient, at least up to the top twenty institutions ranked by $R \& D$ spending, indicates that any allocation bias is minimal.

4. Does the number of articles published in the two years immediately preceding the receipt of NIH funds have a positive impact on the level of NIH funding?

The Tobit model indicates that the number of articles published in the immediate two years prior to the receipt of NIH extramural grant funds has a positive and statistically significant impact on the amount of funding at the 0.00 level of probability. For the total amount of NIH grants received, the number of articles in the prior two years contributes $\$ 64,885.47$, contributing $\$ 34,813.10$ to the average grant award. However, as indicated by the negative coefficients for the second derivative of the estimated total 
grant award and average grant amounts attributed to the number of articles in the two years prior, there are diminishing marginal returns.

5. Does the average number of citations per recent publication positively impact the level of NIH funding?

For the immediate two years preceding the application for an NIH grant, the number of citations has a positive and statistically significant impact on receipt of such funds at the 0.00 probability level. The number of career citations has a statistically significant but small impact. However, the second derivative of the average number of citations has a negative coefficient. This and the estimated marginal returns for total grant and average grants per citations indicate that there are diminishing returns to the number of citations.

6. Is there a difference in publication performance between NIH recipients and nonrecipients?

The data show a consistently lower publication rate for those academics who do not receive NIH funds. This pattern holds regardless of gender, academic position, or department. NIH non-recipients published on average 2.8 articles in the two years prior to 2008, while NIH recipients published on average 5.3. This trend is similar for citations. 
7. Do academics who license an innovation/invention through the university’s Office of Technology Transfer (OTT) receive more NIH funding than other recipients?

Only 3.2\% of the sample has licensed an invention. Comparatively, NIH recipients who licensed an invention averaged \$566,864 in total grant funds, compared to the average of $\$ 515,927$ for the sample. When controlling for articles published, average citations, career citations, departments, and rank, the licensing of technology contributes positively and is statistically significant at the 0.10 level for total grant and average grant and at the 0.00 level for number of grants. The licensing of an invention contributes $\$ 154,244.70$ to the total grant amount.

8. Do academics who are part of a spinout receive more NIH funding than do other recipients?

A very small number of academics in this sample (0.2\%) have been involved in a spinout. However, being involved in spinning out a business contributes positively to the receipt of total NIH funds. The coefficient for spinning out a business is the highest of all the variables at $\$ 586,712$ with a probability level of 0.10 . Comparatively, those recipients who spun out a company average $\$ 785,395$, while the sample average is $\$ 515,927$. Spinning out a small business has a positive and statistically significant impact on average dollars per grant at the 0.05 level. 
9. Does being listed as an inventor on a university's patent application positively contribute positively to the receipt of NIH funding?

One hundred and sixty-two academics in the sample (5.2\%) have received a patent for an invention. Patenting an invention does have a statistically significant impact on the total receipt of $\mathrm{NIH}$ grants at the 0.10 level. It has no statistical impact on the average grant amount. It must be noted that the data here are restricted to those academics who are cited as an inventor in patents submitted by their university and do not include patents submitted in their own names or by other organizations. The results reflect this constricted approach.

Given the problems with the data, a firm conclusion as to whether the probability level for Patents, Licenses, and Spinouts would increase or decrease with better data would require additional research. Nonetheless, the positive association and statistical significance of all three variables may be a consequence of the three factors noted in the literature review. The first is the growing impact of the Bayh-Dole Act, which encourages universities to license and patent inventions. Mowery et al. (2004) noted a substantial increase in university patenting following the passage of the Act. The second factor is current academics - attracted by the possibility of substantive remuneration, as exemplified by the wealth garnered by the academic founders of the early biotechnology firms (Hughes, 2011; Robbins-Roth, 2000)—may now be licensing and patenting more of their research results. Aldridge and Audretsch (2010) noted such a trend for scientists receiving grants from the National Cancer Institute. Finally, the culture within 
departments may contribute to individuals’ decisions to license or patent (Bercovitz and Feldman, 2008). Taken together, these three factors suggest that a cultural shift may be occurring in the normative behavior of scientists toward a more entrepreneurial and commercial-oriented attitude to research. Such a shift may impact where research efforts are directed, which may, in turn, contribute to the departmental effects shown here in the Tobit models.

\section{$\underline{\text { Policy Implications }}$}

The tapestry woven by this study presents a clear picture of the importance of individual academic performance. The picture is more complex with regards to highly cited academics, as the Tobit models indicate that being highly cited does not guarantee increasing returns. Likewise, career citations have only a small statistically significant impact. In addition, the negative coefficients of the second derivatives of both articles published in 2006-07 and their associated citations indicate diminishing marginal returns. These are, of course, the key measures of the highly cited academic’s performance. The descriptive statistics, on the other hand, indicate that highly cited academics receive more NIH funds and are more productive.

The complexity and its subtle impact on policy is reflected in the interactions between a number of variables. The number of academy members is positively associated with university ranking in terms of total research and development expenditure. More academy members are also positively correlated with the size of a 
university's endowment. When considering the fact that the presence of stars in a department generally increases the number of publications (Agrawal, McHale, and Oettle, 2012), there appears to be a subtle halo effect.

Agrawal, McHale, and Oettle (2012), in their study of a star's impact on Evolutionary Biology Departments, concluded: “Our findings suggest that starrecruitment strategies may be most effective where a cadre of related incumbents is already present and the organization has a flow of new hiring slots sufficient to take advantage of the improved quality of potential new recruits” (p. 20). This research suggests that while that hiring strategy may be valid, how institutions define stars and on which departments they focus their recruitment efforts may be equally important.

An observation regarding Yale’s improvement in patenting and spinning out companies is telling, echoing Cole’s (2009) statement regarding absolute advantage: “As a private university, Yale can offer competitive salaries to senior employees recruited from industry” (Breznitz, 2014, p. 71). The ability of top-ranked universities, such as Yale, to pay "competitive salaries” for the talent they desire is enhanced by the resources of their large endowments. This makes it difficult for lower-ranked universities to compete for talent. When combined with the trend noted by Zucker and Darby (2006), lower-ranked universities may be at an absolute disadvantage. This returns us to the question Rhode (2006) raised: “Is it worth it?”

The answer to that question depends on the policy objective. However, if one assumes that lower-ranked universities must pay a premium above what the elite universities would be willing to pay-and perhaps the lower rank, the larger the 
premium — this work indicates that the idea of a positive return on that investment may be problematic in such a circumstance.

While this study focused on the year 2008, in order to determine if academics who moved from one university to another had maintained contracts with NIH after the move, I made a cursory examination. The examples come from curricula vitae listed by ISI Thomason Reuters Highly Cited Academics and other academics' curricula vitae. The results are presented in Appendix B, Table A. Based on this very cursory review of nine academics, seven of whom are highly cited, two things become clear. First, NIH contracts are maintained, often with an increase in the amount received. Second, consistent with the findings of Zucker and Darby (1996), there is a tendency to move from a lower-ranked university to one of higher rank. There are four exceptions: Ronald Kessler, Paul Watkins, Michael Levine, and Joseph Beckman. Most relevant is Joseph Beckman, who moved from the University of Alabama to Oregon State University. When he left the University of Alabama, his peak grant was $\$ 844,550$. After several years at Oregon State University, his largest grant amount was $\$ 1,353,927$. While not systematic, these examples indicate that obtaining a Highly Cited Academic could result in higher levels of NIH funds for his or her new university.

However, given the diminishing marginal returns to publications and citations, the small career-citation coefficients, and the negative coefficient for the highly cited categorical variable, when universities recruit a star, they must make sure that the star is on top of his or her game, both in terms of current publications and receipt of NIH funds. If he or she is current, obtaining higher-than-average returns seems likely. Merely having 
a title contributes little and may even hurt the university's attempt to move up in rankings.

The work of Bania et al. (1991) and the development of Stanford add additional refinement to the picture. Universities move up in rankings by being competitive in a specific field, as opposed to trying to identify the right mix of fields. The statistical significance of various departmental groupings strengthens this idea of focusing on specific departments.

Equally helpful may be the development of an entrepreneurial atmosphere in the focus department and at the university. Bercovitz and Feldman (2008) found that the culture within a department — and particularly the attitude of the Department Headincreases the licensing activity of academics in that department.

Yale’s experience in strengthening its OTT staff and streamlining processes in order to increase licensing and spinouts provides another focal point. This in turn can have a substantive impact on the receipt of NIH dollars, on local economic development activities, and on the creation of a constructive advantage.

Unlike the findings of Bania et al. (1991), however, this study indicates that the amount of Science and Engineering Space has a small but statistically insignificant and negative coefficient. Thus, rapidly expanding the amount of Science and Engineering space may not lead to the receipt of additional NIH funds. 
$\underline{\text { Summary }}$

This study concerned 3,092 academics at twenty-four universities drawn from those in the top twenty and below in terms of receipt of NIH funds. Universities in these categories are considered to be the most volatile. Thus, the examination here of the performance of individual academics, institutional characteristics, and external factors may help inform what contributes the most to the receipt of NIH funds. The 3,092 academics represent $53.3 \%$ of the study population. Non-recipients of NIH funding comprise the majority of the sample. The distribution of non-recipients is similar for women, 58.5\%, and for men, 56.6\%. With regards to performance measures, nonrecipients of NIH grants have lower performance than recipients have.

A key determinant of the receipt of NIH funds is individual performance, as measured by the number of articles published and average citations per article in the two years immediately prior to the grant application. To the extent that these criteria represent the quality of the research proposal, allocation of NIH funds is based on merit.

Professors receive more NIH money than do associates and assistant professors. Similarly, professors produce more articles and have higher citation rates. Consistent with the findings throughout this study, on average, NIH recipients produce more articles and have higher citation rates than do non-recipients of NIH funds, regardless of rank.

The data indicate that being highly cited alone does not contribute to an increase in NIH funding; there is a positive but small coefficient associated with number of career citations. 
The second derivative of articles published in 2006-07 and average citations per article is negative and statistically significant at the 0.00 probability level. Taken together, these results, along with the estimated decreasing marginal returns, indicate that there are decreasing returns for common academic productivity measures with regards to the receipt of NIH grant funds.

The specific field of an academic also impacts the receipt of NIH funds. While the categories used in this study are broad, the bias toward specific fields is clear even though productivity levels are similar. This bias may reflect a changing emphasis in biotechnology research.

Licensing technology contributes positively to the receipt of NIH funds. Being involved in spinning out a business, patenting an invention, and licensing an invention also all contribute positively to the receipt of NIH funds. These relationships and the departmental bias support the notion that there is an increasing emphasis on commercialization in biotechnology research.

The data show complex interactions. Individual performance is a key determinant to obtaining NIH funding, as are an academic’s rank and field. Gender is not an important factor. While some institutional and environmental variables also contribute to the obtaining of NIH funds, they are secondary to individual effort.

There is an expiration date, however, on the results of individual efforts. This puts pressure on the academic who wants to receive NIH funds to continually produce. In the highly competitive biotechnology grant environment, where only $28 \%$ of applicants successfully received NIH Research Grants in 2008, publish or perish has a 
very significant and specific meaning. In the past, academics published copiously in the early periods of their careers. As they aged, however, their publication rates declined. In the biotechnology fields, however, increasing commercialization and increasingly entrepreneurial attitudes towards research may be changing this pattern. With a short shelf life for publications and citations and the positive associations of licensing, patenting, and spinouts with NIH grants, publication must be continuous and commercial activities must be regularly pursued. Combining these processes with the shifting research emphasis in specific departments may be creating a new group of stars.

The definition of these new stars reflects that of Darby and Zucker (2006) in terms of impact, articles, citations, grant dollars received, inventions licensed, patents received, and involvement in spin outs. It differs in terms of the current, up-to-date nature demanded of academic production. For universities seeking to move up the Carnegie Ladder, the difference in emphasis might be conceptualized as the difference between obtaining a single home-run hitter and obtaining several academics who consistently hit doubles and triples. While home-run hitters may capture a lot of attention, the latter are in fact the Money Ball Players. 


\section{REFERENCES}

Aces, Sultan J., David B. Audretsch, Pontus Braunerhjelm, and Bo Carlsson. 2011. "Growth and Entrepreneurship.” Small Business Economics, published online 15 February.

Acs, Zoltan J., Pontus Braunerhjelm, David B. Audretsch, and Bo Carlsson. 2009. "The Knowledge Spillover Theory Of Entrepreneurship.” Small Business Economics, 32: 1530 .

Acs, Zoltan J. and Attila Varga. 2005. "Entrepreneurship, Agglomeration and Technological Change.” Small Business Economics, 24: 323-34.

Acs, Zoltan J. and Catherine Armington. 2004. "Employment Growth and Entrepreneurial Activity In Cities.” Regional Studies, 38, no. 8: 911-27.

Acs, Zoltan J., Felix R. FitzRoy, and Ian Smith. 2002. "High-technology Employment and R\&D in Cities: Heterogeneity vs. Specialization.” The Annals of Regional Science, 36: 373-86.

Adams, Stephen B. 2009. "Follow the Money: Engineering at Stanford and UC Berkeley During the Rise of Silicon Valley.” Minerva, 47: 367-90.

Adams, James D. 2006. “Learning, Internal Research, and Spillovers.” Economics of Innovation and New Technology, 15, no. 1: 5-36.

Adams, James D., Roger J. Clemmons, and Paula E. Stephan. 2006. "How Rapidly Does Science Leak Out?” Rensselaer Working Paper in Economics, no. 0612. Troy, NY:

Department of Economics, Rensselaer Polytechnic Institute.

Adams, James D. and Zvi Griliches. 1998. "Research Productivity in a System of Universities.” Annales D’Economie Et De Statistique, no. 49/50: 127-62.

Agarwal, Ajay, John McHale, and Alexander Oettle. 2012. "Why Stars Matter.” NBER Working Paper no. 20012, March.

Agarwal, Saurabh, Vinay Gupta, and Sharmistha Bagchi-Sen. 2006. "Insights into US Public Biotech Sector Using Patenting Trends.” Nature Biotechnology, 24, no. 6: 643-51.

Agarwal, Ajay and Rebecca Henderson. 2002. "Putting Patents in Context: Exploring Knowledge Transfer from MIT.” Management Science, 48, no. 1: 44-60.

Agrawal, Ajay and Iain M Cockburn. 2002. "University Research, Industrial R\&D, and the Anchor Tenant Hypothesis” (NBER Working Paper 9212). 
Aldridge, Taylor and David B. Audretsch. 2010. "Does Policy Influence the Commercialization Route? Evidence from National Institutes of Health Funded Scientists.” Research Policy, 39: 583-88.

Ali, Mir M., Partha Bhattacharyya, and Anthony J Olejniczak. 2010. “The Effects of Scholarly Productivity and Institutional Characteristics on the Distribution of Federal Research Grants.” The Journal of Higher Education, 81, no. 2 (March/April): 164-78.

Allison, Paul D. and J. Scott Long. 1987. "Interuniversity Mobility of Academic Scientists.” American Sociological Review, 52, no. 5: 643-52.

Almeida, Paul and Bruce Kogut. 1999. "Localization of Knowledge and The Mobility of Engineers in Regional Networks.” Management Science, 45, no. 7: 905-17.

Argyris, Chris. 1973. “Some Limits of Rational Man Theory.” Public Administration Review, 33, no. 3: 253-67.

Arrow, Kenneth J. 1962. “The Economic Implications of Learning by Doing.” The Review of Economic Studies, 29, no. 3: 155-73.

Arrow, Kenneth J. 2000. "Increasing Returns: Historiographic Issues and Path Dependence.” European Journal of History of Economics, 7, no. 2: 171-80.

Arthur, W. Brian. 1996. “Increasing Returns and the New World Of Business.” The Harvard Business Review, July-August: 1-10.

Arthur, W. Brian. 2009. The Nature of Technology: What it is and How it Evolves. New York: Free Press.

Asheim, Bjorn T. and Merics S. Gertler. 2005. “The Geography of Innovation: Regional Innovation Systems.” In The Oxford Handbook of Innovation, edited by Jan Fagerberg, David C. Mower, and Richard R. Nelson, 291-317. Oxford: Oxford University Press.

Audretsch, David B. 1995. Innovation and Industry Evolution. Cambridge, MA: MIT Press.Audretsch, David B. 2001. "The Role Of Small Firms In U.S. Biotechnology Clusters.” Small Business Economics, 17: 3-15.

Audretsch, David B. 2007. The Entrepreneurial Society. Oxford: Oxford University Press.

Audretsch, David B. and T. Taylor Aldridge. 2009. "Scientist Commercialization as Conduit of Knowledge Spillovers.” Annuals of Regional Science 2 43: 897-905.

Audretsch, David B. and Maryann P. Feldman. 1996. "R\&D Spillovers and The Geography Of Innovation and Production.” The American Economic Review, 86, no. 3: 630-40. 
Audretsch, David B. and Paula E. Stephan. 1996. "Company-Scientist Location Links: The Case of Biotechnology.” American Economic Review, 86, no. 3: 641-52.

Auerswald, Philip and Rajendra Kulkarni. 2008. "Placing Innovation: An Approach to Identifying Emergent Technological Activity.” Economic Innovation and New Technology, 17, no. 7: 733-50.

Auranen, Otto and Mika Nieminen. 2010. "University Research and Publication Performance: An International Comparison.” Research Policy, 39: 822-34.

Austin, John and Britany Affolter-Caine. 2006. The Vital Center: A Federal-State Compact to Renew The Great Lakes Region. Washington, DC: The Brookings Institution Metropolitan Policy Program.

Azoulay, Pierre, Joshua S. Graff Zivin, and Gustoavo Manso. 2009. “Incentives and Creativity: Evidence From The Academic Life Sciences” (NBER Working Paper 15466). Cambridge, MA: National Bureau of Economic Research.

Bagchi-Sen, Sharmistha. 2003. “An Empirical Analysis of Migration in InformationIntensive Work in The United States.” The Service Industries Journal, 23, no. 1: 136-66.

Baldi, Stephane. 1995. "Prestige Determinants of First Academic Job For New Sociology PhDs 1985-1992.” The Sociological Quarterly, 36, no. 4: 777-89.

Bania, Neil, Michael S. Fogarty, Michael J Ginzberg, Charles E. Post, and Mohan Reddy. 1991. University Research Performance. Cleveland: Cleveland Technology Leadership Council.

Bania, Neil, Randall W. Eberts, and Michael S. Fogarty. 1993. "Universities and the Startup of New Companies: Can We Generalize From Route 128 and Silicon Valley?” The Review Of Economics And Statistics, 75, no. 4: 761-66.

Bartik, Timothy J. 1993. "Who Benefits from Local Job Growth: Migrants or the Original Residents?” Regional Studies, 27, no. 4: 297-311.

Bartley, Katherine F. 2006. "Technology And The Convergence of U.S. Urban Migration Patterns: 1970-2000.” Growth and Change, 37, no. 1: 82-106.

Baser, Onur and Elda Pema. 2004. "Publications Over the Academic Lifecycle: Evidence for Academic Economists.” Economic Bulletin, 1, no. 1: 1-8.

Battelle, John. 2005. The Search: How Google and Its Rivals Rewrote the Rules of Business and Transformed Our Culture. New York: Portfolio.

Battelle, John. 2006. Growing The Nation's BioScience Sector State Bioscience Initiatives. Battelle Technology Partnership Practice and SSTI. 
Bercovitz, Janet and Maryann Feldman. 2008. “Academic Entrepreneurs: Organizational Change at the Individual Level.” Organization Science, 19, no. 1(January/February): 6989.

Berger, Suzanne. 2005. How We Compete: What Companies Around The World Are Doing to Make It in Today's Global Economy. New York: Currency/Doubleday.

Berkum, Scott. 2010. The Myths of Innovation. Sebastopol: O’Reilly.

Berry, Christopher R. and Glaeser, Edward L. 2005. “The Divergence Of Human Capital Levels Across Cities” (HIER Discussion Paper Number 2091). Cambridge, MA: Harvard Institute for Economic Research.

Black, Grant C. 2006. “Geography and Spillover: Shaping Innovation Policy Through Small Business Research.” In Shaping Science and Technology Policy: The Next Generation of Research, edited by David H. Guston and Daniel Sarewitz, 77-97. Madison: University of Wisconsin Press.

Bloom-Kohout, Margaret E., Krishna B. Kumar, and Neeraj Sood. 2009. "Federal Life Sciences Funding and University R\&D” (NBER Working Paper 15146). National Bureau of Economic Research.

Boyack, Kevin W. and Paul Jordan. 2011. "Metrics Associated With NIH Funding: A High-Level View.” Journal of the American Medical Informatics Association, 18, no. 4: 423-31.

Bozeman, Barry and Sooho Lee. 2003. "The Impact of Research Collaboration on Scientific Productivity.” School of Public Policy, Georgia Institute of Technology.

Brewer, Dominic, Susan M. Gates, and Charles A. Goldman. 2001. In Pursuit of Prestige: Strategy and Competition in U.S. Higher Education (Technical Paper DRU2541-EDU). Rand Corporation.

Breznitz, Shiri M. 2014. The Fountain of Knowledge: The Role of Universities in Economic Development. Stanford: Stanford University Press.

Buccola, Steven, David Ervin, and Hui Yang. 2009. "Research Choice and Finance In University Bioscience.” Southern Economic Journal, 75, no. 4: 1238-55.

Butler, Linda. 2004. "What Happens When Funding Is Linked To Publication Counts?” In Handbook of Quantitative Science And Technology Research, edited by Henk F. Moed and Wolfgang Glanzel, 389-405. Dordrectch: Kluwer Academic Publishers.

Caballero, Ricardo J. and Adam B. Jaffe. 2002. "How High are the Giants' Shoulders: An

Empirical Assessment of Knowledge Spillovers and Creative Destruction in a Model of Economic Growth.” In Patents, Citations, \& Innovations: A Window on the Knowledge 
Economy, edited by Adam B. Jaffe and Manuel Trajtenberg, 89-151. Cambridge, MA: MIT Press.

Camerer, Colin F. and Ernst Fehr. 2006. “When Does ‘Economic Man’ Dominate Social Behavior?” Science, 311, no. 6: 47-52.

Campbell, Eric G., Greg Koski, and David Blumenthal. 2004. The Triple Helix: University, Government, and Industry Relationships in the Life Sciences (Working Paper 04-12). AEI-Brookings Joint Center for Regulatory Studies.

Carlino, Gerald, Satyajit Chatterjee and Robert Hunt. 2006. Urban Density and The Rate of Invention (Working Paper no. 06-14). Federal Reserve Bank of Philadelphia.

Casper, Steven. 2007. "How Do Technology Clusters Emerge And Become Sustainable? Social Network Formation and Inter-Firm Mobility Within the San Diego Biotechnology Cluster.” Research Policy, no. 36: 438-55.

Center for Measuring University Performance, The. 2007. Annual Report. Capaldi, Elizabeth D., John V. Lombardi, Craig W. Abbey, and Diane D. Craig. The Top American Research Universities 2008 Annual Report. Arizona State University.

Centina, Karin K. 1991. "Merton’s Sociology of Science: The First and the Last Sociology of Science.” Contemporary Sociology, 20: 522-26.

Chesbrough, Henry. 2006. Open Innovation: The New Imperative for Creating and Profiting from Technology. Boston: Harvard Business School Press.

Chiesa, Vittorio and Davide Chiaroni. 2005. Industrial Clusters in Biotechnology: Driving Forces, Development Processes and Management Practices. London: Imperial College Press.

Christensen, Clayton M. and Henry J. Eyring. 2011. The Innovative University: Changing the DNA of Higher Education from the Inside Out. San Francisco: Jossey-Bass.

Cockburn, Iain M. and Rebecca M. Henderson. 1998. “Absorptive Capacity, Coauthoring Behavior, and the Organization of Research in Drug Discovery.” The Journal Of Industrial Economics, 46, no. 2: 157-82.

Cohen, Wesley M., Richard R. Nelson, and John P. Walsh. 2002. "Links and Impacts: Survey Results on the Influence of Public Research on Industrial R\&D.” Management Science, 48, no. 1: 1-23.

Cole, Alexander. 2003. On Tacit Knowledge, Industrial Districts and the Social Embeddedness of Creativity, or Why Scholars Have Known More Than They Could Tell About Tacit Knowledge and Regional Competitive Advantage. Paper prepared for DRUID Summer Conference, June 12-14, Copenhagen. 
Cole, Jonathan R. 2009. The Great American University: Its Rise to Preeminence, Its Indispensable National Role, Why It Must Be Protected. New York: PublicAffairs Press.

Cole, Stephen and Jonathan R. Cole. 1967. "Scientific Output and Recognition: A Study in the Operation of the Reward System in Science.” American Sociological Review, 32, no. 3: 377-90.

Cooke, Philip. 2006. “Global Bioregional Networks: A New Economic Geography of Bioscientific Knowledge.” European Planning Studies, 14, no. 9: 1265-85.

Cortright, Joseph. 2002. “The Economic Importance of Being Different: Regional Variations in Tastes, Increasing Returns, and the Dynamics of Development.” Economic Development Quarterly, 16, no. 3: 3-16.

Cortright, Joseph and Heike Mayer. 2002. Signs of Life: The Growth of Biotechnology Centers in the U.S.. Brookings Institute Center on Urban and Metropolitan Policy.

Carrasco, Raquel and Javier Ruiz-Castillo. 2014. "The Evolution of the Scientific Productivity of Highly Productive Economists.” Economic Inquiry, 52, no. 1 (January): $1-16$.

Darby, Michael R. and Lynne G. Zucker. 2003. “Grilichesian Breakthroughs: Inventions of Methods of Inventing and Firm Entry in Nanotechnology” (NBER Working Paper 9825). Cambridge, MA: National Bureau of Economic Research.

De Bellis, Nichola. 2009. Bibilometric and Citation Analysis: From Science Citation Index to Cybermetrics. Lanham, MD: Scarecrow Press.

Delgado, Mercedes, Michael Porter, and Scott Stern. 2010. "Clusters and Entrepreneurship” (Working Paper). Washington, DC: Center for Economic Studies, U.S. Bureau of Census.

Desmet, Klaus, and Fafchamps, Marcel. 2005. "Changes in the Spatial Concentration of Employment Across US Counties: A Sectoral Analysis 1972-2000.” Journal Of Economic Geography, 5: 261-84.

Dey, Eric L., Jeffrey F. Milem, and Joseph B. Berger. 1997. "Changing Patterns of Publication Productivity: Accumulative Advantage or Institutional Isomorphism?” Sociology of Education, 70, no. 4: 308-23.

Dietz, James S. and Barry Bozeman. 2005. “Academic Careers, Patents, and Productivity: Industry Experience as Scientific and Technical Human Capital.” Research Policy, 34: 349-67.

Druss, Benjamin G. and Steven C Marcus. 2005. "Tracking Publication Outcomes of National Institutes of Health Grants.” The American Journal of Medicine, 118: 658-63. 
Ellison, Glenn and Edward L. Glaeser. 1997. "Geographic Concentration in U.S. Manufacturing Industries: A Dartboard Approach.” Journal Of Political Economy, 105, no. 5: 889-927.

Estrin, Judy. 2009. Closing the Innovation Gap: Reigniting the Spark of Creativity in a Global Economy. New York: McGraw Hill.

Etzkowitz, Henry. 2008. The Triple Helix. New York: Routledge.

Etzkowitz, Henry and Loet Leydesdorff. 2000. “The Dynamics of Innovation: From National Systems and 'Mode 2' to a Triple Helix of University-Industry-Government Relations.” Research Policy, 29: 109-123.

Evans, Heather K. 2011. "Reflecting on a Decade of Women's Publication in Four Top Political Science Journals.” PS: Political Science and Politics, 44, no. 4 (October): 79398.

Faggian, Alessandra and Philip McCann. 2006. "Human Capital Flows and Regional Knowledge Assets: A Simultaneous Equation Approach.” Oxford Economic Papers, 52: 475-500.

Feeney, Mary K. and Eric W. Welch. 2014. “Academic Outcome among Principal Investigators, Co-Principal Investigators, and Non-PI Researchers.” Journal of Technology Transfer, 39: 111-33.

Feinberg, Robert M. and Gregory N. Price. 2004. "The Funding of Economics Research: Does Social Capital Matter for Success at the National Science Foundation?” Review of Economics and Statistics, 86, no. 1: 245-52.

Feldman, Maryann P. 2007. "Perspectives on Entrepreneurship and Cluster Formation: Biotechnology in the US Capitol Region.” In The Economic Geography of Innovation, edited by Karen R. Polenske, 241-60. Cambridge: Cambridge University Press.

Feldman, Maryann P. and David B. Audretsch. 1999. "Innovation in Cities: ScienceBased Diversity, Specialization and Localized Competition.” European Economic Review, 43: 409-29.

Feldman, Maryann P. and Johanna L Francis. 2003. "Fortune Favors the Prepared Region: The Case of Entrepreneurship and the Capitol Region Biotechnology Cluster.” European Planning Studies, 11, no. 7: 765-88.

Feldman, Maryann P. and Maryellen R. Kelley. 2006. “The Ex-ante Assessment of Knowledge Spillovers: Government R\&D Policy, Economic Incentives and Private Firm Behavior.” Research Policy, 35: 1509-21. 
Feldman, Maryann P. and Pierre Desrochers. 2003. "Research Universities and Local Economic Development: Lessons from the History of Johns Hopkins University.” Industry \& Innovation, 10, no. 1: 5-24.

Feldman, Maryann P. and Pierre Desrochers. 2004. "Truth for its Own Sake: Academic Culture and Technology Transfer at Johns Hopkins University.” Minerva, 42: 105-126.

Feldman, Maryann P. and Richard Florida. 1994. "The Geographic Sources of Innovation: Technology Infrastructure and Product Innovation in the United States.” Annuals Of The Association Of American Geographers, 84, no. 2: 210-29.

Ferber, Marianne A. 1988. “Citations and Networking.” Gender and Society, 2, no. 1 (March): 82-89.

Ferrand, Yann, Christina M. L. Kelton, Ke Chen, and Howard A. Stafford. 2009. "Biotechnology in Cincinnati: Clustering or Colocation?" Economic Development Quarterly, 23, no. 2: 127-40.

Fingleton, Bernard, Danilo C. Igliori, Barry Moore, and Raakhi Odedra. 2007. “Employment Growth and Cluster Dynamics of Creative Industries in Great Britain.” In The Economic Geography of Innovation, edited by Karen R. Polenske, 60-84. Cambridge MA:.

Foray, Dominique. 2004. The Economics of Knowledge. Cambridge, MA: MIT Press.

Fogarty, Michael S., Amit K. Sinha, and Adam B. Jaffe. 2002. ATP and the U.S. Innovation System: A Methodology for Identifying Enabling R\&D Spillover Networks with an Application to Microelectronic-Mechanical Systems (MEMS) and Optical Recording. Cleveland: Case Western Reserve University Press.

Foray, Dominique and Bengt-Ake Lundvall. 1998. “The Knowledge-Based Economy: From the Economics of Knowledge to the Learning Economy.” In The Economic Impact of Knowledge, edited by Dale Neef, G. Anthony Siesfeld, and Jacquelyn Cefola, . Boston: Butterworth-Heinemann. 115-122.

Fox, Mary Frank. 1983. "Publication Productivity Among Scientists: A Critical Review.” Social Studies of Science, 13: 285-305.

Friedman, Yali. 2004. Building Biotechnology: Starting, Managing, and Understanding Biotechnology Companies. New York: Biotech LLC.

Friedman, Yali. 2009. The Business of Biotechnology: Profit from the Expanding Influence of Biotechnology. Washington, DC: Logos Press.

Fujita, Masahisa. 2007. "Towards the New Economic Geography in the Brain Power Society.” Regional Science and Urban Economics, 37: 482-90. 
Fujita, Masahisa and Jacques-Francois Thisse. 2001. Economics of Agglomeration: Cities, Industrial Location and Regional Growth. Cambridge: Cambridge University Press.

Gallo, Carmine. 2011. The Innovation Secrets of Steve Jobs. New York: McGraw-Hill.

Geiger, Roger L. 2008. “The Riddle of the Valley.” Minerva, 46: 127-32.

Geiger, Roger and Irwin Feller. 1995. "The Dispersion of Academic Research in the 1980s.” Journal of Higher Education, 66. no. 3: 336-60.

Gibbons, James F. 2000. “The Role of Stanford University: A Dean’s Reflection.” In The Silicon Valley Edge, edited by Chong Moon Lee, William F Miller, Marguerite Gong Hancock, and Henry S. Rowen, . Stanford: Stanford University Press. 1-15.

Gillett, R. 1991. "Pitfalls in Assessing Research Performance by Grant Income.” Scientometrics, 22, no. 2: 253-63.

Gingras, Yves, Vincent Lariviere, Benoit Macaluso, and Jean-Pierre Robitalille. 2008. PLOSOne, 3, no.12 (December): 1-8.

Glaeser, Edward L. and Edward Saiz. 2003. “The Rise of Skilled Cities” (NBER Working Paper 2005). Cambridge, MA: National Bureau of Economic Research.

Glaeser, Edward L., Hedi D. Kallal, Jose A. Scheinkman, and Andrei Shleifer. 1992.

“Growth in Cities.” Journal of Political Economy, 100, no. 61: 1126-52.

Glaeser, Edward L. and Joshua D. Gottlieb. 2006. "Urban Resurgence and the Consumer City” (HIER Discussion Paper 2109). Harvard Institute of Economic Research.

Glaeser, Edward L. and Joshua D. Gottlieb. 2009. "The Wealth of Cities: Agglomeration Economies and Spatial Equilibrium in the United States” (Working Paper). Cambridge, MA: Harvard University and National Bureau of Economic Research.

Glaeser, Edward L. and Matthew G. Resseger. 2009. “The Complementary Between Cities and Skills” (NBER Working Paper 15103). Cambridge, MA: National Bureau of Economic Research.

Glaeser, Edward L and William Kerr. 2008. "Local Industrial Conditions and Entrepreneurship: How Much of the Spatial Distribution Can We Explain?” (Working Paper). Washington, DC: Center for Economic Studies, U.S. Bureau of Census.

Glaeser, Edward L., William Kerr, and Giacomo Ponzetto. 2009. “Clusters of Entrepreneurship” (Working Paper). Washington, DC: Center for Economic Studies, U.S. Bureau of Census. 
Goldin, Claudia and Lawrence F. Katz. 2008. The Race Between Education and Technology. Cambridge, MA: Belknap Press.

Goldstein, Harvey. 2005. "The Role of Knowledge Infrastructure in Regional Economic Development: The Case of the Research Triangle.” Canadian Journal of Regional Science, 28, no. 2: 199-220.

Goldstein, Harvey A. and Catherine S. Renault. 2004. "Contributions of Universities to Regional Economic Development: A Quasi-experimental Approach.” Regional Studies, 38, no. 7: 733-46.

Gottlieb, Paul D. and George Joseph. 2006. “College-To-Work Migration of Technology Graduates and Holders of Doctorates Within the United States.” Journal of Regional Science, 46, no. 4: 627-59.

Gottlieb, Paul D. and Michael Fogarty. 2003. "Educational Attainment and Metropolitan Growth.” Economic Development Quarterly, 17, no. 4: 325-36.

Greenwood, Michael J. 1975. "Research on Internal Migration in the United States: A Survey.” Journal of Economic Literature, 13, no. 2: 397-433.

Graham, Hugh Davis and Nancy Diamond. 1997. The Rise of American Research Universities: Elites and Challengers in the Postwar Era, Baltimore: Johns Hopkin University Press.

Griliches, Zvi. 1984. "R \& D and Innovation: Some Empirical Findings-Comments.” In $R$ \& D, Patents, and Productivity, edited by Zvi Griliches. Chicago: Chicago University Press.

Grove, Andrew S. 1988. Only The Paranoid Survive. London: Harper-Collins Business, Hammersmith.

Gujarati, Damodar N. 2003. Basic Econometrics (4 ${ }^{\text {th }}$ ed.). Boston: McGraw-Hill.

Hall, Bronwyn H. 2006. "Empirical Studies of Innovation in the Knowledge Driven Economy” (NBER Working Paper 12320). Cambridge, MA: National Bureau of Economic Research.

Hannas, A. Cader. 2008. “The Evolution of the Knowledge Economy.” Regional Analysis and Policy, 38, no. 2: 117-29.

Henderson, Rebecca, Adam Jaffe, and Manuel Trajtenberg. 2002. "Universities as a Source of Commercial Technology: A Detailed Analysis of University Patenting 19651985.” In Patents, Citations \& Innovations: A Window On The Knowledge Economy, edited by Adam B. Jaffe and Manuel Trajtenberg, . Cambridge, MA: MIT Press. 
Henderson, J.. Vernon. 2008. “Understanding Knowledge Spillovers.” Regional Science and Urban Economics, 37: 497-508.

Hendrix, Dean. 2008. “An Analysis of Bibliometric Indicators, National Institutes of Health Funding, and Faculty Size at Association of American Medical Colleges Medical Schools 1997-2007.” Journal of the Medical Literature Association, 96, no. 4: 324-34.

Hesli, Vicki L. and Jae Mook Lee. 2011. "Faculty Research Productivity: Why Do Some of Our Colleagues Publish More than Others?” Political Science and Politics, 44, no. 2 (April): 393-408.

Hicks, Diana, Tony Breitzman, Dominic Olivastro, and Kimberly Hamilton. 2001. "The Changing Composition of Innovative Activity in the US: A Portrait Based on Patent Analysis.” Research Policy, 30: 681-703.

Hill, Edward W. and Iryna Lendel. 2007. "The Impact of the Reputation of Bio-Life Science and Engineering Doctoral Programs on Regional Economic Development.” Economic Development Quarterly, 21, no. 3: 223-43.

Hounshell, David A. 1996. "The Evolution of Industrial Research in the United States.” In Engines of Innovation, edited by Richard S. Rosenbloom and William J. Spencer, 1386. Boston: Harvard Business School Press.

Hughes, Sally Smith. 2011. Genentech: The Beginnings of Biotech. Chicago: University of Chicago Press.

Jacob, Brian and Lars Lefgren. 2007. "The Impact of Research Grant Funding on Scientific Productivity” (NBER Working Paper 13519). Cambridge, MA: National Bureau of Economic Research.

Jaffe, Adam B. 1989. "Real Effects of Academic Research.” American Economic Review, 79, no. 5: 957-70.

Jaffe, Adam B., Michael S. Fogarty, and Bruce A. Banks. 2002. "Evidence from Patents and Patent Citations on the Impact of NASA and Other Federal Labs on Commercial Innovation.” In Patents, Citations \& Innovations: A Window on the Knowledge Economy, edited by Adam B. Jaffe and Manuel Trajtenberg, 261-85. Cambridge, MA: MIT Press.

Jaffe, Adam B., Manuel Trajtenberg and Rebecca Henderson. 1993. “Geographic Localization of Knowledge Spillovers as Evidenced by Patent Citations.” The Quarterly Journal of Economics, August, 576-598.

Jimenez-Contreras, Evaristo, Felix de Moya Anegon and Emilio D. Lopez-Cozar. 2003. "The Evolution of Research Activity in Spain: The Impact of the National Commission for the Evaluation of Research Activity (CNEAI).” Research Policy, 32, no. 1: 123-42. 
Johnson, Steve. 2010. Where Good Ideas Come From: The Natural History of Innovation. New York: Riverhead Books.

Jones, Jill. 2003. Empires of Light: Edison, Tesla, Westinghouse and the Race to Electrify the World. New York: Random House.

Kennedy, Peter. 2003. A Guide to Econometrics ( $5^{\text {th }}$ ed.). Cambridge, MA: MIT Press.

Kenney, Martin and Urs Von Burg. 2000. "Institutions and Economies Creating Silicon Valley.” In Understanding Silicon Valley: The Anatomy of an Entrepreneurial Region, edited by Martin Kenney. Stanford: Stanford University Press.

Kienholz, Michelle L. and Jeremy M Berg. 2014. How the NIH Can Help You Get Funded: An Insider's Guide to Grant Strategy. New York: Oxford University Press.

Kim, E. Han, Adair Morse, and Luigi Zingales. 2009. “Are Elite Universities Losing Their Competitive Edge?” Journal of Financial Economics, no. 93: 353-81.

Koo, Ju. 2005. “Knowledge-Based Industry Clusters: Evidenced by Geographical Patterns of Patents in Manufacturing.” Urban Studies, 42, no. 9: 1487-505.

Koplin, H. T. 1971. Microeconomic Analysis: Welfare and Efficiency in Private and Public Sectors. New York: Harper and Row.

Korn, Peter. 2012. “Biotech’s Broken Promise.” Portland Tribune, April 12: 1-2.

Korn, Peter. 2009. “Bioscience Bust?” Portland Tribune, May 14: 1-2.

Kulmann, S., and E. Arnold. 2001. "RCN in the Norwegian Research and Innovation System" (Background Report no. 12 in the Evaluation of the Research Council of Norway). Oslo: Royal Norwegian Ministry for Education, Research and Church Affairs.

Kundsen, Brian, Richard Florida, Gary Gates, and Kevin Stolarick. 2007. "Urban Density, Creativity and Innovation” (unpublished paper).

Lacy, Sarah. 2006. Once You're Lucky, Twice You're Good: The Rebirth of Silicon Valley and the Rise of Web 2.0. New York: Gotham Books.

Lane, Jason E. and D. Bruce Johnstone (Eds.). 2012. Universities and Colleges as Economic Drivers: Measuring Higher Education's Role in Economic Development. Albany: SUNY Press.

Lapovsky, Lucie. 2009. Endowment Spending: External Perceptions and Internal Practices. Wilton, CT: Commonfund Institute.

Lecuyer, Christophe. 2007. Making Silicon Valley: Innovation and the Growth of High Tech, 1930-1970. Cambridge, MA: MIT Press. 
Lee, Sam Youl, Richard Florida, and Zoltan J. Acs. 2004. “Creativity and Entrepreneurship: A Regional Analysis of New Firm Formation.” Regional Studies, 38, no. 8: 879-91.

Lendel, Iryna. 2010. “The Impact of Research Universities on Regional Economies: The Concept of University Products.” Economic Development Quarterly, 24, no. 3: 210-30.

Leslie, Stuart W. and Robert H. Kargon. 1996. "Selling Silicon Valley: Frederick Terman’s Model for Regional Advantage.” The Business History Review, 70. no. 4: 43572.

Lester, Richard K. 2005. Universities, Innovation, and the Competitiveness of Local Economies: Summary Report from Local Innovation Project, Phase 1. Cambridge, MA: Industrial Performance Center, Massachusetts Institute of Technology.

Levin, Sharon G. and Paula E. Stephan. 1991. "Research Productivity Over the Life Cycle: Evidence from Academic Scientists.” The American Economic Review, 81, no. 1: 114-32.

Leydesdorff, Loet. 2006. The Knowledge Based Economy: Modeled, Measured, Simulated. Boca Raton, FL: Universal Publishers.

Leydesdorff, Loet and Martin Meyer. 2006. "Triple Helix Indicators of KnowledgeBased Innovation Systems: Introduction to the Special Issue.” Research Policy, 35: 1441-49.

Liebowitz, Stan J. and Stephen E. Margolis. 1999. Winners, Losers \& Microsoft: Competition and Antitrust in High Technology. Oakland: The Independent Institute.

Lindsey, D. 1991. "The Relationship Between Performance Indicators for Academic Research and Funding: Developing a Measure of Return on Investment in Science.” Scientometrics, 20, no.1: 221-34.

Link, Albert, and Christopher Ruhm. 2009. "Public Knowledge, Private Knowledge: The Intellectual Capital of Entrepreneurs” (NBER Working Paper 14797). Cambridge, MA: National Bureau of Economic Research.

Link, Albert N. and Donald S. Siegel. 2007. Innovation, Entrepreneurship, and Technological Change. Oxford: Oxford University Press.

Link, Albert and John T. Scott. 2003. “The Growth of Research Triangle Park.” Small Business Economics, 20: 167-75.

Livingston, Jessica. 2007. Founders At Work: Stories of Startups’ Early Days. New York: Apress. 
Long, J Scott. 1978. "Productivity and Academic Position in the Scientific Career." American Sociological Review, 43, no. 6: 889-908.

Lowe, Robert A. and Claudia Gonzalez-Brambila. 2007. "Faculty Entrepreneurs and Research Productivity.” Journal of Technology Transfer, 32: 173-94.

Lowen, Rebecca S. 1997. Creating the Cold War University: The Transformation of Stanford. Berkeley, CA: University of California Press.

MacRoberts, M. H, and Barbara R. MacRoberts. 1996. "Problems of Citation Analysis.” Scientometrics, 36, no. 3: 435-44.

Mangematin, Vincent, Paul O’Reilly, and James Cunningham. 2014. "PIs as Boundary Spanners, Science and Market Shapers.” Journal of Technology Transfer, 39: 1-10.

Mansfield, Edwin. 1984. "R\&D And Innovation: Some Empirical Findings.” In $R \& D$, Patents, And Productivity, edited by Zvi Griliches, 127-48. Chicago: University of Chicago Press.

Mansfield, Edwin. 1985. “How Rapidly Does New Industrial Technology Leak Out?” The Journal of Industrial Economics, 34: 217-23.

Mansfield, Edwin. 1991. “Academic Research and Industrial Innovation.” Research Policy, 20: 1-12.

Mayer, Heike. 2003. “Taking Root in the Silicon Forest: The Role of High Technology Firms as Surrogate Universities in Portland, Oregon.” Dissertation submitted January 17, 2003. Portland, OR: Portland State University.

Mayer, Heike. 2006. "What is the Role of Universities in High-tech Economic Development? The Case of Portland, Oregon and Washington DC.” Local Economy, 21, no. 3: 292-315.

Mayer, Heike. 2010. “Catching Up: The Role of State Science and Technology Policy in Open Innovation.” Economic Development Quarterly, 24, no. 3: 195-209.

Maynard, Micheline. 2003. The End of Detroit: How The Big Three Lost Their Grip on the American Car Market. New York: Doubleday.

McAllister, P. R. and T. Condon. 1985. "Econometric Analysis of Biomedical Research Publishing Patterns.” Scientometrics, 7, No. 1-2: 55-75.

McAllister P.R. and F. Narin. 1983. "Characterization of the Research Papers of United States Medical Schools.” Journal of the American Society for Information Science, 34, no. 2: 123-31. 
McGraw, Thomas K. 2007. Profit of Innovation: Joseph Schumpeter and Creative Destruction. Cambridge, MA: Belknap Press.

McMillian, G. Steven, Francis Narin, and David L. Deeds. 2000. “An Analysis of the Critical Role of Public Science in Innovation: The Case of Biotechnology.” Research Policy, 29: 1-8.

Merges, Robert P., Peter S. Menell, and Mark A. Lemley. 2010. Intellectual Property in the New Technological Age (5 ${ }^{\text {th }}$ edition). Austin, TX: Wolters Kluwer Law \& Business.

Merton, Robert K. 1968. “The Matthew Effect in Science.” Science, 159, no. 3810: 5663.

Moed, H. F., W. J. M. Burger, J. G. Frankfort, and A. F. J. Van Raan. 1985. “The Use of Bibliographic Data for the Measurement of University Research Performance.” Research Policy, 14: 131-49.

Mokyr, Joel. 2002. The Gifts of Athena: Historical Origins of the Knowledge Economy. Princeton, NJ: Princeton University Press.

Mowery, David C., and Richard R. Nelson, Bhaven N. Sampat, and Arvids A. Ziedonis. 2004. Ivory Tower and Industrial Innovation. Stanford: Stanford Business Books.

Muth, Richard F. 1971. “Migration: Chicken or Egg?” Southern Economic Journal, 37, no. 3: 295-306.

Nelson, Richard R. 1996. The Sources of Economic Growth. Cambridge, MA: Harvard University Press.

Nevens, T. Michael. 2000. “Innovation in Business Models.” In The Silicon Valley Edge, edited by Chong Moon Lee, William F. Miller, Marguerite Gong Hancock, and Henry S. Rowen, . Stanford: Stanford University Press.

Newman, M. E. J. 2004. "Coauthorship Networks and Patterns of Scientific Collaboration.” Proceedings of the National Academy of Sciences, 101, Supplemental 1, 5200-205.

North, Douglass C. 1990. Institutions, Institutional Change and Economic Performance. New York: Cambridge University Press.

O’hUallachain, Breandan and Leslie, Timothy F. 2005. "Spatial Convergence and Spillovers in American Invention.” Annals of the Association of American Geographers, 95, no. 4: 866-86.

O’Mara, Margaret Pugh. 2005. Cities of Knowledge: Cold War Science and the Search for the Next Silicon Valley. Princeton, NJ: Princeton University Press. 
Overtveldt, Johan Van. 2007. The Chicago School: How The University of Chicago Assembled the Thinkers Who Revolutionized Economics and Business. Chicago: B2 Books.

Packard, David. 1995. The HP Way. New York: Collins Business Essentials.

Pagel, P. S. and J. A. Hudetz. 2011a. "H-Index is a Sensitive Indicator of Academic Activity in Highly Productive Anesthesiologists: Results of a Bibliometric Analysis." ACTA Anesthesia Scand., 55: 1085-89.

Pagel, P. S. and J. A. Hudetz. 2011b. “An Analysis of Scholarly Productivity in United States Academic Anesthesiologists by Citation Bibliometrics.” Anesthesia, 66: 873-78.

Pao, Miranda Lee. 1991. "On the Relationship of Funding and Research Publications.” Scientometrics, 20, no. 1: 257-81.

Parker, John N., Christopher Lortie, and Stefano Allesina. 2010. “Characterizing a Scientific Elite: The Social Characteristics of the Most Highly Cited Scientists in Environmental Science and Ecology.” Scientometrics, 85: 129-43.

Parolo, Pietro Della Briotta, Raj Kumar Pan, Rumi Ghosh, Bernardo A Huberman, Kimmo Kaski, and Santo Fortunato. 2015, “Attention Decay in Science.” arXiv:1503.01881v1 (physics.soc-ph) March 6: 1-12.

Partridge, Mark D. and Dan S. Rickman. 2006. "An SVAR Model Of Fluctuations In U.S. Migration Flows and State Labor Market Dynamics.” Southern Economic Journal, 72, no. 4: 958-80.

Pisano, Gary P. 2006. Science Business: The Promise, the Reality, and the Future of Biotech. Boston: Harvard Business School Press.

Pollman, Thus. 2000. "Forgetting and the Ageing of Scientific Publications." Scientometrics, 47, no. 1: 43-54.

Ponomariov, Branco and P. Craig Boardman. 2008. “The Effects of Informal Interactions on Collaborative Research Between University and Industry Scientists.” Journal of Technology Transfer, 33, no. 3: 301-13.

Quon, Andrew. 2001. “Changes in U.S. Medical Schools’ NIH Rankings, 1990-2000.” Analysis, Association of American Medical Colleges, 1, no. 3. 1-2.

Redner, Sidney. 2005. “Citation Statistics from 110 Years of Physical Review.” Physics Today, June: 49-54.

Reich, Leonard S. 2002. The Making of American Industrial Research: Science and Business at GE and Bell, 1876-1926. London: Cambridge University Press. 
Reinhart, Martin. 2009. "Peer Review of Grant Applications in Biology and Medicine: Reliability, Fairness and Validity.” Scientometrics, 81, no. 3: 789-809.

Rhode, Deborah L. 2006. In Pursuit of Knowledge. Stanford: Stanford University Press.

Robbins-Roth, Cynthia. 2000. From Alchemy to IPO: The Business Of Biotechnology. New York: Basic Books.

Romer, Paul M. 1986. “Increasing Returns and Long-Run Growth.” Journal of Political Economy, 94, no. 5, 1002-38.

Rose, M. Richard. 1986. “Pork-Barrel Science vs. Peer Review.” Chronicle of Higher Education, 33, no. 6: 96.

Rosenberg, Nathan and Richard R. Nelson. 1996. "The Roles of Universities in the Advance of Industrial Technology.” In Engines of Innovation: U. S. Industrial Research at the End of an Era, edited by Richard S. Rosenbloom and William J. Spencer, 87-110. Boston: Harvard Business School Press.

Ross, Jeffrey Ian. 2000. "Grants-R-Us: Inside a Federal Grant-Making Research Agency.” American Behavioral Scientist, 43, no. 10: 1704-23.

Ruttan, Vernon W. 2001. Technology, Growth, and Development: An Induced Innovation Perspective. New York: Oxford University Press.

Sanders, Mark. 2007. "Scientific Paradigms, Entrepreneurial Opportunities and Cycles in Economic Growth.” Small Business Economics, 28: 339-54.

Sandstrom, Ulf. 2009. "Research Quality and Diversity of Funding: A Model for Relating Research Money to Output of Research.” Scientrometrics, Vol 79, no. 2: 341-49.

Santoro, Michael D. 2000. "Success Breeds Success: The Linkage Between Relationship Intensity-University Collaborative Ventures.” Journal of High Technology Management Research, 11, no. 2: 255-73.

Saxenian, Annalee. 1996. Regional Advantage: Culture and Competition in Silicon Valley and Route 128. Cambridge, MA: Harvard University Press.

Schweitzer Laura, Daniel I. Sessler, and Nancy Martin. 2008. “The Challenge for Excellence at the University of Louisville: Implementation and Outcomes of Research Resource Investment Between 1996 and 2006.” Academic Medicine, 83, no. 6: 560-67.

Shapiro, Jesse M. 2005. "Smart Cities: Quality of Life, Productivity, and the Growth Effects of Human Capital” (NBER Working Paper 11615). Cambridge, MA: National Bureau of Economic Research. 
Siegel, Donald. 2006. “University-Industry Knowledge Flows: An Overview.” National Science Foundation Workshop: Advancing Measures of Innovation. http://www.nsf.gov/statistics/workshop/innovation06/siegel.pdf-2006-06-29.

Simon, Herbert A. 1973. “Organizational Man: Rational or Self-Actualizing?” Public Administration Review, 33, no. 4: 346-53.

Simon, Herbert A. 1973a. “On the Concept of Organizational Goal.” In Contingency Views of Organization and Management, edited by Fremont E. Kast and James E. Rosenzweig, 120-37. Science Research Associates.

Sorenson, Olav and Jasjit Singh. 2007. "Science, Social Networks and Spillovers.” Industry and Innovation, 14, no. 2: 219-38.

Sorenson, Olav and Lee Fleming. 2004. "Science and the Diffusion of Knowledge." Research Policy, 33, no. 10: 1615-34.

Stephan, Paula E. 1996. “The Economics of Science.” Journal of Economic Literature, 34, no. 3: 1199-1235.

Stephan, Paula E. and Sharon G. Levin. 2001. "Career Stage, Benchmarking and Collective Research.” International Journal of Technology Management, 22, no. 7/8: 676-87.

Stokes, Donald E. 1997. Pasteur's Quadrant: Basic Science and Technological Innovation. Washington, DC: Brookings Institution Press.

Sturgeon, Timothy. 2000. "How Silicon Valley Came to Be.” In Understanding Silicon Valley: The Anatomy Of An Entrepreneurial Region, edited by Martin Kenney, . Stanford: Stanford University Press. 50-47.

Swann, Peter G. M. 2009. The Economics of Innovation: An Introduction. Chelltenham: Edward Elgar Press.

Tatsioni, Athina, Effie Vavva, and John P. A. Ioannidis. 2010. "Sources of Funding for Nobel Prize-Winning Work; Public or Private?” FASEB Journal, 24: 1335-39.

Thorp, Holden and Buck Goldstein. 2010. Engines of Innovation: The Entrepreneurial University in The Twenty-First Century. Chapel Hill: University of North Carolina.

Thursby, Jerry G. and Marie C. Thursby. 2003. "Patterns of Research Licensing Activity of Science and Engineering Faculty” (working paper).

Tiebout, Charles M. 1962. The Community Economic Base Study (Supplementary Paper no. 16). New York: Committee for Economic Development. 
Toole, Andrew A. 2012. "The Impact of Public Basic Research on Industrial Innovation: Evidence from the Pharmaceutical Industry.” Research Policy, 41: 1-12.

Toole, Andrew A. and Dirk Czarnitzki. 2007. "Biomedical Academic Entrepreneurship Through the SBIR Program.” Journal of Economic Behavior \& Organization, 63, no. 4: 716-38.

Toole, Andrew A. and Calum Turvey. 2009. "How Does Initial Public Financing Influence Private Incentives for Follow-on Investment in Early-Stage Technologies?” Journal of Technology Transfer, 34: 43-58.

Trani, Eugene P. and Robert D. Holsworth. 2010. The Indispensable University. Plymouth, UK: American Council of Higher Education.

Trajtenberg, Manuel, Rebecca Henderson, and Adam Jaffe. 1997. "University Versus Corporate Patents: A Window on the Basicness Of Innovation.” Economic Innovation and New Technology, 5: 19-50.

Treyz, George I., Dan S. Rickman, Gary L. Hunt, and Michael J. Greenwood. 1993. "The Dynamics of U.S. Internal Migration.” Review Of Economics And Statistics, 75, no. 2: 209-214.

Van den Besselaar, Peter and Loet Leydesdorff. 2009. "Past Performance, Peer Review and Project Selection: A Case Study in the Social and Behavioral Sciences." Research Evaluation, 18, no. 4: 273-88.

Wagner, Caroline S. 2008. The New Invisible College Science for Development, Brookings Institution Press, Washington D.C.

Walcolt, Susan M. 1999. "High Tech in the Deep South: Biomedical Firms Cluster in Metropolitan Atlanta." Growth and Change, 30, no. 1: 48-74.

Walcolt, Susan M. 2002. "Analyzing an Innovative Environment: San Diego as a Bioscience Beachhead.” Economic Development Quarterly, 16, no. 2: 99-114.

Wanner, Richard A., Lionel S. Lewis, and David I. Gregorio. 1981. "Research Prodictivity in Academia: A Comparative Study of the Sciences, Social Sciences and Humanities." Sociology of Education, 54, no. 4, October: 238-53.

Wray, K. Brad. 2003. “Is Science a Young Man’s Game?” Social Studies Science, 33, no. 1 (February): 137-49.

West, E. G. 1985. "Literacy and the Industrial Revolution.” In The Economics of The Industrial Revolution, edited by Joel Mokyr, 227-40. Rowman \& Littlefield Publishers. 227-240. 
Whittington, Kjersten Bunker, Jason Owen-Smith, and Walter W. Powell. 2009. "Networks, Propinquity, and Innovation in Knowledge-Intensive Industries." Administrative Science Quarterly, 54: 90-122.

Wood, Fiona. 1990. "Factors Influencing Research Performance of University Academic Staff.” Higher Education, 19: 81-100.

Woodward, Douglas, Octavio Figueiredo, and Paulo Guimaraes. 2006. "Beyond the Silicon Valley: University R\&D and High Technology Location.” Journal of Urban Economics, 60, no. 1: 15-32.

Yusuf, Shadid. 2007. “University-Industry Links: Policy Dimensions.” In How Universities Promote Economic Growth, edited by Shahid Yusuf and Kaoru Nabeshima, 1-26. Washington, DC: The World Bank.

Zhang, Junfu and Nikesh Patel. 2005. The Dynamics of California's Biotechnology Industry. San Francisco: Public Policy Institute of California.

Zucker, Lynne G. and Michael R. Darby. 1996. "Star Scientists and Institutional Transformation: Patterns of Invention and Innovation in the Formation of the Biotechnology Industry.” Proceedings of the National Academy of Sciences, 93: 12709716.

Zucker, Lynne, G. and Michael R. Darby. 2006. "Movement of Star Scientists and Engineers, and High-Tech Firm Entry” (NBER Working Paper 12172). Cambridge, MA: National Bureau of Economic Research.

Zucker, Lynne G. and Michael R. Darby. 2007. "Virtuous Circles in Science and Commerce.” Papers in Regional Science, 86, no. 3: 445-70.

Zucker, Lynne G., Michael R. Darby, and Jeff Armstrong. 1998. “Geographically Localized Knowledge Spillovers or Markets.” Economic Inquiry, 36: 65-86.

Zucker, Lynne, G., Michael R. Darby, and Marilynn B. Brewer. 1998. “Intellectual Human Capital and the Birth of U.S. Biotechnology Enterprises.” American Economic Review, 88, no. 1: 290-306.

Zucker, Lynne, Michael R. Darby, and Jeff S. Armstrong. 2002. "Commercializing Knowledge: University Science, Knowledge Capture, and Firm Performance In Biotechnology.” Management Science, 48, no. 1: 138-53.

Zucker, Lynne G., Michael R. Darby, Jonathan Furner, Robert C. Liu, and Hongyan Ma. 2006. "Minerva Unbound: Knowledge Stocks, Knowledge Flows and New Knowledge Production” (NBER Working Paper 12669). Washington, DC: National Bureau of Economic Research 


\section{APPENDIX A}

Tobit Regressions without NIH Dollar Outliers and with National Academy Members Interactive Variable 
Table A

Tobit Regression Without Outliers (Over 3 Million Total Grant Dollars)

Variable

Gender Female

Meddegree

Degree MDPhD

Total Art 200607

ArtSqd

AverCites 200607

AvCites Sqd

Career Cites 2007

DeptBasic Sci

Molbiochemmicro

NeroSciGenetics

EconDept

MedNursingDent

AsstProf

AssocProf

Liscenses

Spinout

PrivateUniv

RegNE

RegSE

RegMiddle

RegWest

PerBachelor

MetroPop2010

AcademyMembers

LandGrant

Number OrgNIH2008

NumberInst

MedSch

RankTotRDExp2008

TenFaculty2012

FullTimeGradStd

PatentApplication200207

Endowment2008

SciEngSpaceperStudyPop

Constant

Number of Observations

Confidence Level
Coefficient

31536.76

*-128824.4

*187085.2

*51465.32

*-1005.43

*42919.4

*-1312.98

11.8

*-249879.6

**115908.7

*195548

***-295035.8

**78501.72

*-437184.4

*-248712.8

*189289

**573371.1

$-126794.2$

155655.4

**-145543.6

$-103224.1$

27655.21

2826.72

**.014

*-13062.02

**-152950.9

***-2952.82

2206

**93043.24

**-2692.58

$-67.07$

11.94

61593.37

$-720$.

39082.69

3064

$* 0.00$ t-statistic

1.08

$-3.08$

3.11

9.8

$-5.39$

4.65

$-3.05$

1.45

$-5.78$

2.6

3.61

$-1.63$

2.31

$-10.18$

$-8.01$

2.8

2.24

$-1.44$

1.63

$-2.49$

$-1.09$

0.31

1.11

2.53

$-2.78$

$-2.46$

$-1.66$

0.42

1.94

$-2.31$

$-1.47$

0.27

1.08

0.93

$-1.36$

$-1.36$

$* * 0.05 \quad * * * 0.10$ 
Tobit Regression with Interactive Number of Academy Members Variable.

Variable

Gender Female

Meddegree

Degree MDPhD

Total Art 200607

ArtSqd

AverCites 200607

AvCites Sqd

Career Cites 2007

DeptBasic Sci

Molbiochemmicro

NeroSciGenetics

EconDept

MedNursingDent

AsstProf

AssocProf

Liscenses

Spinout

PrivateUniv

RegNE

RegSE

RegMiddle

RegWest

PerBachelor

MetroPop2010

AcademyMembers

InterAcadRank

LandGrant

Number OrgNIH2008

NumberInst

MedSch

RankTotRDExp2008

TenFaculty2012

FullTimeGradStd

PatentApplication200207

Endowment2008

SciEngSpaceperStudyPop

Constant

Number of Observations

Confidence Level

$* 0.00$
Coefficient

29343.1

$-53196.63$

**195957.4

*65061.52

*-1279.54

*55863.86

*-1668.3

**23.94

*-276750.2

*194804.2

*275655.7

$-335734.3$

**11300.7

*-660416.7

*-360323.3

***152683. 6

***576023.8

$-121537.7$

190536.7

**-155228.8

$-91482.62$

46832.62

1404.88

**0.0167

$-1488.01$

**-5762.67

**-137154

$-3496.57$

4472.7

$* * 121760.7$

**-3179.05

$-71.66$

16.88

***138372. 1

\section{0}

$-857.14$

$-22682.76$

3078 t-statistic

0.78

$-1$

2.52

9.64

$-5.34$

4.72

$-3.03$

2.32

$-4.94$

3.39

3.95

$-1.43$

2.56

$-7.89$

$-7.31$

1.75

1.75

$-1.07$

1.54

$-2.04$

$-0.74$

0.41

0.43

2.36

$-0.17$

$-2.21$

$-1.71$

$-1.49$

0.66

1.96

$-2.12$

$-1.22$

0.29

1.91

0.54

$-1.25$

$-0.07$

$* * 0.05$

$* * * 0.10$ 


\section{APPENDIX B}

Movement of Academics and Receipt of NIH Funds 
Table A

Movement of Academics and Receipt of NIH Funds

\begin{tabular}{|c|c|c|c|c|c|c|c|c|}
\hline Name & Position & Field & University & & Year & & & \\
\hline \multirow[t]{4}{*}{$\begin{array}{l}\text { David H. } \\
\text { Ledbetter }\end{array}$} & Professor & $\begin{array}{l}\text { Molecular } \\
\text { Biology/ } \\
\text { Genetics }\end{array}$ & $\begin{array}{c}\text { U of Chicago } \\
\text { (48) }\end{array}$ & 1999 & 2000 & 2001 & 2002 & 2003 \\
\hline & Highly Cited & & & 305989 & 313049 & 501403 & 501413 & 0 \\
\hline & & & Emory (35) & 2005 & 2006 & & & \\
\hline & & & & 405139 & 407488 & & & \\
\hline \multirow[t]{4}{*}{$\begin{array}{l}\text { Ronald C } \\
\text { Kessler }\end{array}$} & Professor & Neuroscience & $\begin{array}{c}\mathrm{U} \text { of Michigan } \\
\text { (10) }\end{array}$ & 1992 & 1993 & 1994 & 1995 & 1996 \\
\hline & Highly Cited & & & 1325935 & 1254650 & 1501001 & 1887701 & 282072 \\
\hline & & & Harvard (33) & 1997 & 1998 & 1999 & 2000 & 2001 \\
\hline & & & & 717438 & 1307320 & 6298503 & 7196239 & 5433952 \\
\hline \multirow[t]{4}{*}{$\begin{array}{l}\text { Susan G } \\
\text { Anara }\end{array}$} & Professor & Neuroscience & $\begin{array}{l}\text { OR Hlth Sci } \\
\text { Ctr (64) }\end{array}$ & 1999 & 2000 & 2001 & 2002 & 2003 \\
\hline & Highly Cited & & & 323265 & 280209 & 285218 & 547015 & 195984 \\
\hline & & & $\begin{array}{c}\mathrm{U} \text { of } \\
\text { Pittsburgh } \\
\text { (22) }\end{array}$ & 2004 & 2005 & 2006 & & \\
\hline & & & & 410135 & 416090 & 205661 & & \\
\hline \multirow[t]{4}{*}{$\begin{array}{l}\text { Joseph S } \\
\text { Beckman }\end{array}$} & Professor & $\begin{array}{c}\text { Biology/ } \\
\text { Biochemistry }\end{array}$ & $\begin{array}{c}\mathrm{U} \text { of Alabama } \\
\text { (38) }\end{array}$ & 1997 & 1998 & 1999 & 2000 & 2001 \\
\hline & Highly Cited & & & 246298 & 629317 & 563967 & 844550 & 151479 \\
\hline & & & $\begin{array}{c}\text { OR State Univ } \\
\text { (63) }\end{array}$ & 2001 & 2002 & 2003 & 2004 & 2005 \\
\hline & & & & 459785 & 1833390 & 1636927 & 1353927 & 1353927 \\
\hline \multirow[t]{4}{*}{$\begin{array}{c}\text { Paul B } \\
\text { Watkins }\end{array}$} & Assoc/Prof & Pharmacology & $\begin{array}{c}\mathrm{U} \text { of Michigan } \\
\text { (10) }\end{array}$ & 1995 & 1996 & 1997 & 1998 & \\
\hline & Highly Cited & & & 309560 & 317503 & 274547 & 389924 & \\
\hline & & & $\begin{array}{c}\text { U of NC } \\
\text { Chapel Hill } \\
\text { (19) }\end{array}$ & 1999 & 2000 & 2001 & 2002 & 2003 \\
\hline & & & & 378050 & 386889 & 395992 & 621537 & 1173729 \\
\hline
\end{tabular}




\begin{tabular}{|c|c|c|c|c|c|c|c|c|}
\hline $\begin{array}{l}\text { Michael } \\
\text { Levine }\end{array}$ & Professor & $\begin{array}{l}\text { Biology/ } \\
\text { Genetics }\end{array}$ & $\begin{array}{l}\text { U of San } \\
\text { Diego (6) }\end{array}$ & 1995 & 1996 & & & \\
\hline & Highly Cited & & & 238787 & 223937 & & & \\
\hline & & & $\begin{array}{c}\text { U of Berkeley } \\
\text { (17) }\end{array}$ & 1997 & 1998 & 1999 & 2000 & 2001 \\
\hline & & & & 232755 & 406370 & 745509 & 829766 & 1005722 \\
\hline $\begin{array}{l}\text { Wen-Hwa } \\
\text { Lee }\end{array}$ & Professor & $\begin{array}{l}\text { Molecular } \\
\text { Biology/ } \\
\text { Genetics }\end{array}$ & $\begin{array}{l}\text { U TX HSC } \\
\text { (83) }\end{array}$ & 1996 & 1997 & 1998 & 1999 & 2000 \\
\hline & Highly Cited & & & 566565 & 587511 & 599445 & 583086 & 613346 \\
\hline & & & $\begin{array}{c}\text { U CA Irvine } \\
\text { (62) }\end{array}$ & 2001 & 2002 & 2003 & 2004 & 2006 \\
\hline & & & & 270825 & 1764156 & 1375067 & 683008 & 304375 \\
\hline $\begin{array}{l}\text { Patricia D } \\
\text { Hurn }\end{array}$ & Professor & & $\begin{array}{l}\text { OR Hlth Sci U } \\
\text { (64) }\end{array}$ & & & 2008 & 2009 & 2010 \\
\hline & & & & & & 2120312 & 1824591 & 202736 \\
\hline & & & $\begin{array}{c}\text { U TX Austin } \\
\text { (32) }\end{array}$ & & & 2011 & 2012 & 2013 \\
\hline & & & & & & 322208 & 370951 & 352649 \\
\hline $\begin{array}{l}\text { Susan } \\
\text { Hickman }\end{array}$ & Assistant & & $\begin{array}{l}\text { OR Hlth Sci U } \\
\text { (64) }\end{array}$ & & & 2008 & 2009 & 2010 \\
\hline & & & & & & 192500 & 231000 & 502736 \\
\hline & Associate & & Indiana U (37) & & & 2011 & 2012 & 2013 \\
\hline & & & & & & 322208 & 307923 & 352649 \\
\hline
\end{tabular}

